(Aus dem Anatomischen Institut zu Tübingen.)

\title{
Untersuchungen über Spermatogenese.
}

\author{
Von
}

Ir. v. Lenhossék in Tübingen.

Hierzu Tafel XII, XIII, XIV u. 1 Textfigur.

„Unsere Kenntnisse über den Ausreifungsprocess der Spermatozoen sind noch weit davon entfernt, vollständig abgeschlossen zul sein", sagt F. Hermann im Jahre 1893 (s. Literatur, 1893, S. 218), und die Sachlage ist seitdem, trotz des Erscheinens bemerkenswerther, ja grundlegender Arbeiten über unser Thema, keine andere geworden. Eine Wiederaufnahme des hochinteressanten, auch für die grossen Fragen der Befiuchtung bedentungsvollen Gegenstandes schien daher vollauf gerechtfertigt, urnsomehr als die histologische Technik seit den letzten einschlägigen Arbeiten wieder einige nicht unwesentliche Fortschritte zu verzeichnen hat. Ich habe hier in erster Reihe die $\mathrm{M} . \mathrm{Hei}$ denhain'sche Eisenhämatoxylinmethode in Auge; es schien mir Aussicht vorbanden zu sein, durch Anwendung dieses Verfahrens wieder etwas mehr von den Einzelheiten des verwickelten Vorganges in Erfahrung bringen zu können, als es bei der bis vor Kurzem verfügbaren Technik möglich war. Noch ein Zweites kan hinzu. Durch die neuen Forschungen über Centrosom und Befruchtung ist in die alte Frage der Spermatogenese ein völlig neues Moment hineingetragen worden, das eine gänzlich neue Fragestellung, fast möchte man sagen eine "Umwerthung aller Werthe" zur Folge haben musste. Die Fragen: wo liegt das Centrosom im Spermatozoon? welchen Antheil nimmt es bei dessen Bildung? - Fragen, die sich die Forscher auf diesem Gebiet noch vor zehn Jahren nicht träumen liessen — sind jetzt zu Hauptproblemen geworden. Vom Standpunkte dieser Fragen aus konnte man trotz der vorhandenen grossen Literatur ganz unbefangen an eine Neubearbeitung des Gegenstandes berantreten.

Diese beiden Momente also, die Fortschritte der Technik 
und die neuen Fragestellungen waren die Hauptveranlassung, dass ich mich seit dem Herbst des vorigen Jahres (1896) dem schwierigen Thema "Spermatogenese" widmete. Mit grossem Eifer warf ich mich zunächst auf die Untersuchung des Hodens verschiedener Sängethierspecies (Mensch, Katze, Ziegenbock, Kaninchen, Ratte, Igel, Maulwurf); indessen ward meinem Streben nach möglichst „breiter Forschungsgrundlage" ${ }^{\prime}$ bald ein Riegel vorgeschoben durch die Erkenntniss der ausserordentlichen Complikation des Gegenstandes. Als es mir klar wurde, dass, wenn auch nicht in principiellen Punkten, so doch in vielen Einzelheiten die Sache bei den verschiedenen Säugern etwas anders liege, als immer wieder die Anfertigung neuer Präparate, nach verschiedenen Methoden behandelt, nöthig wurde, musste die Hoffnung schwinden, auf diesem Wege in absebbarer Zeit überhaupt zum Ziele zu kommen, und so sah ich mich denn genöthigt, mich auf den Hoden eines einzigen Thieres zu beschränken.

Ich wählte hierzu die Ratte. Der Grund dieser Wahl lag für mich vor allem in der leichten Verschaffbarkeit dieses $0 \mathrm{~b}-$ jectes, andererseits in dem Umstande, dass von den Hoden aller Wirbelthiere gerade der Rattenboden am häufigsten untersucht worden ist; bei dieser Wahl schien mir daher ein Anschluss an schon gethane Arbeit am ehesten möglich, die Gefahr, meine Zeit durch Verweilen bei secundären Vorfragen zu verzetteln, am meisten ausgeschlossen zu sein. Dass der Rattenhoden für die Untersuchung ein so einzig günstiges Object darstelle, ein Lob, das ihm viele Forscher spenden, kann ich nicht obne weiteres unterschreiben; ich sehe nicht ein, inwiefern er ein besseres Object sein soll, als der Hoden anderer Säugethiere; ja was die Grösse seiner Elemente betrifft, scheint er mir sogar hinter dem Hoden der Katze zurückzustehen. Aber wie gesagt, jene zwei Gesichtspunkte waren für mich ausschlaggebend und sie werden dem Rattenhoden wohl auch künftighin manche Bearbeiter zuführen.

Ich will hier noch bemerken, dass meine Untersuchungen schon im März dieses Jahres (1897) abgeschlossen waren, und dass ich alle im Nachfolgenden mitzutbeilenden Ergebnisse bereits in einer vorläufigen Mittheilung kurz veröffentlicht habe, die unter dem Titel: „Teber Spermatogenese bei Sängethieren" Anfangs April hier in Tubingen erschien und gleich nach ihrem Erscheinen an zahlreiche Fachgenossen versandt wurde. 


\section{Technik.}

Von Fixirungsflüssigkeiten wandte ich vor allem mit gutem Erfolg das Sublimat an. Freilich habe ich damit diese guten Erfolge nicht gleich zu Anfang erzielt; es dauerte ziemlich lange, bis sich die richtige Art und Weise der Anwendung dieses Mittels herausstellte. M. H e i d e $\mathrm{nh}$ a in sagt (1896, S. 11): „Sublimat taugt übrigens bei Weitem nicht für alles: noch nie habe ich einen Hoden mit diesem Mittel auch nur annähernd gut conserviren können." Dieser Ausspruch deckt sich vollkommen mit meinen eigenen Erfahrungen, soweit es sich um die herkömmliche Anwendungsweise des Mittels handelt. Anders stellt sich aber die Sache, wenn man das Sublimat in einer besonders energischen Weise zur Anwendung bringt. Das von mir ausprobirte Verfahren besteht im Folgenden. Zunächst muss man auf den von Hermann (1893, S. 220) besonders hoch, ja entschieden zu hoch angeschlagenen Vortheil verzichten, den Hoden im Ganzen zu fixiren. Das Sublimat dringt durch die Albuginea nur unvollkommen ein, und auch das Einspritzen von Sublimat in das Hodengewebe führt zu keinem Ziele, da das Quantum, das man einspritzen kann, nicht ausreicht, um die Elemente gehörig zu fixiren. Wenn ich auch Hermann einräume, dass es zum Zwecke einer tadellosen Fixirung des Situs der Elemente sicherer ist, eine Methode anzuwenden, bei der der Hoden nicht zerschnitten zu werden braucht, so muss ich doch sagen, dass man auch bei der anderen Methode oft sehr schöne Bilder erhält, an denen man die Elemente vollkommen in ihrem normalen festen Zusammenschluss vor sich hat. Liegt aber auch eine geringe Auflockerung der Zellschichten vor, so hat dies für das Studium der einzelnen Elemente nichts zu bedeuten; ich muss es entschieden bestreiten, dass durch diese kleinen Lageverschiebungen die Elemente so aig mitgenommen werden sollten, wie es $\mathrm{H}$ ermann hinstellt. - Man zerschneidet also den Rattenhoden vorsichtig mit dem Rasiermesser in 3-4 Stücke und lässt diese in ein grösseres Schälchen mit concentrirter Sublimatlösung (in $0,50 \%$ igem Kochsalz gelöst) fallen, die schon vorher auf eine Temperatur von etwa $35^{\circ} \mathrm{C}$. erwärmt worden ist. Darin bleiben die Stiicke mindestens 24 Stunden, während welcher Zeit das Ganze immer auf der gleichen Temperatur erhalten 
bleiben muss. Ich habe dies gewöhnlich in der Weise bewerkstelligt, dass ich das Schälchen auf dem Paraffinofen stehen liess, dessen Aussenseite bei der gewöhnlichen, zur Einbettung benützten Erwärmung ungefähr diese Temperatur anfweist. Die Stücke werden bei dieser Behandlung ganz hart, oft geradezu steinhart, womit freilich der Uebelstand einhergeht, dass das Anfertigen von grösseren, dünnen Schnitten nachher oft auf Schwierigkeiten stösst. Man kann diesen Schwierigkeiten dadurch theilweise begegnen, dass man zur Entwässerung vor der Einbettung nicht absoluten, sondern nur $96 \%$ igen Alkohol nimmt; wahrscheinlich thut es auch ein nocb schwächerer Alkohol. Der Bildung von Sublimatniederschlägen in den Geweben habe ich zum Theile schon dadurch vorgebeugt, dass ich die Stücke aus dem Sublimat direkt auf eine Stunde in eine weingelbe Lösung von Jodtinetur in $50 \%$ igem Alkohol brachte, die vorher ebenfalls auf die genannte Temperatur erwärmt worden war. Die Nachbärtung in Alkohol erfordert nur 2-3 Tage.

Die $5 \mu$ dicken Schnitte wurden nach der Eiweisswassermethode ${ }^{1}$ ) aufgeklebt und auf mehrere Stunden wieder in eine weingelbe alkoholische Jodlösung verbracht, wodurch auch die letzten Spuren von Sublimatniederschlägen in Lösung übergehen.

Die Hermann'sche und Flem ming'sche Lösung lassen die Behandlung des Hodens in toto zu. Man verfährt hierbei am besteu in der Weise, dass man von der betreffenden Flüssigkeit ungefähr eine Pravazspritze voll in das Parenchym des noch in seinen Hüllen liegenden Hodens injicirt und dann den Hoden in die Flüssigkeit hineinwirft. Gewöhnlich ist das Hodengewebe schon nach einer halben Stunde soweit erstarrt, dass man nun einen Einschnitt wagen darf, ohne eine Verschiebung der Kanälchen befürchten zu müssen. Nach einer weiteren Viertelstunde kann man den Hoden in mehrere Stuicke theilen, doch ist dies beim Rattenhoden nicht unbedingt nothwendig, da die Lösung schon nach dem ersten Einschnitt oder Durchschnitt wegen der sehr lockeren Beschaffenheit des Zwischengewebes

1) Diese Methode hat vor der Gull and'schen einfachen Wassermethode den Vortheil, dass sie ein Universalverfahren ist, d. h. bei allen möglichen Fixirungen gleich sicher funktionirt. Hier ist wirklich eine weitere Vervollkommnung kaum mehr denkbar. 
das ganze Hodenparenchym leicht durchdringt, wenn auch die Intensität der Einwirkung an der Schnittfläche immer am grössten ist. Aber ich habe bei der $\mathrm{H}$ erma nn'schen Methode die Wahrnehmung gemacht, dass man die besten Bilder gerade nicht von der Oberfläche her bekommt, wo das Mittel, und besonders der Osminmantheil darin, in voller Stärke zur Wirksamkeit gelangt ist, sondern aus etwas tieferen Schichten.

Ein vortreffliches Mittel zur Fixirung des Hodens babe ich in einem Gemisch von Sublimat, Alkohol und Eisessig gefunden, mit etwas anderem Verhältniss dieser Stoffe als in rom $R$ ath's (1896, S. 287) aus den gleichen Bestandtheilen zusammengesetzter Lösung. Meine Formel lautet:

$$
\begin{aligned}
& \text { Sublimat conc. }=75 \text { cem. } \\
& \text { Alcohol abs. }=25 \quad " \\
& \text { Eisessig }=5 \mathrm{n}
\end{aligned}
$$

Es ist dies die beste von den verschiedenen Combinationen, die ich noch durchprobirte und deren Anfählung hier keinen Zweck hätte. Man lässt dieses Gemisch auf den in mehrere Stücke getheilten Hoden einen Tag lang einwirken, auch bei einer Temperatur von $30-35^{\circ} \mathrm{C}$. Besonders schön treten bei dieser Fixirung, offenbar durch die Essigsäureeinwirkung, die Faserbildungen in den Mitosen hervor: die Fasern der Spindel sowohl wie die der Polstrahlung. Für die Darstellung der ruhenden Kerne fand ich diese Methode allerdings nicht besonders günstig; in dieser Hinsicht hat mir das Sublimat, in der angegebenen Weise angewendet, die besten Bilder gegeben.

Von Färbungen diente als Hauptverfahren die Eisenhämatoxylinfärbung, immer in Verbindung mit einer leichten ErythrosinNachfärbung; die Bilder, die diese Doppelfärbung giebt, sind vielleicht die schönsten, die die hentige Histologie überhaupt liefern kann. Der Hauptwerth des Eisenhämatoxylinverfahrens in seiner Anwendung auf das Studinm der Spermatogenese liegt einerseits darin, dass es das Centrosom in allen Zellen des Samenkanälchens (mit Ausnahme der Fusszellen) zur Ansicht zu bringen geeignet ist, andererseits darin, dass es auch den Axenfaden von dem ersten Augenblick seines Auftretens an mit der grössten Schärfe als feines schwarzes Fädchen verfolgen lässt. - Lehrreiche Anschauungen verdanke ich auch der Flemmin g'schen Dreifachfärbung; das Centrosom vermochte ich zwar damit nie- 
mals in ganz befriedigender Weise darzustellen, was ich durchaus nur meiner eigenen Ungeübtheit in der Handhabung der wie es scheint heiklen Methode zuschreibe; aber in anderer Beziehung hat sich die Methode sehr bewährt.

Wunderschöne Bilder erhält man durch die Combination einer Hämalaun- und Erythrosinfärbung, besonders an Objecten, die mit Sublimat-Alkohol-Eisessig fixirt worden sind. Man lïsst die aufgeklebten diunnen Schnitte 1-2 Tage in dem P. Mayerschen Hämalaun liegen und färbt dann leicht in Erythrosin nach. Besonders werthvoll ist diese Methode zur Darstellung der "Sphäre"; auch für die Mitosen ist sie gut. Gute Dienste hat mir schliesslich eine reine Magentarothfärbung geleistet, besonders an Objecten, zu deren Fixirung folgendes Gemisch benutzt worden war:

$$
\begin{aligned}
& \text { Sublimat conc. }=50 \mathrm{ccm} . \\
& \text { Platinchlorid } 1 \%=50 \\
& \text { Eisessig }
\end{aligned}
$$

Es ist mir öfters gelungen, mit dieser Färbung die Centrosomen an den Spindelpolen, sowie auch die in den Zwischenzellen des Hodens darzustellen. Ich kann die Färbung ferner empfehlen zum Studium der merkwürdigen Veränderungen, die die "Sphäre" in den Spermatiden erfährt.

Die Untersuchung wurde ausschliesslich mit Hülfe des Z eiss'schen Apochromaten 2,0 mm Apert. 1,30 vorgenommen. Auch an hellen Tagen erwies sich die Benutzung künstlichen Lichtes (Auerbrenner mit Sammellinse und blanem Glas zwischen Lichtquelle und Mikroskop) bei den starken Vergrösserungen, mit denen ich arbeitete, als unentbehrlich. Bei den Zeichnungen konnte ein Zeichenapparat nicht benutzt werden, da die Umrisse, die man damit von den verhältnissmässig kleinen Zellen erhalten konnte, nicht gross genug waren, um alle die feinen Einzelheiten, auf die es bei dieser Untersuchung ankam, in sie eintragen $\mathrm{zu}$ können. Es ist also die jeweilige Grösse einer Zeichnung nicht etwa als der Ausdruck der realen Vergrösserung aufzufassen; auch muss ich bemerken, dass es mir nicht immer gelungen ist, in den Zeichnungen das richtige gegenseitige Grössenverhältniss der einzelnen Elemente zu treffen. 


\section{Topographische Uebersicht.}

Untersucht man den in Thätigkeit befindlichen Hoden eines Säugethieres, so wird man bekanntlich schor an einem einzigen Schnitte, sofern er eine gewisse Anzahl von Samenkanälchendurehschnitten umfasst, alle Stadien der Spermatogenese nebeneinander auffinden können. Der ganze Vorgang der Spermatogenese, der aus einer Anzahl vorbereitender "Reifetheilungen" und aus der Umwandlung der letzten Zellgeneration zu Samenfäden besteht, schiebt sich nach Art einer Welle üher die Längsausdehnung des Samenkanälchens fort. Bei der Ratte kennen wir auch die Wellenlänge, d. h. die Länge der Strecke, an deren Endpunkten sich die ersten und letzten Stadien der Spermatogenese finden; sie beträgt nach den mühsamen und zuverlässigen Untersuchungen v. E bner's (1888, S. 283) durchschnittlich $32 \mathrm{~mm}$. Der wellenförmige Bildungsmodus hat, wie Benda (1887, S. 108) mit Recht bemerkt, den Vortheil, dass dadurch die Continuität der Samenbereitung gesichert wird.

So bietet also ein Hodenpräparat dem aufmerksamen Beobachter ein sehr buntes Bild dar, in dem sich wohl Niemand ohne eingehende Beschäftigung mit dem Gegenstande wirklich zurechtfinden wird. Viele Jahre sind verflossen, viele Mühe hat es gekostet, bis man gelernt hat, diese mannigfaltigen Bilder in richtigen Zusammenhang mit einander zu bringen, sie als einzelne Phasen der Spermatogenese in richtiger Reihenfolge mit einander zu verknüpfen. Wenn man sich fragt, wer eigentlich zuerst eine zusammenhängende, übersichtliche, unseren heutigen Vorstellungen entsprechende Darstellung von dem Vorgang der Spermatogenese, natürlich mit Beschränkung auf die gröberen, topographischen Verhältnisse, bei einem Säuger gegeben hat, so kann die Antwort meiner Ansicht nach nicht anders ausfallen, als dass dies H. B row n war (1885). Freilich fusst B rown schon fast in allen Hauptpunkten auf den Vorarbeiten Anderer, namentlich Renso n's (1882), aber das Verdienst bleibt ihm gesichert, dass er es war, der sich den ganzen Vorgang in seinem Zusammenhange zuerst, in der Hauptsache wenigstens, in zutreffender und abgerundeter Weise zurecht gelegt hat; auch gehören seine $\mathrm{Ab}$ bildungen zu den besten der ganzen einschlägigen Literatur. - Viel ansfübrlicher und mit viel grösserer Genauigkeit finden wir dann 
den Vorgang nach seiner topographischen Seite hin behandelt bei späteren Forschern, unter denen Benda (1887) und vor Allen v. Ebner (1888) hervorragen.

v. Ebner hat den ganzen Process bei der Ratte in zwölf Bildern übersichtlich dargestellt und daran das allmähliche Ausreifen der Zellgenerationen erklärt. Da der Vorgang aber ein continuirlicher ist, da alle Zellen sich allmählich fortentwickeln, so wird diese Zahl natürlich auch nur eine relativ geringe Anzahl aus der Continuität der Entwickelung heransgegriffener "Momentbilder" darstellen können. Auf der anderen Seite aber scheint mir fur das praktische Bedürniss der ersten Orientirung. die Zahl etwas zu gross zu sein. Ich selbst habe mich am Anfang meiner Studien in der erdrückenden Mannigfaltigkeit der verschiedenen Bilder, in denen ich zuerst ratblos hin- und hermikroskopirte, dadurch zurechtgefunden, dass ich nach den markantesten Bildern, die mir immer wieder entgegengetreten waren, fünf Stadien unterschied, und diese mir durch Nachzeichnen und aufmerksame Analyse genau einzuprägen suchte. Diese fünf "Leitbilder" dürften zur ersten Orientirung in der That auch vollkommen genügen. Sie stellen die auffallendsten, von einander am meisten abweichenden Zelleombinationen dar; an ihnen hat man einen festen Halt, auf sie lassen sich die etwas abweichenden Zwischenformen leicht zurückführen.

Ich habe diese fünf Stadien zu Nutz und Frommen des Lesers auf den Figuren 1-5 zur Ansicht zu bringen gesucht und möchte daran eine kurze Charakteristik der einzelnen Bilder anknüpfen. Es wird sich anf diese Weise wohl anch am leichtesten die Terminologie darlegen lassen, der ich mich zu bedienen gedenke. Sie schliesst sich vollkommen der jetzt allgegemein üblichen La Valette St. George'schen an, unter Hinzufügung einzelner kleiner Zusätze.

Fig. 1 stellt wohl das bekannteste von all den Bildern dar, die ein Präparat aus dem Rattenhoden darbietet. Es ist das typische, in den Lehrbüchern bevorzugte Bild, an dem alle Zellkategorien vertreten, an dem die regelmässigen Zellsäulen in ungefähr gleichen Abständen durch die Fortsätze der Sertolischen Zellen oder Fusszellen durchsetzt sind. Dies der Grund, warum ich diesem Bilde den Vortritt einrïume: sonst könute man dies nicht rechtfertigen. Denn das Bild bezeichnet weder 
den Anfang noch das Ende jener "Welle"; es liegt dem Ende des Cyclus nahe. - Als äussere Begrenzung der Samenkanälchen sehen wir vor allem die Membrana propria; sie stellt sich bei der Ratte als ein dünnes Häutchen dar, das aber trotz seiner Dünne unverkennhar ans mehreren Lamellen zusammengesetzt ist und von Stelle zu Stelle mit platten, auf dem Querschnitte stäbchenförmig erscheinenden Bindegewebskernen versehen ist, die theils auf der äusseren Oberfläche der Membran, theils zwischen ihren Lamellen liegen.

Die erste Lage der Zellauskleidung des Hodenkanälchens setzt sich nun aus zwei Zellgattungen zusammen. Diese sind: 1. die Spermatogonien, kleine, niedrige, der Membran dicht angeschmiegte Zellen, mit wenig Cytoplasma und kleinem, sehr dunklem, stark färbbarem Kern von ovaler, seltener rundlicher Gestalt. Hin und wieder treten uns unter diesen Zellen mitotische Theilungsfiguren entgegen, seltener allerdings in diesem als im nächstfolgenden Bilde. Diese in den Figuren nicht berücksichtigten Theilungen sind klein und deshalb schwer analysirbar, man kann nur soviel feststellen, dass sie sich dem gewöbnlichen Mitosentypus ansehliessen; ihre Theilungsachse liegt stets parallel der Kanalwand. Man findet sie bald sporadisch, bald auch zu dreien oder vieren beisammen. 2. Die Sertoli'schen Zellen oder Fusszellen Benda's. Sie liegen in ungefähr gleichen Abständen von einander, $1-3-6$ Spermatogonien zwischen sich fassend. Der Kern ist gross, hell, rund oder dreieckig, mit lumenwärts gerichteter, mehr oder weniger ausgezogener Spitze. Sehr charakteristisch ist das grosse, runde, central gelegene Kernkörperchen darin. Der Zellkörper gebt durch einen halsartig verdünnten Theil in den Fortsatz über, der, dicht eingezwängt zwischen den Zellsäulen, gegen das Lumen hinzieht und auf diesem Stadium stets schon ein Bündel fast ganz ausgereifter Spermatozoen in sich fasst. Diese Spermatozoen liegen zn 8-9 in einer Fusszelle, oft ganz unten in der Nähe des Kerns, die Spitze ihres hakenförmigen Kopfes nach der Kanalwand gerichtet, ihre Krïmmung in der Mehrzahl in gleichem Sinne, nach der einen oder anderen Seite wendend; der Complex ihres vom Kopfe bereits ganz zurückgezogenen Zellkörpers hängt in Form schmaler, länglicher Lappen in das Lumen des Kanals hinein, aber nicht unregelmässig, sondern in der Weise, dass alle Lappen 
mit einander eine regelmässige, einwärts durch eine gerade Linie abgegrenzte Schicht bilden. Aus den Lappen ragen noch die schon recht langen Schwänze hervor, auch wieder nicht durcheinandergewirrt, sondern durch ihren parallelen Verlauf eine regelmässige, wirbelartige Zeichnung im Lumen hervorrufend.

Die zweite Schicht wird von einer einzigen Lage bedeutend grösserer, runder oder eckiger, etwas lockerer angeordneter Zellen gebildet, deren Kern sich im Zustande eines mässig dichten Knäuels befindet. Es sind das die Spermatocyten oder Henle'sche Zellen (v. Ebner), speciell jene Entwickelungsstufe dieser Zellgattung, die ich als "kleine Spermatoc yten" bezeichnen möchte. Weiter nach innen folgen jetzt, durch die Fusszellenfortsätze wie in Fächer eingeschlossen, in 4--5 Lagen aufgethürmt, die S p e r m a ti d e n, kleinere, zumeist eckige, oft leicht in die Länge gezogene Zellen mit kleinerem, hellem, rundem Kern, in Präparaten mit tadellosem Situs der Elemente auf das Dichteste zusammengedrängt. In den meisten ist in dieser Phase schon die erste Spur des Achsenfadens wahrnehmbar (auf der Zeichnung nicht berücksichtigt): wir haben es hier also mit den unmittelbaren Bildnern der Samenfäden zu thun.

In Bild 2 tritt uns als Hauptveränderung der Schwund der Fusszellenfortsätze entgegen. Die dadurch frei gewordenen Spermatozoen liegen nun einwärts von den Spermatiden, dicht nebeneinander in Reih nnd Glied aufgestellt, eine besondere, sehr regelmässige Schichte bildend. Unter dieser Spermatozoenlage folgen aber nicht gleich die Spermatiden, sondern es ist da eine neue, wieder beiderseits ziemlich geradlinig abgegrenzte Lage entstanden, die aus zerfallenem Cytoplasma, aus stark chromatophilen Kugeln verschiedener Grösse und aus Fetttröpfchen, Zerfallsprodukten des Cytoplasmas der Spermatiden und Fusszellenfortsätze besteht (s. darüber genauer bei v. E bn e r 1888, S. 266). Der Ausfall der Fusszellenfortsätze hat auf alle die übrigen Schichten etwas modificirend eingewirkt, ihrer Anordnung durchweg einen einfacheren Habitus verleihend. Die Spermatogonien liegen jetzt - obgleich auf sie a priori kaum ein Einfluss durch die veränderte Sachlage anzunehmen wäre - doch etwas regel-. mässiger nebeneinander, als vorhin; sie bieten geradezu das Bild eines einschichtigen, niedrigen Epithels dar, das sich gegen die 
nächste Schichte fast geradlinig abgrenzt. Die Fusszellen haben natürlich durch die Atrophie ihres Fortsatzes ein wesentlich verändertes Aussehen angenommen: sie stellen jetzt flache Zellen dar mit so wenig Protoplasma, dass der nun stets rundliche oder leicht elliptische aber sonst unveränderte grosse Kern auf der Lumenseite in der Regel gar nicht von Plasma bedeckt ist. Die die zweite Schichte bildenden Spermatocyten liegen noch immer in einer einzigen Lage. Sie sind gegen Bild 1 kaum merklich grösser geworden; der Kern befindet sich in einem Uebergangsstadium vom dichten zum lockeren Knäuel. - Die Spermatiden sind natürlich nicht mehr zu Säulen geordnet, sondern bilden ein gleichmässiges Lager. Bezüglich ihres inneren Baues wäre hier zu bemerken, dass sich vom 1. zum 2. Bilde wichtige Vorgänge in ihrem Inneren abgespielt haben, vor allem die regelmässige Einstellung der zwei cytoplasmatischen Ein-

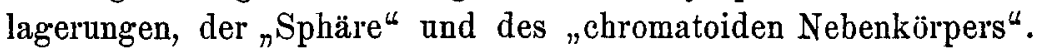
Denn während im Stadium 1 diese zwei, erst im weiteren Laufe dieser Arbeit genauer zu besprechenden Zellbestandtheile eine ganz willkürliche Position in der Zelle einnehmen, ist jetzt insofern eine auffallende Veränderung eingetreten, als die Sphäre immer oder wenigstens zumeist an dem der Kanalwand zugewendeten Pol des Kernes, der chromatoide Nebenkörper am gegenüberliegenden Pol angetroffen wird. In Fig. 2 sind diese Einzelheiten nicht angedeutet. Schliesslich sieht man oft, dass die Spermatiden nun allmählich anfangen, eine lockerere, freiere Anordnung anzunehmen.

Dieses Stadium bildet den Schluss des Entwickelungscyclus der Spermatozoen; gewöhnlich erstreckt es sich, wie v. Ebner zuerst nachgewiesen hat, über eine längere Abtheilung der Samenkanälchen, daher es das häufigste Bild ist, dem man an den Präparaten begegnet. Es stellt alșo gewissermaassen eine Ruhepause im Vorgang der Spermatogenese dar.

Mit dem Bilde 3 setzt der nene Cyclus ein. Die reifen Spermatozoen sind aus dem Lumen verschwunden oder zu einem unregelmässigen, axial gelegenen Klumpen zusammengeballt, stellen also schon ein völlig ausgestossenes "Secret" dar. Die Spermatiden sorgen für den Ersatz, indem sie sich in diesem Bilde anschicken, sich zu Spermatozoen umzuwandeln. Man bat es aber erst mit den ersten Stadien zu thun. Wir sehen den Kern in 
den der Kanalwand zugekehrten Pol der Zelle gerückt, so dass das Zellplasma mehr und mehr als ein Anhang des Kerns erscheint; der Achsenfaden ist schon ziemlich lang, aber noch immer sehr zart und unscheinbar. Dies ist auch das Stadium, wo sich die Neubildung des unlängst erst verschwundenen Fortsatzes der Fusszellen in ihren ersten Andeutungen wieder einleitet; die Spermatiden haben aber erst zum kleinen Theile den Anschluss an den Fortsatz gefunden. Die Elemente der zweiten Schichte, die Spermatocyten, zeigen sich in vergrösserter

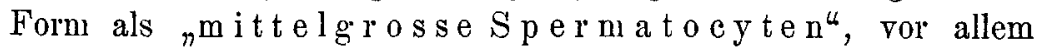
ist aber bemerkenswerth, dass der Kern nun ganz in den $\mathrm{Zu}$ stand eines lockeren Knäuels eingetreten ist; anch ist das die Phase, wo im Kern der merkwürdige "Intranuclearkörper" in die Erscheinung tritt, als linsenförmiges, wandständiges Gebilde. - Angesichts all dieser Veründerungen ist auffallend, dass die Spermatogonien in der Regel keine merklichen Fortschritte aufweisen; nur manchmal zeigt sich, als Varietät, eine zeitliche Verschiebung in ihrem Verhalten, insofern als sie schon in diesem Bilde jenen Zustand erkennen lassen, der ihnen sonst erst im nächsten Bilde zukommt.

Bild 4 bietet ein wesentlich verändertes Aussehen dar. Auf den ersten Blick scheint es, als wären die Spermatiden alle spurlos verschwanden. Thatsächlich sind sie aber noch alle da, nur haben sie ibren Spermatiden-Charakter bereits so gut wie aufgegeben und liegen nun nicht mehr frei, sondern als nunreife Spermatozoen" wieder büschelweise eingepflanzt in die Fortsätze der Fusszellen. Zwischen dem vorigen Bilde und diesem hat sich also jener merkwürdige Vorgang vollzogen, den B end a (1887) "C o p u lation" genannt hat. Der Protoplasmaanhang der "unreifen Spermatozoen ", wie man sie eigentlich jetzt schon bezeichnen muss, hängt in breiten Lappen.in das Lumen des Kanales hinein. Wir haben wieder also, wie in Fig. 1, das Bild eines typischen ${ }_{n}$ Samenständers" vor uns, mit dem Unterschied nur gegen Bild 1 , dass der die Samenfidden enthaltende oder richtiger von den noch mit dem Zellkörper verbundenen Samenfäden selbst gebildete Theil hier viel breiter ist als dort, indem er geradezu fächerartig auseinandergeht; der ganze "Spermatoblast" erscheint hier fast pinienartig, was daher kommt, dass es sich bier eben um jüngere Stadien der Spermatozoen handelt, um Uebergangsformen 
zwischen Spermatiden und Spermatozoen, bei denen der protoplasmatische Zellkörper noch nicht so in die Länge gezogen, noch nicht so stark abgestreift ist, wie dort. Sebr ausgesprochene Veränderungen haben die Spermatocyten erfahren: sie sind nun zu grossen, plumpen Elementen herangewachsen, und zwar betrifft die Vergrösserung sowohl den Zellkörper wie den Kern. Diese ngrossen Spermatocyten" sind stets etwas in die Länge gezogen, gewöhnlich spindelförmig, in zwei Zipfeln auslaufend, mit der Längsachse natürlich immer senkrecht auf die Kanalwand gestellt. An den meisten Stellen bilden sie noch immer eine einfache Lage, aber vielfach kann es mehr oder weniger vollkommen zur Entstehung von zwei Lagen kommen, was sich ja leicht daraus erklären lässt, dass die stark ver: grösserten Zellen nunmehr nicht alle in einer Linie Platz finden können. Ilrr Cytoplasma ist hell, leicht granulirt, ohne jede Spur einer radiären oder anderweitig fibrillären Structur. Der grosse, helle Kern zeigt seine Cbromatinmasse in merkwürdige ringförmige Doppelchromosomen angeordnet. Im Cytoplasma tritt die "Sphäre" lebhaft hervor. - Auch die Spermatogonien sind nicht unverändert geblieben. Wir sehen sie ein wenig vergrössert und zu rundlichen Zellen umgewandelt. Bei dieser Gestalt können sie sich natirlich nicht mehr so innig wie früher der Kernmembran anlegen; aber sie sind über das Maass des Nothwendigen hinans von der Kernmembran abgehoben, von ihr gewöhnlich durch die jetzt verbreiterten Basaltheile der Fusszellen getrennt. Das Wesentlichste aber ist, dass sich der Kern nummehr bei allen im Zustande eines sehr eng gewundenen Spirems befindet. Dieser Knäuel färbt sich sehr stark, die Zellen treten daher nicht weniger lebhaft hervor als sie es früher als ruhende Spermatogonien gethan haben. Man könnte diese Zellen ihrem Habitus nach schon als Spermatocyten bezeichnen; doch scheint mir praktischer, sie als „Uebergangsspermatogonien“ aufzufassen, wie sie denn auch v. Ebner noch zu den Spermatogonien rechnet. Eine bemerkenswerthe Thatsache lässt sich hierbei konstatiren: die Spermatogonien stellen sich alle unter dieser Spiremform dar, man sielit sich vergebens nach einem Rest von gewöhnlichen Spermatogonien, nach "Reservezellen" mit vollkommen rubenden Kernen um. Ich nenne diese Thatsache „bemcrkenswerth", weil sie ein wenig Verlegenheit bereitet 
bei der Erklärung der spermatogenetischen Vorgänge in der herkömmlichen Weise; es soll dieser Punkt weiter unten nochmals zur Sprache kommen. Schliesslich sei erwähnt, dass, wie schon oben angegeben, die Basaltheile der Fusszellen jetzt beträchtlich breiter geworden sind; damit hängt wohl auch zusammen, dass die Kerne dieser Zellen jetzt niemals eine dreieckige, sondern stets eine mehr oder weniger abgeplattete Form zeigen.

In Bild 5 finden wir die Spermatocyten in mitotischer Theilung begriffen, wodurch sich dieses Bild von allen anderen Stadien der Spermatogenese lebhaft unterscheidet; schon mit schwachen Vergrösserungen wird man die Stellen, an denen diese Mitosen liegen, leicht auffinden können. Die Theilung erfolgt schubweise, daher man die Mitosen nur selten einzeln, vielmehr gewöhnlich wie in Herden zusammengedrängt, auf bestimmte Abschnitte der Kanälchen beschränkt findet. Im Allgemeinen sind diese „Mitosenherde" spärlich vertheilt; nach den Zählungen v. Ebner's fällt auf 55 Samenkanälchendurchschnitte nur ein einziges Kanälchen mit Mitosen. Auch erstreckt sich das Mitosengebiet niemals auf längere Strecken des Kanälchens, sogar niemals auf dessen ganzen Umfang; es nimmt vielmebr gewöhnlich nur ein Segment oder einige getrennte Segmente des Querschnittes in Anspruch. Wie v. Ebner (1891) zuerst nachgewiesen bat, giebt es bei der Ratte zwei Formen von Spermatocytenmitosen: grosse und kleine. Die beiden Gattungen liegen niemals untermischt miteinander, sondern gruppenweise allein für sich; einmal findet man eine Gruppe von ngrossen", an einer anderen Stelle eine Gruppe von nkleinen" Mitosen; letztere dürften etwas seltener sein, woraus man folgern kann, dass die Zell- und Kerntheilung an den kleineren Mitosen rascher abläuft als an den grossen. Der Unterschied in der Grösse ist ziemlich beträchtlich. Wenn man z. B. das Stadium der Aequatorialplatte zum Vergleiche benützt, so findet man bei den grossen Mitosen eine Zellenlänge von $26-32 \mu-$ es schliessen sich diese Mitosen in Betreff ihrer Grösse direkt an die grossen Spermatocyten an - bei den kleinen eine solche von $16-18 \mu$, ein bedeutender Unterschied! Freilich findet man auch Formen, bei denen man in Verlegenheit geräth, welcher man sie von den beiden Kategorien zutheilen soll.

v. E B e r hat an diese Beobachtung die Schlussfolgerung. geknüpft, dass die beiden Mitosentypen zeitlich verschiedenen 
Theilungen derselben Zelle entsprechen; es würden sich demnach die Spermatocyten zweimal hintereinander theilen.

Nach genauer Prüfung des sehr schwierigen Gegenstandes muss ich mich vollkommen der v. E b n er'schen Ansicht anschliessen. Der überzeugendste Beweis für ibre Richtigkeit liegt für mich in der Thatsache, dass man in der Nähe dieser Mitosen, namentlich aber der grossen, oft auch eingesprengt zwischen ihnen eine spermatidenähnliche, ziemlich grosse besondere Zellform findet mit vollkommen rthendem Kern, die man auf keine andere Weise erklären kann als indem man annimmt, dass sie die ruhende Zwischenform darstellt zwischen erster und zweiter, zwischen grosser und kleiner Mitose. Diese Zellen hat schon v. Ebner beschrieben und auch richtig gedeutet; nach der hei Salamandra, Nematoden u. s. w. üblichen Terminologie sollte man sie als ${ }^{\mathrm{S}} \mathrm{p}$ ermat o c y te n II. Ordn un $\mathrm{g}^{*}$ bezeichnen; allein da sie sich mehr schon an den Spermatidentypus anschliessen, möchte ich sie eher nach ilurem Entdecker ${ }^{\circ}$. Ebner's che

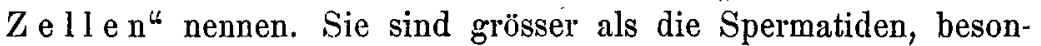
ders aber grösser als die aus der zweiten Theilung hervorgegangenen jungen Spermatiden, die erst durch eine geringe $\mathrm{Za}$ nahme ihres Protoplasmas und namentlich ihres Kernes den normalen Umfang einer Spermatide zu erreichen haben. Die Grössendifferenz zwischen den beiden Zellengattungen, den $\nabla$. Ebnerschen Zellen und den Spermatiden, zeigt sich nirgends markanter als an solchen Stellen, wo sie untermischt miteinander liegen, was in der Umgebung der kleinen Mitosen keine Seltenheit ist. In der Nähe der grossen Mitosen findet man niemals kleine junge Spermatiden, sondern immer nur grosse Spermatocyten und, von diesen immer getrennt, v. E $\mathrm{b}$ e r'sche Zellen. - Ob die zweimalige Theilung fur die Spermatocyten die Geltung eines durchgreifenden Gesetzes hat, möchte ich freilich nicht mit Bestimmtheit vertreten; ich will es nicht verschweigen, dass ich ab und zu Wahrnehmungen gemacht habe, die mir den Verdacht nahe legten, dass sich auch die Producte der ersten Theilung, die v. E b n e r'schen Zellen, za regelrechten Spermatiden umgestalten können durch allmähliche Verkleinerung des Kerns. Diese Variabilität würde also darauf hinweisen, dass der Wiederholung der Spermatocytentheilung eine principielle Bedeutung nicht zukommt. Indessen scheint mir das eine sicher, 
dass der gewöhnlichere, typische Modus jedenfalls in der zweimaligen Theilung gegeben ist, wie sie ja auch bei den Spermatocyten von Salamandra, Nematoden, Insecten 11. s. w. die Regel bildet, freilich ohne dass dort eine Rubeform zwischen die zwei Zelltheilungen eingeschaltet wäre, wie dies bei der Ratte bestimmt der Fall ist. Meine Erfahrungen stehen hier also in Widerspruch mit denen M o ore's (1893), der für die Ratte nur eine einmalige Spermatocytentheilung annimmt, stehen dageg'en in Uebereinstimmung mit denen von $\mathrm{v} . \mathrm{M} \mathrm{i} \mathrm{hálk} \mathrm{ovi} \mathrm{es} \mathrm{(1895,}$ S. 15), der sich bezïglich der Ratte, der Maus und des Meerschweinchens ebenfalls für eine $2-3$ malige Theilung der Spermatocyten ausspricht.

Man findet bei beiden Theilungen alle Stadien der Mitose vor, am bäufigsten sind aber die Aequatorialplattenstadien, wobei die Achse der Spindel vorherrschend, aber nicht ausnahmslos, senkrecht auf die Kanalwand steht; sie kann auch eine mit dieser parallele oder eine andere Lage aufweisen. Die Mitosen liegen in 2-3 Schichten tibereinander, als helle, rundliche Zellen, die sich schon durch den schwächeren Farbenton ihres Cytoplasmas ron den umgebenden Zellen deutlich abheben. Auf die weiteren Einzelheiten der Kern- und Zelltheilung soll an einer späteren Stelle in einem besonderen Kapitel eingegangen werden.' Ich bemerke, dass in Fig. 5 nur die grossen Spermatocytenmitosen zur Ansicht gebracht sind.

Was das Verhalten der übrigen Zellgattungen in diesem Bilde betrifft, so ist gegenüber dem vorangehenden Bilde alles beim alten geblieben. Die Spermatogonien zeigen auch hier alle das oben geschilderte, durch die Bezeichnung „Uebergangsspermatogonien" charakterisirte Verhalten; auch die Fusszellen stellen sich unter demselben Bilde dar wie vorbin, als typische "Samenständer", oben in Verbindung mit 6-8 unreifen Spermatozoen, deren Cytoplasma in breiten, fingerförmigen Lappen in das Lumen hineinragt. Es liegt also ausser den grossen Spermatocyten Alles unverändert vor. - An dieses Bild schliesst sich nun wieder, als das nächste Stadium im Cyclus, Bild 1 an; den Uebergang vermitteln solche Stellen, an denen die Mitosen schon mit E b n e r'schen Zellen resp. jüngern Spermatiden untermischt sind.

Durch Vergleichung der charakterisirten Bilder ist es nun unschwer, sich jenen Vorgang in den Zellen des Samenkanälchens, 
der in der Bildung der Samenfäden gipfelt, zurecht zu legen. Den Ausgangspunkt der Entwickelung stellen die Spermatogonien, die kleinen ruhenden Zellen an der Membr. propria in den Bildern 1-3 dar; sie vermehren sich auf mitotischem Wege. Allmählich treten nun diese Zellen in die, Wachsthumsperiode ein, indem sie an Cytoplasma zunehmen, und auch ihre Kerne bestimmte Veränderungen erleiden. Im ersten Stadium ihrer Umwandlung präsentiren sie sich als Uebergangsspermatogonien, wie sie uns in den Bildern 4 und 5 entgegentreten. Wenn sich die grossen Spermatocyten mitotisch getheilt und sich neue Spermatiden gebildet haben, erfolgt eine weitere Vergrösserung der Zelle, und wir stehen den kleinen Spermatocyten gegenüber, wie sie für das 1. und 2. Bild charakteristisch sind. Hand in Hand mit ihrem Wachsthum rücken sie nun einwärts, von der Kanalwand weg, sie stellen nun nicht mehr die erste, sondern die zweite Schichte von der M. propria aus gerechnet dar. Allmählich reifen sie dann zu den "mittelgrossen Spermatocyten" des 3. Bildes und zuletzt zu den "grossen Spermatocyten" des 4. Bildes heran. Jetzt treten sie in die ${ }^{\mathrm{T}} \mathrm{T}$ eilungsper i o d $\mathrm{e}^{4}$ ein, indem sie einer zweimaligen Theilung (Bild 5) unterliegen, wobei natürlich bei der zweiten Mitose die Menge des Zellplasmas bedeutend geringer sein muss als bei der ersten daher ngrosse und kleine Mitosen". Zwischen den beiden Theilungen aber liegt eine vollkommene Ruheform, die "Spermatocyte zweiter Ordnung " oder ${ }_{n} v$. E b ner'sche Zelle ${ }^{4}$. Erst als die Theilungsprodukte dieser letzteren erkennen wir die jungen Spermatiden, wie wir sie in Bild 1 nnd 2 in mehreren Lagen aufgeschichtet sehen. Jetzt setzt die zweite Hälfte des ganzen Vorganges eiu, die eigentliche Samenfadenbildung, die Umwandlung der Spermatiden zu Spermatozoen - die Zellen gelangen in ibre letzte Phase, in die ${ }_{n} \mathrm{Um}$ wa $\mathrm{ndlung} \mathrm{spe}$ riode. Die Umwandlung erfolgt durch eine Art von Herauswanderung des elliptisch gewordenen Kerns aus seinem Zellkörper in der Richtung nach der Kanalwand, ein Vorgang, dessen ersten Stadien wir auf Bild 3 begegnen. Das Cytoplasma weicht mehr und mehr zurück und bildet bald gleichsam nur einen Anhang des sich zum Spermatozoenkopfe umwandelnden Kerns. Bis zu dieser Stufe sieht man die Spermatiden noch immer frei in den obersten Schichten der Zellauskleidung des Samenkanälchens 
liegen. Nun leitet sich aber jener merkwürdige Vorgang ein, dessen Verständniss früher so grosse Schwierigkeiten bereitet hat, ja dem wir vom Gesichtspunkte eines causalen Erkennens auch noch beute wie ejnem Räthsel gegenüber stehen: die bis dahin ruhenden ${ }_{\text {F }}$ usszellen ${ }^{4}$ unten an der Membrana propria treten nun in eine aktive Periode ein: sie lassen eine zunächst kurze, dann länger werdende stielförmige Verlänǵerung lumenwärts aus sich hervorgeben, und dieser Fortsatz übt eine merkwürdige Attraktionskraft auf die in der Umbildung zu Spermatozoen begriffenen Spermatiden aus. Je eine bestimmte Zahl davon gruppirt sich büschelartig um je einen Fortsatz herum and tritt mit $\mathrm{ihm}$ in eine so innige Verbindung, dass die Fusszelle nun mit den ihr anhaftenden Spermatiden gleichsam ein einheitliches Gebilde darzustellen scheint, den „Spermatoblasten $^{\text {" }}$ von v.Ebner oder den "Samenständer ${ }^{\prime \prime}{ }^{1}$ ). Es kann keinem

1) Ich benütze diese Stelle, um über die Sertoli'schen oder Fusszellen einige Bemerkungen unterzubringen. Ich möchte namentlich darauf hinweisen, dass ich keine Zellgattung kenne, an der eine fibrilläre Differenzirung des Cytoplasmas schöner zum Ausdruck käme, als an diesen Zellen. An Präparaten, die mit Hermann'scher Lösung fixirt sind, scheinen sie manchmal wie fast ausschliesslich aus feinen, parallel und geradlinig verlaufenden Fibrillen zusammengesetzt, die unten fächerförmig divergirend an der Membrana propria inseriren, oben frei auslaufen. Diese fibrilläre Structur ist zuerst von Svä̈n und Masquelin (1883, S. 791) beim Stier beschrieben und seitdem sehr häufig bestätigt worden. Interessant ist das Verhalten dieser Fibrillen oben an der Stelle, wo die Samenfadenköpfe in der Sertoli'schen Zelle stecken. Nach Benda (1887) sollen sich diese Fibrillen an den Spermatozoenköpfen inseriren, und zwar je an einem Kopf eine Fibrille. Diese Angabe findet in meinen Erfahrungen keine Stütze, vielmehr sehe ich an passenden Präparaten ganz deutlich, dass die Fibrillen zwischen den Köpfen frei endigen, ohne sich mit ihnen zu verbinden, dass also die Spermatozoon zwischen die Fibrillen hineingesteckt sind. Da der Protoplasmalappen der jungen Spermatozoen erst jenseits der Endigung der Fibrillen beginnt, gewinnt man den Eindruck, dass die Verbindung der Spermatiden mit dem Fortsatz der Fusszelle nicht eigentlich auf einer Verschmelzung der beiderseitigen Protoplasmaantheile, einer Copulation im Sinne Benda's, sondern lediglich auf einem innigen Contact beruht. Die Zwischenräume zwischen den Fibrillen bilden wohl die Bahnen für die Fett- und Eiweissstoffe, aus denen das junge Spermatozoon das Material für sein Wachsthum schöpft. Die von P l a t o (1896) beschriebenen Kanäle der Membrana propria unter den Fusstheilen der Sertoli'schen Zellen beruhen wohl auf Täu- 
Zweifel unterliegen, dass diese Verbindung, für die B e n $d$ a, wie schon gesagt, den Namen "Copulation" vorgeschlagen hat, für den Ausreifungsvorgang der angehenden Spermatozoen von allergrösster Bedeutung, ja ganz unentbehrlich ist, indem hierdurch die jungen Spermatozoen bis zu ihrer vollen Entwicklung fixirt und mit den zu ihrem Wachsthum nöthigen Nahrungsstoffen versehen werden. Allmählich sehen wir nun, wie die Spermatozoen ihrer entgültigen Gestalt entgegenreifen, wie ihr Kopf die charakteristische Hakenform annimmt, wie sich die Geissel in die Länge zieht und auch an Stärke zunimmt, wie ein ${ }_{n}$ Verbindungsstück" in seiner typischen Gestaltung zum Ausdrucke kommt.

Während dieser ganzen Zeit aber sind die Spermatozoen bündelweise festgehalten von dem Fortsatz einer Fusszelle; erst wenn das Spermatozoon seinen fertigen Zustand vollkommen erreicht und dadurch die zur Erfüllung seiner Anfgabe nothwendigen Eigenschaften erlangt hat, löst sich diese Verbindung, indem jener Fortsatz schwindet (Bild 2), und nun können die freigewordenen Samenfäden ihren Weg antreten.

In einer Beziekung aber erfordert diese Darstellung noch eine Ergänzung. Wir haben geseben, dass sich die Spermatogonien während ihrer allmählichen Umwandlung zu Spermatocyten mehr und mehr von der Kanalwand ablösen und einwärts rücken. An ihrer früheren Stelle erscheint nun wieder eine Schichte gewöhnlicher, wandständiger, ruhender Spermatogonien. Woher sind diese entstanden? Nach der gangbaren Annahme sollten bei der Umwandlung einer jeden Spermatogoniengeneration zu Spermatocyten einzelne Spermatogonien in unverändertem $\mathrm{Zu}$ stande an der Kanalwand zurtickbleiben, und diese sollen dann als Reservematerial den Ausgangspunkt für den nächsten Nachschub bilden. Ich habe natïlich selbst Anfangs diese Meinung gehegt, wie überrascht war ich aber, als ich auf dem Bilde 4 und 5 die Wahrnehmung machen musste, dass bier ausnahmslos alle Spermatogonien jene Veränderungen aufwiesen, die fǜ die "Uebergangsspermatogonien" charakteristisch sind, d. h. dass

schung; ich habe die Membrana propria bei allen von mir untersuchten Säugethieren auch bei Plato's Hauptobject, der Katze, immer als zusammenhängende Haut gesehen; der Eintritt der Nahrungsstoffe in das Iniere des Samenkanälchens muss auf dem Wege der Filtration und Diffusion erfolgen. 
der Kern bei allen zu einem sehr feinfädigen Spirem umgewandelt erscheint; vergebens suchte ich nach jenen unveränderten „Reservezellen". So ganz einfach also, wie es die bisherigen Darstellungen schildern, kann die Sache nicht liegen; ich sehe nach reiflichem Nachdenken keine andere Möglichkeit der Erklärung, als durch die Annahme, dass sich der neue Spermatogonienvorrath bei der Ratte in der Weise bildet, dass nach Ablauf der Spermatocytentheilung - also in dem Stadium zwischen Bild 5 und 6 - sich nicht alle Uebergangsspermatogonien weiter zu Spermatocyten umwandeln, sondern einzelne davon immer wieder in den frtuheren vollkommenen Ruhezustand zurückkehren, um als Spermatogonien wieder an die Wandung heran zu rücken, sich bald mitotisch auf die frühere Zahl ergänzend. Für diese Annahme spricht auch der Umstand, dass die Zahl der Uebergangsspermatogonien entschieden grösser ist als die der Spermatocyten; bilden doch beide Zellgattungen für sich allein je eine zusammenhängende Lage, wobei doch bei den viel grösseren Dimensionen der Spermatocyteu weniger Elemente in der zweiten Reihe neben einander Platz finden können, als dies in der ersten Reihe bei den kleineren Cebergangsspermatogonien der Fall ist.

\section{Die Sphäre in den Spermatocyten.}

Bei den meisten Färbungen tritt in den Spermatocyten, schon bei schwachen Vergrösserungen erkennbar, ein runder, scharf begrenzter Körper in die Erscheinung, ein Produkt des Cytoplasmas, in der Nachbarsehaft des Kernes gelegen: das Gebilde, das neuerdings als "Archiplasma“" oder "Sphäre“ bezeichnet wird, früher dagegen gewöhnlich als „Nebenkern“ aufgefasst wurde. Man kann dieses Gebilde durch gewisse Doppelfärbungen mit einer Schärfe zur Ansicht bringen, die nichts zu wünschen übrig lässt. B e $\mathbf{n}$ d a (1892) bat es z. B. durch eine Combination von Lichtgrün F. S. und Safranin sehr distinkt darstellen können; es nimmt hierbei eine intensiv grüne Färbung an, während der Kern roth und das Cytoplasma nur leicht grün gefuirbt erscheint. Auch die von $R$ a w it z (1895) eingeführte Behandlungsweise (Tanninbrechweinstein-Fuchsinfärbung) scheint zu ihrer Darstellung hervorragend geeignet zu sein. Ich selbst habe, gleich Meves (1896) und Niessing (1896) in der M. 
H e i d e nha in' schen Eisenhämatoxylinfärbung, besonders in Verbindung mit einer leichten Nachfärbung in Erythrosin, eine recht günstige Methode gefunden, um die Sphäre darzustellen; sie nimmt dabei durch das Eisenbämatoxylin einen leicht grauen Ton an, dem die Erythrosinnachfärbung dann noch eine röthliche Farbennuance beifiigt. Aber am schärfsten gelang es mir, die Sphäre hervorzuheben mit einer Doppelfärbung in Hämalaun und Erythrosin, besonders an Präparaten, die mit Sublimat-AlkoholEisessig fixirt worden waren. Man erhält mit dieser Methode sehr klare und zierliche Bilder; der Kern färbt sich in violetter Farbe, das Zellplasma nimmt einen leichten Rosaton an, die Sphäre aber tritt bei richtiger Anwendung der Fürbemittel in intensiver Rubinfärbung lenchtend aus der blassen Umgebung hervor und lenkt dadurch auf den ersten Blick, oft noch vor dem Kern, die Aufmerksamkeit auf sich. Dieses dentliche Hervortreten der Sphäre ermöglicht es, sie gleich von den ersten Stadien ihrer Entstehung an nachzuweisen und sie bis zu jenen Phasen der Spermatocytentheilung zu verfolgen, wo sie sich durch Auflösung. dem Blicke entzieht.

Suchen wir die „Sphäre" zum Zwecke eines genaueren Studiums dort auf, wo sie den Höhepunkt ibrer Entwicklung erreicht, nämlich in den mittelgrossen und grossen Spermatocyten des 3. und 4. Bildes (Fig. 7-10). Sie präsentirt sich hier fast immer als eine regelmässige, grosse $\mathrm{Kugel}^{1}$ ) mit einem Durchmesser von ungefäbr $4 \mu$, also nicht ganz ein Drittel des Kerndurchmessers $(14-16 \mu)$ an Grösse erreichend, glatt und regelmässig begrenzt, entweder in direkter Berthrung mit dem Kern oder doch in seiner nächsten Nähe liegend. Jene zackigen, unregelmässigen Sphärenformen, die bei Salamandra von $M$ e $v$ es und $R$ awitz beschrieben sind, kommen hier in den Spermatocyten nicht vor; wir stehen hier, wie gesagt, einer regelmässigen Kugelform gegenüber, nur manchmal ist diese durch eine schwach elliptische Form ersetzt. In der überwiegenden Mebrzahl der Fälle finden wir sie streng in der Längsachse der Zelle gelegen und zwar weitaus häufiger lumenwärts rom Kern als auf der anderen Seite.

1) In den Spermatocyten des Menschen finde ich sie nicht rund, sondern elliptisch, dem Kern flach aufgedrückt. Bei Katze, Meerschweinchen und Igel ist sie rund. 
Man kann also sehr wohl ron einer gewissen Gesetzmässigkeit in der Lagerung der Sphäre sprechen, nur ist diese Gesetzmässigkeit nicht als eine „regula sine exceptione“ aufzufassen. Zählungen, die ich nach dieser Richtung hin vorgenommen habe, zeigten, dass die Sphäre in 93 Fällen von 100 streng in der Zellachse lag; in 7 Fällen aber fand sie sich seitlich neben dem Kern. Von den 93 Fällen hatte die Sphäre 75 mal an der Lumenseite des Kerns und nur $18 \mathrm{mal}$ auf dessen der Kanalwand zugekehrten Seite ihren Sitz.

Die Sphäre besteht ihrem ganzen färberischen Verhalten nach aus einer besonderen Verdichtung des Zellkörpers, obne jede Betheiligung von chromatischen Elementen; sie stellt ein richtiges cytoplasmatisches Gebilde dar. Sie muss von ziemlich consistenter Beschaffenheit sein. Dies erkennt man am schönsten an solchen Stellen misslungener Sublimatpräparate, wo das Zellplasma der Spermatocyten ganz oder theilweise zerstört erscheint: die Sphärenkugeln zeigen sich hier oft in wohlerhaltenem $\mathrm{Zu}$ stande, als ob sie geradezu mit Nadeln künstlich isolirt worden wären. Nicht also lediglich um ein optisches oder färberisches Pbänomen handelt es sich hier, sondern um einen realen, scharf abgegrenzten widerstandsfähigen Körper, der in das gewöhnliche Zellplasma als etwas von ihm differentes eingebettet ist.

Die Abgrenzung der Sphäre gegen das Cytoplasma scheint an den meisten Präparaten aus dem Rattenhoden durch gar nichts anderes als durch den Rand der Sphärensubstanz selbst gegeben zu sein. Nur an Eisenhämatoxylinpräparaten, die ich sehr lange in der Eisenalaunlösung liegen liess, oder die ich zu schwach entfärbt hatte, sah ich an ihrem Rande schwarze Körner und Schollen, oft so viele, dass sie um die Sphäre einen förmlichen Reif bildeten, der freilich niemals ganz zusammenhängend, sondern immer an vielen Stellen unterbrochen erschien. Ich möchte aus dieser Erscheinung so viel folgern, dass die Sphärensubstanz in ilıren Randschichten von etwas ungleichmässiger Dichtigkeit ist. Ein ,,schönes, scharf und dunkler als die Rindensubstanz gefärbtes Körnerstratum“, wie es Niessing (1896, S. 118) als Begrenzung der Sphäre beim Neerschweinchen regelmässig fand, habe ich bei der Ratte vergeblich gesucht. Es nnterliegt keinem Zweifel, dass hier der neuerdings von $M$. 
H e i d e n ha in (1894, S. 644) präcisirte Sphärenbegriff, wonach die "Sphäre" kein selbstständiges Organ-der Zelle, sondern nur eine durch das van Beneden'sche Mikrosomenstratum hervorgerufene optische Erscheinung sei, nicht zur Anwendung gelangen kann; es ist hier etwas anderes im Spiele.

An den Hämalaun-Erythrosinfärbungen, aber auch, wenngleich nicht so deutlich, an anderweitigen Präparaten, erkennt man die ron $\mathrm{M}$ e ves und $\mathrm{N}$ i es s ing beschriebene Erscheinung, dass die Sphäre aus einer dunkler schattirten äusseren und einer blasseren inneren Schichte besteht. Die Abgrenzung beider Zonen gegeneinander ist freilich nicht immer gleich deutlich; auch scheint das Breitenverhältniss zwischen ihnen etwas wechselnd zu sein. Ferner ist bemerkenswerth, dass das hellere Innenfeld etwas excentrisch liegen kann. An Hämalaun-Erythrosin- sowie an Magentarothpräparaten wird man nur selten in der Mitte der helleren Innenzone wieder eine dunklere centrale Stelle vermissen, die an solchen Präparaten aber immer nur als ein diffuser, schattenhafter Fleck und niemals etwa als ein scharf begrenztes Körnchen erscheint.

Niessing's Angabe (1896, S. 116), dass die Sphäre des Meerschweinchens "von einer Menge feinster radiär gestellter Protoplasmafibrillen" durchsetzt sei, ferner dass sie mehrere kugelschalenartig angeordnete concentrische Körnerstrata aufweise, veranlassten mich, der Frage nach der inneren Beschaffenheit der Sphäre besondere Beachtung zu schenken. In beiden Beziehungen waren meine Beobachtungen bei der Ratte vollkommen negativ; von Fibrillen sah ich niemals eine Spur, weder in der Sphäre, noch aber im Cytoplasma der ruhenden Spermatocyten; Granulationen fanden sich öfters in der Sphäre, doch immer nur sporadisch und ohne jede Andeutung einer regelmässigen Anordnung. Ich gebe $z u$, dass negative Erfahrungen gegenüber positiven Angaben immer nur von sehr bedingtem Werth sind; indessen ist hier zu berücksichtigen, dass ich mich genau derselben Methode bedient hatte, wie $\mathrm{N}$ i ess ing. Meiner Ueberzeugung nach besitzt die Sphäre in den Spermatocyten der Ratte keine fibrilläre Struktur, sondern besteht aus einer compakten, homogenen Protoplasmaverdichtung; ebenso stellen die Schollen, die man darin öfters wahrnimmt, nichts typisches, nichts regel- 
mässiges dar. Also weder eine fibrilläre, noch eine granuläre Beschaffenheit konmt der Sphäre zu.

Die Eisenhämatoxylinpräparate fügen zu diesen Einzelheiten eine wichtige Thatsache hin\%u: den Nachweis des Centrosoms in der Sphäre, oder richtiger der Centrosomen, denn immer handelt es sich um ein kleines Körnchenpaar. Eine leichte oder ganz gewöhnliche Sache ist es freilich nicht, diese Gebilde gefärbt zu erbalten; man wird auch an den relativ gelungensten Präparaten viele Sphären ganz leer, andere wieder so granulirt finden, dass man unter den vorhandenen Körnern die Centrosomen nicht sicher herauszufinden im Stande ist ${ }^{1}$ ). Daneben aber wird man $a b$ und $z \mathfrak{u}$ immer Zellen finden, in denen man sich einer tadellosen Centrosomenfärbung erfreuen kann und die der Forschung nach dieser Seite hin als sichere Grundlage dienen können. Die besten Anschauungen der Centrosomen erhielt ich an Präparaten aus dem Hoden des Katers und zwar aus einem Object, das nicht mit Sublimat, sondern mit H e r ma n n'scher Lösung fixirt worden war. Aber auch von der Ratte besitze ich manche Präparate, an denen ich die Centrosomen der Spermatocyten überzeugend demonstriren kann.

Die Centralkörperchen sind also, wie gesagt, immer in der Zweizahl vorhanden. Man findet sie als zwei kleine, aber doch noch leicht sichtbare, rundliche, gleich grosse Körnchen, neben einander gelegen, aber ohne mit einander in Berïhrung zu stehen, gewöhnlich in der Mitte der Sphäre. Letzteres - ist aber nicht ausnahmslos der Fall. Oft zeigen sie eine etwas excentrische Lagerung und besonders bäufig sieht man sie gegen den Kern hingeritckt, manchmal mit ihm in direkter Berührung, so dass sie also ganz an den Rand der Sphäre zn liegen kommen. Das ist namentlich der Fall in den vorgerückteren Stadien der grossen Spermatocyten (s. Fig. 9): hier liegen sie

1) Beim Meerschweinchen ist der Nachweis der Centrosomen noch dadurch besonders erschwert, dass sich jene erwähnte centrale dunkle Substanz innerhalb der hellen Innenzone, in die offenbar die Centrosomen eingebettet sind, an Eisenhämatoxylinpräparaten mit Vorliebe ganz schwarz färbt. Man erhält so in der Mitte der Spermatocytensphäre oder auch excentrisch ein grosses schwarzes Korn (s. Niessing's Fig. 1 und 2), das offenbar noch etwas mehr ist, als eine Verklumpungsfigur der beiden Centrosomen. 
stets in der Nähe der Kernmembran, ein Verhalten, das man schon als erste Phase jenes Vorganges auffassen kann, durch den die Centrosomen die Sphäre verlassen, um zur Bildung der Spindelpole auseinander $z \mathfrak{u}$ weichen. Bei einer solchen Lage ist die gegenseitige Stellung der beiden Centralkörperchen natürlich eine gegebene: die sie verbindende Linie fällt mit der Kernoberfläche zusammen oder läuft wenigstens parallel mit ihr; in allen anderen Fällen aber kann ihre gegenseitige Stellung eine ganz beliebige sein, wie man das durch Vergleichung der Fig. 7 u. 8 erkennen wird.

Im Allgemeinen erscheinen die Centralkörperchen in den Spermatocyten der Ratte an meinen Präparaten genau unter demselben Bilde, wie sie Meves (1894 und 1896) von Salamandra darstellt. Eine Vermehrung der Centralkörperchen auf drei, wie sie $\mathrm{N}$ i ess in $g$ fand, vermochte ich nicht sicher festzustellen. Die typische Zahl ist jedenfalls zwei.

An den Eisenhämatoxylinpräparaten ist es mir niemals gelungen, eine verbindende Substanz zwischen den beiden Centralkörnchen nachzuweisen. Hier' treten aber ergänzend die Bilder ein, die man mit anderen Färbungen erhält. Ich hatte erwähnt, dass bei der Färbung mit Hämalaun und Erythrosin in der Mitte der Sphäre eíne dunkle Stelle zur Erscheinung kommt. Der dunkle Fleck entspricht der Stelle, an der die Centralkörperchen gewöhnlich liegen, und doch können es diese allein nicht sein, die jene Erscheinung hervorrufen, denn dazu ist der Fleck $z u$ breit, zu diffus, zu einheitlich. Als plausibelste Erklärung bietet sich also die Annahme, dass hier eine besondere blasse Substanz im Spiele ist, in die die Centrosomen eingebettet liegen und durch die sie mit einander verknüpft werden: eine Centrodesmose im Sinne von M. H e i d e $\mathrm{n}$ h a i n. Dass diese Substanz an den Eisenhämatoxylinbildern nicht zur Ansicht gelangt, liegt wohl hauptsächlich daran, dass bei dieser Färbung die ganze Sphäre eine dunkle, graue Farbe annimmt.

Mit vorstehender Beschreibung kann natürlich ein Verständniss der „Sphäre“ noch nicht erreicht sein; die wichtigsten Aufklärungen müssen wir vielmehr von der Untersuchung der Frage erwarten: wie entsteht dieses. Gebilde? Zum Studium dieser Frage scheint mir der Rattenhoden ein besonders gitnstiges Object zu sein. Denn während im Katzenhoden z. B. die Sphäre 
in den meisten Spermatogonien schon als fertiges kräftig entwickeltes Gebilde vor uns liegt, lässt sich bei der Ratte ihr allmähliches Werden in den Spermatogonien recht gut beobachten. In den meisten Spermatogonien - d. h. in den kleinen, ruhenden Zellen an der Kanalwand - vermisst man sie. $A b$ und zu gelingt es aber schon in diesen Zellen (Fig. 6), mit Hülfe der Hämalaun-Erythrosin-Doppelfärbung ihre ersten Spuren nachzuweisen in Form einer ganz kleinen, sich in charakteristischer Weise dunkel färbenden flachen Stelle in unmittelbarer Berührung mit dem Kern. Deutlicher und nunmehr ausnahmslos nachweisbar tritt sie hervor als linsenförmiges, dem Kern an einer beliebigen Stelle ebenfalls dicht anliegendes Klümpchen in den ,Uebergangsspermatogonien" (Fig. 4 und 5). In den "kleinen" und "mittelgrossen" Spermatocyten nimmt : sie dann allmählich an Umfang zu und bläht sich Hand in Hand damit zur Kugelgestalt auf; schon bei den mittelgrossen Spermatocyten (Fig. 7 und 8) ist diese Form vollkommen ausgesprochen. Von der Trennung einer Rinden- und Marksubstanz ist auf dieser Stufe noch nichts zu sehen, die Sphäre erscheint noch immer von ganz gleichmässiger innerer Beschaffenheit; erst in den "grossen " Spermatocyten prägt sich diese Gliederung aus, in dem Stadium, in dem die Sphäre zu ibrer grössten Ausdelınung herangewachsen ist (Fig. 9 und 10). In allen Phasen ihrer Entwicklung beherbergt die Sphäre die Centralkörperchen.

Aus dem dargelegten Entwicklungsvorgang ergiebt sich also, dass die „Sphäre" als eine selbstständige, spontane Differenzirung des Cytoplasmas aufzufassen ist, die wohl im Anschluss an die Centrosomen, aber ohne Beziehungen zu anderen in der Zelle schon vorhandenen Gebilden entsteht. Vor allen Dingen lässt sich also eine Analogie unseres Gebildes ausschliessen mit jenen in den Samenbildungszellen von wirbellosen Thieren so weit verbreiteten, in ihrer Form so mannigfaltig wechselnden Körpern, die ihrer Herkunft nach auf Reste der achromatischen Spindel bei der mitotischen Theilung der betreffenden Zellen zurückzuführen sind, und die in den letzten Jahren von Platner, Zimmermann, Bolles Lee, Calkins, v. Erlanger u. A. so genau untersucht worden sind ${ }^{1}$ ). Beschränkt man, wie das v. E r -

1) Vergl. hierüber das ausführliche Referat von v. Erlanger (1896 und 1897), namentlich dessen III. Theil. 
la nge e (III) verlangt, die von Büts c hli (1871) eingeführte Bezeichnung "Nebenkern" auf derartige Spindelderivate, so kann man sagen, dass die Säugethiere ïberhaupt keinen wahren „Nebenkern" in ihren Samenzellen besitzen, denn auch der weiter unten zu besprechende "chromatoide Nebenkörper" hat mit der Spindel bestimmt nichts $\mathrm{zu}$ thun.

Um was handelt es sich hier aber? Wenn ich im Anschluss an die von $\mathrm{Hermann}, \mathrm{Meres}, \mathrm{Niessing} \mathrm{u.} \mathrm{A.}$ benutzte Terminologie das Gebilde bisher obne Vorbehalt stets als "Sphäre" bezeichnet habe, so könnte vielleicht der Leser daraus den Schluss ziehen, dass ich unsere "Sphäre" für identisch halte mit dem, was va n Beneden als ,Spluère attractive" in die Literatur eingefibrt hat. Dies ist aber keineswegs mein Standpunkt. Auf keinen Fall liegt hier eine ähnliche Bildung vor, wie etwa der je nach der Färbung helle oder dunklere Hof, der bei Lenkocyten und vielen anderen Zellen das Centrosoma umgiebt und dessen Bedeutung mir noch immer nicht vollkommen anfgeklärt zu sein scheint. Auch mit B o v e r i's "Archiplasma", wie es in den Eizellen von Nematoden vorhanden zu sein scheint, darf man, glaube ich, den hier vorliegenden Körper nicht obne weiteres in eine Linie stellen. Zwar würde Boveri's Definition der "Astrosphäre" (1895, S. 35) nals desjenigen Complexes, der sich im Umkreis des Centrosoma als etwas der Substanz oder Struktur nach Specifisches von dem indifferenten Protoplasma unterscheiden lässt" - recht gnt auf unsere "Sphäre" passen ; indessen ergiebt sich doch auf der anderen Seite ans dem Verhalten unserer "Sphäre" bei der Theilung der Spermatocyten, ebenso wie auch aus ihrer Unabhängigkeit von den Centrosomen in den Spermatiden, aus zwei Punkten, die noch einzeln zur Sprache kommen sollen, sicher die Thatsache, dass hier doch wohl etwas anderes im Spiele ist, als bei dem B overi'schen Archiplasma.

Die Ansicht also, die ich mir über die Bedeutung der Sphäre gebildet habe, stimmt vollkommen mit der von v. Kostan e cki (1896, S. 213) und v. Erlanger (1897, S. 171) ausgesprochenen überein. Auch mir scheint, wie v. Kostanecki, die Sache so zu liegen, „dass wir es hier mit ganz specifischen Stoffen zu thun haben, die, um den Centralkörper sich gruppirend, eine vollkommene Kugel bilden, die aber ganz verschieden ist 
von dem, was wir sonst als Sphäre bezeichnen." Es liegt hier meiner Meinung nach etwas ganz Besonderes, Specifisches, nur den germinativen Zellen Eigenthümliches vor; denn etwas ganz Analoges ist, so viel ich weiss, in keiner andern Zellgattung nachgewiesen worden, wenigstens nicht ganz in ähnlicher Form. Verdichtungen des Cytoplasmas um das Centrosoma und die wahre "Sphäre" herum kommen zwar auch in anderen Zellen vor, so z. B. in den Knorpelzellen des Frosches (M e ves 1895), in den Spinalganglienzellen desselben Thieres ( $L$ e $n$ b o s s é k 1895), bei welch letzteren ich jene Verdichtung als „Plasmosphäre“ bezeichnet habe; indessen lassen sich diese mdeutlichen, leichten diffusen Verdichtungen in der Umgebung jener Centralgebilde doch wohl kaum in direkte Parallele setzen mit dem scharf begrenzten, selbstständigen Körper, der in den Spermatocyten als „Sphäre" die Centralkörperchen beherbergt, höchstens könnte man in ihnen die ersten Andentungen eines solchen Gebildes erblicken.

Eine scharf umschriebene Verdichtung des Cytoplasmas um das Centrosoma herum, wie sie hier vorliegt, ist in den Spermatocyten allgemein verbreitet, nicht nur bei Säugethieren und Wirbelthieren, sondern auch bei Wirbellosen. Man findet über diesen Gegenstand die ausführichsten Mittheilungen in dem sorgfältigen, auch eigene Beobachtungen enthaltenden Referate v. Erlanger's, besonders in dessen letztem IV. Abschnitt. Es scheint aber, dass bei Wirbellosen die ${ }_{n}$ Sphäre" insofern eine etwas andere Zusammensetzung besitzt, als sie einen stark körnigen Bau aufweist. So schildert z. B. v. Erlanger (1897, S. 2) die unserer "Sphäre" entsprechende ,Kernhaube" bei Blatta als ein Gebilde, das zablreiche, ziemlich ansehnliche Körner enthält, welche in der lebenden Zelle sehr deutlich hervortreten, während das übrige Cytoplasma von Körnern relativ ganz frei ist." Anders liegt aber die Sache bei Säugern (Ratte, Katze, Meerschweinchen, Igel, Mensch): die Sphäre lässt hier keinen körnigen, sondern einen homogenen Bau erkennen, und deshalb könnte ich mich auch nicht der v. Erla n ger'schen Terminologie anschliessen, in der die ,Sphäre" als "Centrodentoplasma" bezeichnet wird - offenbar wegen der Aehnlichkeit der körnigen Spbäre der Wirbellosen mit dem körnigen Deutoplasma mancher Eizellen. 
Aus den weiteren Mittheilungen wird hervorgehen, dass die Sphäre später in Spermatiden eine grosse Rolle zu spielen berufen ist bei der Bildung der Appendiculargebilde am vorderen Ende des Samenfadenkopfes. Hierin scheint mir der Schlüssel zu liegen für ein Verständniss der Bedeutung der "Sphäre“. Ich bin der Meinung, dass man sie nicht von einem allgemeinen Standpunkte aus aufzufassen, sondern schon ron den ersten Stadien ihrer Entstehung an als eine besondere Differenzirung des Zellplasmas zu betrachten hat, die schon in Beriehung steht $\mathrm{zu}$ dem merkwürdigen Umwandlungsvorgang der Spermatiden zu Spermatozoen, gewissernaassen die erste Anlage gewisser Theile des Spermatozoenkopfes bildend. In dieser Ansicht werde ich namentlich sehr bestärkt durch die Beobachtung, dass die Sphäre in den Spermatocyten des Meerschweinchens, bei dem ja bekanntlich jene accessorischen Gebilde, am vorderen Pol des Spermatozoenkopfes eine so aussergewöhnlich starke Entwicklung erreichen, besonders umfangreich ( $5-6 \mu$ gross) und auffallend scharf begrenzt ist; es zeigt sich hier also schon ein gewisser Parallelismus zwischen der Mächtigkeit der „Kopfkappe“, des „Akrosomas" und der der Spermatocytensphäre.

Wäre unsere "Sphäre" gleichwerthig mit der van B en e d e n-M. H e i d e n h a i n'schen "Attractionssphäre" oder mit B overi's Archiplasma, so müsste sich dies namentlich bei der mitotischen Theilung, der die Spermatocyten zuletzt unterliegen, durch ein bestimmtes Verhalten kundgeben. Die Sphäre müsste entweder spurlos verschwinden, in den Polstrahlungen aufgehen, oder aber sie müsste sich Hand in Hand mit dem der Theilung vor ausgehenden Auseinanderweichen der Centrosomen in zwei gleiche Sphären theilen, die dann die Centrosomen auf ihrer Wanderung nach den Spindelpolen hin begleiten, für diese nach wie vor eine Umhüllung bildend. Keine aber von diesen beiden Voraussetzungen trifft zu. Ich habe in dieser Beziehung folgendes Verhalten feststellen können. Wenn sich der Kern der grossen Spermatocyten zur Theilung anschickt, so findet man, dass die Centrosomen aus der Sphäre herauswandern; sie weichen auseinander und man findet sie dann nackt, ohne jede Sphärenunbüllung, an den Polen der Spindel. Wider alles Erwarten schwindet die alte, von ihren Centrosomen verlassene Sphäre nicht sofort, sondern lässt sich noch in ungetheiltem Zustande als ein etwas geschrumpfter, 
noch immer lebhaft färbbarer Körper seitlich neben der Spindel nachweisen während der ganzen Phase der Spindelbildung und auch der Aequatorialplatte; erst mit dem Beginn der Metakinese entzieht sie sich dem Blicke, offenbar Anrch Aufösung und gleichmässige Vertheilung ibrer Substanz auf das ganze Cytoplasma der sich theilenden Zelle; muss sich doch ihre Substanz in gleicher Menge in den beiden Theilungshälften der Zelle finden, da sie sich doch in den Tochterzellen zu je einer neuen Sphäre zu reconstruiren hat. Die Nachweisbarkeit der Sphäre während der ersten Stadien der Spermatocytentheilung war bisher, wie ich sehe, nicht bekannt. Die Sphäre stellt sich jetzt freilich, wie in den Fig. 11 und 12, immer in etwas reducirtem Zustande dar; auch hat sie ihre frühere regelmässige Kugelform eingebtisst, ist bald in die Länge gezogen, bald eingebuchtet, manchmal auch in mehrere Stücke zerfallen, zeigt nunnehr unregelmässige Ränder und in ihrem Imnern Ungleichmässigkeiten - all dieses weist schon auf ihre bald erfolgende Auflösung hin, aber nachweisbar bleibt sie noch immer, so lange, bis die Tochterchromosomen nicht anseinanderzuweichen beginuen. - Dabei zeigt der Sphärenrest in der Mehrzahl der sich zur Theilung anschickenden Zelle eine bestimmte Lagerung. Wir finden ihn nämlich mit auffallender Häufigkeit weder dem Spindelpol, noch dem Aequator entsprechend gelagert, welch letztere Lage eigentlich die naturgemässe wäre, sondern in einer Mittelstellung, seitlich neben dem einen der Spindelpole, gewöhnlich fast ganz an die Peripherie gertickt. Vorausgesetzt also, dass die Sphäre keinen Ortswechsel erfahren hat, sondern an der Stelle ibres früheren Sitzes geblieben ist, müsste man annehmen, dass sich die Spindelachse und somit auch die Achse der sich theilenden Zelle zu der früheren Zellachse unter einem Winkel von etwa $45^{\circ}$ verhält. Freilich kann hier von einer strengen Gesetzmässigkeit wieder nicht die Rede sein, denn es lassen sich auch Fälle beobachten, wo der Spindelrest eine polare oder aquatoriale Lage aufweist.

Nit der Auflüsung des Gebildes ist die erste Etappe in der Geschichte der "Sphäre" zum Abschluss gekommen. Sie hat damit ihre Rolle durchaus noch nicht ausgespielt. Sobald die erste Mitose der Spermatocyten vollzogen ist und als erste Generation von Tochterzellen die v. Ebner'schen Zellen er- 
scheinen, sehen wir die Sphäre in diesen wieder auftauchen, in ihrer charakteristischen Kugelform, wie früher, in der Nachbarschaft des Kernes gelegen; nur um ein Geringes kleiner als in den Spermatocyten I. Ordnung. Auf welche Weise sie sich hier von Neuem gebildet hat, blieb mir unklar; offenbar geht der Vorgang ihrer Reconstitution sehr rasch vor sich. Bei der zweiten Spermatocytentheilung verhält sie sich genau so, wie bei der ersten. Auch hier gelingt es, den Sphärenrest in den ersten Phasen der Mitose, bis zu dem Eintritt der Metakinese, nachzuweisen. Auch hier verschwindet sie aber dann, um in den Tochterzellen der zweiten Theilung, der Spermatiden, wieder zu erscheinen. Ibr Verhalten in diesen, ihre Endschicksale, sollen später den Gegenstand einer besonderen Betrachtung bilden;

Zum. Schlusse mögen hier einige historische Bemerkungen über die Sphäre in den Spermatocyten der Säugethiere Platz finden. Einer der ersten, der die Sphäre in den Spermatocyten (nicht in den Spermatiden!) gesehen hat, ist unstreitig Renson. Auf S. 304 seiner Arbeit (1882) findet sich die Angabe, dass in den Spermatocyten der Ratte neben dem Kern ein stark lichtbrechender, unregelmässiger Körper liege, der sich mit Pikrokarmin nicht fürbe und konstant zu sein scheine. Auf S. 317 benennt Renson dieses Gebilde, das er hier als eine "granulation foncée" schildert, als "corpuscule accessoire". Fig. 1-2 lassen, wie unvollkommen sie auch seien, keinen $Z$ weifel darüber, dass dieses accessorische Körperchen wirklich der Sphäre entspricht.

Der erste, der annähernd zutreffende Abbildungen der Spermatocytensphäre gab, war wohl H. Brown (1885); seine Zeichnungen und Angaben beruben auf der Anwendung der Goldmethode, die, wie es scheint, zur Darstellung der Differenzirungen im Cytoplasma der Zellen der Samenkanälchen nicht ungünstig ist. Brown giebt an (S. 347), (lass es ihm gelungen sei, das Gebilde sogar schon in den Spermatogonien (wahrscheinlich sind hier unsere "Uebergangsspermatogonien" gemeint) nachzuweisen, wo es aber etwas kleiner sei als in den Spermatocyten. Während der Mitose dieser letzteren scheint es, als ob das accessorische Körperchen in mebrere Stücke zerfiele. In den Spermatiden taucht aber ein neues accessorisches Körperchen auf und Brown stellt es schon als möglich hin, dass sich dieses Körperchen aus den Resten des früheren accessorischen Körperchens bilde.

Es kann nicht fraglich sein, dass auch Hermann (1889) die Sphäre in den Spermatocyten der Maus gesehen hat. Indessen ist die Schilderung, die Hermann davon giebt, nicht zutreffend. Hermann lässt (S. 76) die "Sphäre", die er als "Nebenkern" bezeichnet, in den vollständig ausgebildeten Spermatocyten aus zwei Bestandtheilen bestehen: „einem ovalen farblosen Körperchen und einem demselben an irgend einer Stelle, meist an einem der Pole ansitzenden, durch Gentiana 
violett tingiblen Knöpfchen". Diese Angabe steht in vollkommenem Widerspruch sowohl mit meinen eigenen Befunden wie nit denjenigen Niessing's; ein solcher Aufbau der Sphäre ist mir nie vor die Augen gekommen. Bei der Betrachtung der Fig. 30 Hermann's, der einzigen, die eine Spermatocyte von der Maus mit dem "Nebenkern" darstellt, erblicken wir ein blasses, durchaus nicht farbloses, sondern braun tingirtes ovales Körperchen in der Nähe des Kerns, das seinem ganzen Aussehen nach der Sphäre zu entsprechen scheint. Unweit davon aber bildet Hermann noch ein viel kleineres, intensiv blau gefärbtes Körnchen ab. Zunächst fällt schon auf, dass dieses Körnchen, das nach Hermann einen Theil des "Nebenkerns" bilden soll, mit dem anderen Theil desselben, der blassen Kugel, gar nicht in direkter Berührung steht, sondern durch einen deutlichen $Z$ wischenraum davon getrennt ist, so dass man fragen muss, weshalb denn H e r In a $n \mathbf{n}$ diese zwei selbständigen. Dinge zu einem Gebilde zusammenfasst. - Ich muss die Existenz eines solchen Körnchens, wenigstens als eines constant in solch typischer Lagerung befindlichen Gebildes, entschieden bezweifeln, wenigstens für die von mir untersuchten Thiere (Ratte u. s. w.). Am wahrscheinlichsten scheint mir noch, dass bei dem Hermann'schen Körnchen ein "ehromatoides Nebenkörperchen" im Spiele war, wie es im Cytoplasma der Spermatocyten bald allein, bald in der Zwei- oder Dreizahl fast regelmässig vorkommt (s. weiter unten). Indessen zeigt dieses Körperchen keine regelmässigen Lagebeziehungen zur Sphäre, und wenn es so nahe zu ihr liegt wie auf der Hermann'schen Figur, was ja gelegentlich vorlsommen mag, so kann es sich bloss um einen Zufall handeln. - Auch eine zweite Angabe Hermann's (S. 78) muss auf Widerspruch stossen. Hermann sagt, dass der Nebenkern in jener Stufe der Spermatocyten, bei der das Chromatin in Kern bereits in Form von Ringen angeordnet ist - das wären also unsere „grossen Spermatocyten" - spurlos verschwunden ist. Ich habe aber gefunden, dass die Sphäre bei der Ratte gerade in diesen Zellen den Gipfelpunkt ihrer Entwicklung erreicht. Hermann's Angabe dürfte sich übrigens daraus erklären, dass die von ihm hauptsächlich angewandite Färbungsmethode, die Safranin-Gentianafürbung, zur Darstellung der Sphäre nicht besonders günstig ist. - Auch die Hypothese, die Hermann über die Entstehung der Sphäre ausspricht (S. 87), dass sie nämlich aus dem Kern ,herausgeschleudert wird“, ist wohl als missg!ückt zu bezeichnen.

Benda (1891) stellte die Sphäre, die er Archiplasma nennt, in den Spermatocyten von verschiedenen Säugethieren mit seiner schon eingangs erwähnten Doppelfärbung dar und bemerkt ganz richtig, dass der "chromatoide Nebenkörper" zu diesem Archiplasma keine constanten Beziehungen erkennen lässt. Bei den Theilungen der Spermatocyten, aus denen die Spermatiden herporgehen, verschwindet das Archiplasma als gesonderter Zelltheil; in den neugebildeten Spermatiden aber (die Benda merkwürdigerweise auch noch Spermatocyten nennt) taucht das Gebilde neben dem Kern sofort wieder auf. 
Die erste ganz ausführliche Beschreibung der Sphäre in den Spermatocyten der Säuger hat ohne Frage Niessing gegeben. Inwiefern meine eigenen Befunde mit den seinigen übereinstimmen, inwieweit sie von ihnen abweichen, wurde schon oben auseinandergesetzt.

\section{Die Veränderungen des Kerus von den Spermatogonien an bis zur Spermatocytentheilung.}

Indem wir die Veränderungen ins Ange fassen wollen, die die Kerne der Zellen der Samenkanälchen bis zur Spermatocytentheilung erfahren, ist es selbstverständlich, dass wir von den Spermatogonien auszugehen haben, die ja nichts anderes darstellen als die vollkommene Ruheform der Zellen, die, in verschiedenen Stadien der Spirembildung begriffen, uns als Spermatocyten entgegentreten.

Die Spermatogonien (Fig. 6) sind bei der Ratte ausserordentlich klein ${ }^{1}$ ), daher die Structur des Kerns schwer zu ergründen ist. Der Kern ist im absoluten Ruhezustand vou elliptischer, seltener von rundlicher Form und erscheint der Membr. propria oft dicht angedrückt, immer aber liegt er mehr oder weniger parallel mit ihr. Er ist sehr dicht structurirt, ausgefullt von einem stark färbbaren Inhalt, wodurch er schon bei schwacher Vergrösserung lebhaft hervortritt. Bei manchen Kernen - besonders der kleineren, rundlichen Form - ist diese Chromofilie so gross, dass der Kern geradezu eine tintenartige Färbung annimmt und Structureinzelheiten gar nicht erkennen lässt. In der Regel ist dies aber nicht der Fall, der Kern weist vielmehr eine scheckige Zeichnung auf. Dieses Bild ist hervorgerufen durch derbe dunkle Massen, die theils in Form von groben Klumpen und von diesen ausgehenden Balken in inneren Theilen des Kernes liegen, theils krustenartig; aber niemals ganz zusammenhängend, der Innenfäche der Kernmembran angelagert sind. Durch gewisse Doppelfärbungen gelingt es nachzuweisen, dass diese Klumpen nicht alle Chromatinmassen sind, sondern dass einige (2-3) davon die Bedeutung von wahren Kernkörperchen haben. Auch die Eisenhämatoxylinfärbung ist geeignet,

1) Bei dem Kater sind sie bedeutend grösser, ja einzelne davon wachsen zu solchem Umfange heran, dass sie die grössten Zellen in den Samenkanälchen bilden.

Archiv f. mikrosk. Anat. Bd. 51 
diese Nucleolen isolirt zur Ansicht zu bringen, wenn man die Entfärbung recht weit treibt, indem dabei in den fraglichen Kernen Alles die Färbung einbüsst bis auf eben die 2-3 Kernkörperchen, die sich, wie auch anderweitig, durch grosse Zähigkeit bei der Abgabe des Farbstoffes auszeichnen. Was zwischen den Chromatinbrocken und Nucleolen liegt, ist wegen der dunklen Färbung nnr schwer analysirbar; nur undeutlich macht sich ab und za eine fädig-körnige Structur bemerkbar. Oft gelingt es übrigens, den oder die Kernkörperchen bei genauer Untersuchung auch ohne färberische Differenzirung, schon durch die streng runde Form inmitten der mehr unregelmässig geformten Chromatinklumpen zu erkennen.

Hier erscheint also die chromatische Substanz noch in vielen Theilstücken angeordnet, niøgends zu zusammenhängenden Fadenbildungen zusammengefügt. Ziemlich rasch vollzieht sich aber ein derartiger Vorgang; denn in den kleinen „Uebergangsspermatogonien" liegt schon ein wohlentwickeltes Spirem vor, allerdings von solcher Dichtigkeit und von solcher Feinheit der Fäden, dass die Frage, ob der Knäuel von einem einzigen oder von mehreren Fäden gebildet wird, unbeantwortet bleiben muss. An den gewöbnlichen Schnitten tritt uns der Knänel fast in der Dichtigkeit eines Filzes entgegen; auf sehr dünnen sehen wir das Fadengewirr in minimale Bruchstücke zertheilt und jetzt erscheint der Kernraum wie von einem Gitter mit ungleichmässigen Maschen durchzogen. Schon jetzt gelingt der Nachweis, dass die Fäden jedenfalls nicht durch Querbrücken mit einander verbunden, sondern selbständig gegen einander abgegrenzt sind, ebenso wie dass sie aus einer Grundmasse und aus feinen Mikrosomen bestehen. Der Knäuel zeigt eine streng runde Form. Eingebettet zwischen die Fäden erkennt man mit Hülfe passender Färbungen die kleinen Nucleolen. Die Kernmembran ist bereits sehr undeutlich geworden, doch kann man sie noch nachweisen.

Wie ist nun aus dem Bilde des ruhenden Kerns das Spirem entstanden? Durch sehr genaue Prüfung vieler hierher gehöriger Kerne glaube ich Anhaltspunkte dafür gewonnen zu haben, dass zwischen den beiden Zuständen ein Zwischenstadium liegt, bei dem sich der Kern durch eine durchgehends feinkörnige Structur auszeichnet; daraus würde also hervorgehen, dass sich jener Vorgang in der Weise vollzieht, dass die gröberen Chromatin- 
schollen in kleine Mikrosomen zerfallen, die, zunächst diffus über den ganzen Kern ausgestreut, sich allmählich reihenweise hinter einander aufstellen und, durch eine anders beschaffene, blasser fürbbare Substanz, das "Linin", mit einander verbunden, den chromatischen Fadenknäuel bilden. Die Zellen, die ich meine, hat schon $\mathrm{Br}$ own gesehen (1885); sie finden sich in seiner Arbeit unter dem Namen nspore cells" beschrieben; doch ist die Deutung Brown's eine andere, indem er diese Zellen gerade umgekehrt für die vollkommen ruhenden, unveränderten Stammspermatogonien hält, in der gewöhnlichen Form der Spermatogonien dagegen schon ein Umwandlungsprodukt dieser Elemente erblickt und sie demgemäss als "growing cells" bezeichnet. Ich balte diese Auffassung in Anbetracht des ganzen Habitus der betreffenden Kerne für verfehlt. Aus der Seltenheit der Brownschen Zellform kann man schliessen, dass das betreffende Kernstadium mit grosser Schnelligkeit abläuft.

Die nächstfolgende Stufe, mit der die Zelle in das richtige Spermatocytenstadium, in die "Wachsthumsperiode", eintritt (Spermatocyten des 1. Bildes, „kleine Spermatocyten ${ }^{4}$ ) kennzeichnet sich durch eine beginnende Vermehrung des Zellplasmas und was den Kern betrifft, durch eine mässige Auflockerung des Knäuels nebst Zunahme des Kernsaftes. Zugleich erscheint der chromatische Faden etwas verdickt; ob diese Verdickung auf einer wirklichen Substanzvermehrung oder zunächst nur auf einer Verkürzung des chromatischen Fadens beruht, lässt sich wobl kaum entscheiden. Noch immer aber haben wir es mit einem ${ }_{n}$ dichten Knäuel $^{*}$ zu thun, noch immer ist tiber die feinere Constitution des Knäuels, über die Art seiner Aufwickelung nichts Bestimmtes. auszusagen. In einem späteren Stadium erst, in dem der ${ }^{\text {mittleren Spermatocyten }}$ (in Bild 3, Fig. 7 u. 8), lichtet sich das Dunkel; jetzt erst tritt der Kern in den Zustand des lockeren Spirems ein und bietet dadurch Angriffspunkte einer näheren Betrachtung. Wir haben einen gewöhnlich runden, seltener schwach ellipsoidischen Kern vor uns. Die Kernmembran ist noch immer erhalten, wenn auch nicht deutlicher als bei den Uebergangsspermatogonien. Der Knäuel zeigt nun einen bedeutend einfacheren Windungstypus; die Zahl der leicht gewundenen Schlingen ist mässig, sie liegen locker ausgebreitet vor dem Beschauer. Der ganze Ha- 
bitus der Schlingen, ihr gegenseitiges Verhältniss muss den Eindruck hervorrufen, dass der Knäuel aus einem einzigen nngetheilten chromatischen Faden besteht, der durch seine schlingenförmigen Umbiegungen das Bild des Knäuels entstehen lässt. Noch suggestiver prägt sich die Einheitlichkeit des Fadens bei den Spermatocyten der Katze (Fig.. 8) aus, indem die Zellen des entsprechenden Stadiums hier etwas grösser sind. Aber ganz sicher lässt sich die Frage, um die Wabrbeit zu sagen, bei der Katze ebensowenig wie bei der Ratte entscheiden und zwar aus dem einfachen Grunde nicht, weil man an feineren Schnitten immer nur Durchschnitte des Kerninhaltes vor sich hat, an dickeren Schnitten dagegen eine Analyse des Spirems unmöglich ist. Auf alle Fälle könnte man nur eine sehr geringe Zahl von chromatischen Fäden zugeben. - In der Verlaufsweise der Schlingen sucht man vergeblich nach Gesetzmässigkeiten, wie sie etwa in dem Rabl'schen Schema aufgestellt sind; die Schlingen, deren Zabl nicht allzugross ist, laufen ziemlich ungezwungen durch den Kern, ihr Bestreben scheint nur darin zu liegen, sich in dem Kernraum - mit Ausnahme einer gleich zu erwähnenden Stelle - mehr oder weniger gleichmässig zu vertheilen. Letzteres möchte ich aus dem Grunde besonders betonen, weil es im Widerspruch steht mit einer Angabe Hermanns (1889, S. 78). Ich finde, dass sich das Spirem bei der Ratte, dem Meerschweinchen und der Katze, nicht nur, wie es Hermann für die Mans angiebt, an der Peripherie des Kernes ansbreitet, sondern dass es gleichmässig auch das Kerninnere durchzieht.

Ein bedeutender Unterschied gegen früher besteht darin, lass nun der chromatische Faden bedeutend dicker ist, vielleicht um das Doppelte und darüber, als früher, was möglicherweise auch hier mit seiner offenbaren Verkürzung zusammenhängt. Die Eisenhämatoxylinbilder gestatten nun noch viel klarer. als vorhin cinen Einblick in die innere Zusammensetzung des Kernfadens. Er besteht aus einer blässer gefärbten Grundsubstanz, dem Linin, und darein eingelagert aus Chromatinmikrosomen, die zumeist die Form rundlicher Körnchen aufweisen. Im Allgemeinen sind diese Chromatintheilchen breiter als das Lininband, das sie zusammenhält: daher das perlschnurartige Aussehen des ganzen Kernfadens. Die Anordnung der Mikrosomen ist durchaus keine gleichmässige, auch wechselt ihre Form und Grösse, daher kommt 
es, dass die Breitendimensionen des Fadens von Stelle zu Stelle wechseln, während freilich im Ganzen die Fadendicke eine durchschnittlich gleiche ist. An Präparaten aus Osmiumgemischen zeigt der chromatische Faden merkwiirdjge zackige Conturen, ein Verbalten, das auch Meves in vielen Abbildungen seiner Arbeit wiedergiebt; ich kann nicht umbin, der Meinung Ausdruck zu geben, dass diese Form dem natürlichen Zustande nicht entspricht, dass vielmehr das Aussehen des Spirems an richtig. fixirten Sublimatpräparaten, wo die Grenzen des Chromatinfadens im Allgemeinen etwas glatter, die dureh die Chromatinmikrosomen bedingten Vorwölbungen mehr rundlich erscheinen, dem natürlichen Verhalten näher kommt.

Zwischen den Schlingen des chromatischen Fadens bemerkt man eine sehr geringe Menge einer gerinnselartigen, leichtkörnigen Masse, die sich mit sauren Farbstoffen blass darstellen lässt.

Nun besteht in Kern dieser Spermatocytenform noch ein merkwürdiges Verhalten, das, wenn auch schon da und dort angedeutet, die Aufmerksamkeit der Forscher bisher nicht in gehörigem Maasse auf sich gezogen hat. Die Windungen des Chromatinknäuels lassen bei den mittelgrossen Spermatocyten stets oder wenigstens sebr häufig eine bald kleinere, bald grössere Stelle an der Kernperipherie frei - sie kann so gross sein, dass sie fast der einen Hälfte des Kerns entspricht -, so dass also ein mit der Luftkammer des Hühnereies vergleichbarer Raum zu Stande kommt; gewöhnlich sieht man eine Schlinge quer an der freien Stelle vorbeiziehen. In dem Raume erblickt man nun stets einen 2-2,5 $\mu$ grossen, elliptischen, linsenförmigen Körper, bald der Kernmembran dicht angelagert, bald auch nicht ganz, aber. immer mit der Oberfläche des Kerns parallel gestellt. Es ist nicht zu verwundern, dass diese so auffallende Anordnung bereits früheren Forschern aufgefallen war. Ich nenne v. Ebner, der sie auf S. 260 seiner Arbeit (1888) beschreibt. Bei v. Ebner aber ebenso wie auch bei Anderen figurirt das Gebilde immer als das Kernkörperchen. So lautet z. B. v. Ebner's Beschreibung folgendermaassen: „Während der Ausbildung des lockeren Knäuels . . . . ist fast immer ein durch seine Grösse ausgezeichnetes, färbbares Korn, das ebenfalls der Kernmembran anliegt (Kernkörperchen), za seben." Mo ore beschreibt das Gebilde (1896 S. 285) als ,a curious secondary nucleolus". 
Auf Grund meiner eigenen Erfahrungen muss ich zum Schlusse kommen, dass die Richtigkeit dieser Deutung mindestens sehr fraglich ist. Was in mir hauptsächlich $Z_{w}$ eifel an der Nucleolennatur des Intranuclearkörpers, wie ich das Gebilde mit einem impräjudicirlichen Namen nennen will, wachgerufen hat, das ist sein färberisches Verhalten. Untersucht man die Spermatocyten in diesem Stadium an Präparaten, die nach der Flemming'schen Dreifachmethode gefärbt sind, so erkennt man im Kern drei Farbentöne. Die chromatischen Schlingen sind blass-roth gefärbt, mit leicht bläulicher Beimischung. Der linsenförmige Körper erscheint noch viel schwächer tingirt; er weist nur den Hanch einer Rosafärbung auf, ohne bläulichen Nebenton. Inmitten dieser schwach tingirten Kernbestandtheile treten mit grosser Schärfe zwei oder drei mittelgrosse, kugelförmige Körper durch intensive, röthlich-violette Färbung hervor. Nach dem färberischen Verhalten, das man an allen anderen Zellkernen bei der in Rede stehenden Dreifachfärbung beobachtet, kann wohl kaum ein Zweifel darüber bestehen, dass diese Gebilde die eigentlichen Nucleolen sind, umsomehr als sich schon von den Spermatogonien an die Nucleolen in dieser Form und Färbbarkeit verfolgen lassen. $\mathrm{Za}$ dem Intranuclearkörper haben diese wahren Nucleolen nur insofern Beziehungen, als einer davon sehr oft in seiner unmittelbaren Nähe, oft auch in direkter Berührung damit gefunden wird. - Vielleicht noch uberzengendere Bilder aber liefert die Eisenhämatoxylinmethode. Bei einem bestimmten mittleren Grade der Differenzirung bekommt man ein merkwürdiges Bild: Die chromatischen Schlingen erscheinen vermöge ihrer dichtgedrängten Chromatinmikrosomen schwarz, noch intensiver schwarz gefärbt sind die Kügelchen, die wir soeben als die eigentlichen Nucleolen gekennzeichnet haben, der linsenförmige Körper dagegen präsentirt sich in blasser, hellgrauer Färbung; lässt man dann noch eine Erythrosin-Nachfärbung folgen, so nimmt er mit Vorliebe einen leicht röthlichen Ton an und tritt dadurch in noch lebhafteren Gegensatz zu dem Kernknäuel und den Nacleolen. Aber die Eisenhämatoxylinbilder vermitteln in einer zweiten Hinsicht neue Aufschlüsse tiber das Gebilde: sie zeigen, dass der Intranuclearkörper durchaus nicht von homogener Beschaffenheit ist, sondern dass er einen mehr oder weniger körnigen Ban aufweist. Diese schwarz 
gefärbten Körnchen, die von etwas verschiedener Grösse sind, liegen hanptsächlich als Randmikrosomen auf der Oberfläche des Gebildes, ungleichmässig vertheilt, indessen scheinen sie auch öfters das Innere desselben zu durchsetzen; freilich ist hier immer die Möglichkeit zu berücksichtigen, dass bei einer Flächenansicht des Körpers die oberflächlich ausgebreiteten Körner als innere erscheinen. Ich habe das Verhalten des Gebildes in der Fig. 7 zur Ansicht gebracht.

Es seien also noch einmal die Momente hervorgehoben, die dagegen sprechen, dass der linsenförmige Intranuclearkörper ohne weiteres mit den Nucleolen in eine Reihe zu stellen sei. Vor allem kommt in Betracht, dass es gelingt, anderweitige Gebilde im Kern nacbzuweisen, die ihrem ganzen färberischen Verhalten nach als Nucleolen aufgefasst werden müssen. Dann ist der körnige innere Bau zu berücksichtigen, wie er, wenigstens in dieser Form, bei den Nucleolen nie in die Erscheinung tritt. Auch die elliptische Gestalt des Gebildes wäre bei einem Kernkörperchen etwas Ungewöhnliches, ebenso wie die Lage und das Verhältniss zu den chromatischen Kernbestandtheilen. Schliesslich scheint mir das Verbalten bei der Eisenhämatoxylinfärbung bemerkenswerth; nach meinen bisherigen Erfahrungen zeichnet sich das Kernkörperchen bei dieser Färbung sonst immer gerade durch das hartnäckige Festhalten des Farbstoffes bei der Differenzirung aus.

Das ganze färberische Verbalten des Gebildes scheint mir darauf hinzuweisen, dass es aus denselben Bestandtheilen zusammengesetzt ist, aus denen sich der Kernfaden aufbaut, nämlich aus Linin und Chromatin, nur in anderer quantitativer Vertheilung, nämlich aus viel Linin, mit spärlichen eingestreuten Chromatinmikrosomen. Damit ist freilich über Herkunft und Bestimmung des Gebildes noch nichts ausgesagt; leider war es mir nicht möglich, itber diese Fragen zu einer bestimmten Anschauung zu gelangen. Der Umstand, dass sich der Intranuclearkörper schon auf der nächsten Spermatocytenstufe nicht mehr nachweisen lässt, sowie dass er nicht bei allen Säugethieren vorhanden zu sein scheint (so habe ich ihn z. B. bei der Katze vergeblich gesucht), spricht gegen eine grössere funktionelle Bedeutung. Da er sich gerade nur bei den „mittelgrossen Spermatocyten" findet, könnte man seine.Gegenwart nur mit einem 
Vorgang in Zusammenhang bringen, der speciell nur diesem Stadium des Kerns eigenthümlich ist, oder sich im unmittelbaren Anschluss an dieses Stadium einzuleiten pflegt. Einen solchen Vorgang kann man in der unmittelbar nach diesem Stadium einsetzenden Quertrennung und Längsspaltung des chromatischen Fadens und der damit verknüpften nChromosomenreduction" erblicken; es würde sich demgemäss um eine einleitende Erscheinung zu diesen Vorgängen handeln. Welche Rolle aber dabei dem sich an die Kernmembran zurtickziehenden Intranuclearkörper zufallen mag;, entzieht sich vollkommen unserer Beurtheilung.

Besondere Beachtung wandte ich der Frage zu, ob sich in der Lage des Gebildes irgendwelche Gesetzmässigkeiten aussprechen. Es kam namentlich in Betracht die Möglichkeit eines regelmässigen Lageverhältnisses einerseits zur Kanalwand oder zum Lumen, andererseits zu innerhalb der Zelle gelegenen anderweitigen Gebilden, speciell der "Sphäre". Auf Grund ausgedehnter Prüfungen kann ich behaupten, dass nach beiden Richtungen hin jede Constanz der Lagerung fehlt. Das Gebilde kann an welcher Stelle immer der Kernperipherie gelagert sein und kann zur Sphäre in einem beliebigen Lageverhältniss stehen.

Während die Zellen nun allmählich zu den ngrossen Spermatocyten" heranwachsen (Fig. 9 und 10), unterliegen auch ibre Kerne eingreifenden Veränderungen. Diese lassen sich stellenweise sehr schön in ibrem continuirlichen Zustandekommen verfolgen, indem man manchmal nebeneinander alle Uebergangsstadien vorfindet; einzelne Punkte des Vorganges blieben trotzdem, wie es sich zeigen wird, etwas schleierhaft.

Vor allem ist die bedeutende Vergrösserung des Kerns hervorzuheben; sie ist in erster Linie auf eine Vermehrung des ${ }_{n}$ Kernsaftes " zurückzuführen. Die Vergrösserung ist continuirlich bis zu dem Punkte, wo die Kernmembran sich aufzulösen, die Spindel sich zu bilden beginnt, kurzum bis die eigentlichen mitotischen Vorgänge einsetzen.

In den grossen Spermatocyten zeigt der Kern in dem 24 bis $30 \mu$ langen Zellkörper eine Länge von 10 bis $14 \mu$. Wenn wir also zurückblicken auf den Ausgangspunkt der Spermatocyten, auf die kleinen Spermatogonien mit ihrem runden Kern, dessen Durchmesser 5 bis $7 \mu$ beträgt, so darf man sagen, dass der 
Kern mindestens auf das Doppelte seiner ursprünglichen Grösse angewachsen ist. Merkwürdigerweise tritt anch vor ibrem Untergange die Kernmembran wieder lebhafter hervor, wovon man sich besonders an Hämalaunfärbungen überzeugen kann; vielleicht ist es gerade der Druck des vermehrten Kernsaftes, der durch die Nothwendigkeit eines grösseren Widerstandes die Verstärkung der Membran veranlasst.

Zwei Veränderungen spielen sich beim Eintritt der Zelle in diese Phase am chromatischen Fadenknäuel des Kerns ab: eine Quertheilung und eine Längsspaltung. Ueber das gegenseitige zeitliche Verhältniss dieser beiden Vorgänge habe ich durch direkte Beobachtung trotz grösster Aufmerksamkeit nichts Bestimmtes feststellen können. Aber nach der ganzen Sachlage scheint es mir weitaus wahrscheinlicher, dass die Quertheilung der Längsspaltung vorausgeht. Wahrscheinlich aber erfolgen beide Vorgänge nicht wie auf je ein Commando, nicht etwa so, dass sich auf einmal alle Quertrennungen, dann auf einmal alle Längsspaltungen vollziehen, sondern mehr allmählich und unregelmässig, d. h. es kann die Längsspaltung an einem bereits von dem Gesammtfaden abgetrennten Chromosom schon eingetreten sein, während sich noch die anderen Chromosomen gar nicht aus dem einheitlichen Faden abgegliedert haben. Hierher gehörige Beobachtungen habe ich ab und zu machen können.

Die Thatsache der Längsspaltung erkennt man unschwer an dem Vorhandensein von dicht beieinander liegenden dünnen Parallelfäden, die allmäblich an Stelle des einheitlich dicken chromatischen Fadens treten. Aber ein merkwtirdiges Verhalten kommt nun an diesen Parallelfäden zum Ausdruck; verfolgt man sie in ihrem Verlaufe nach beiden Seiten hin; so erkennt man, dass sie keine freien Enden haben, sondern schlingenförmig in einander übergehen. Wir haben also die zuerst von van Beneden (1883) an den Eizellen ron Ascaris megalocephala kurz angedeutete, dann von Flemming (1887) bei der Spermatocytentheilung von Salamandra ausführlich beschriebene Erscheinung vor uns, dass die aus der Längsspaltung der cbromatischen Segmente hervorgegangenen Tochterchromosomen sich nicht vollkommen von einander trennen, sondern an den Enden mit einander in continuirlicher Verbindung bleiben, ohne dass man an den betreffenden Stellen die Spur einer Trennung wahrnehmen könnte. Diese Art 
der Darstellung hat freilich die Annahme zur Voraussetzung, dass die Quertrennung des chromatischen Fadens der Längsspaltung zeitlich vorausgeht. Sollte die Sache aber umgekehrt liegen, d. h. zuerst die Längsspaltung und dann erst die Quertrennung erfolgen, so müsste an ihre Stelle eine ảndere, schon von F l e m m ing als Möglichkeit hingestellte Auffassung treten, diejenige nämlich, dass sich die freien Endspitzen der Schwesterchromosomen erst secundär wieder mit einander verbinden. Nach der ganzen Sachlage scheint mir aber die erstere Auffassung wahrscheinlicher. Die ringförmigen ndoppelwerthigen" Chromosomen sind schon von Herm an (1889) im Hoden der Maus beobachtet worden; es ist dies wohl die erste Beschreibung dieses Verhaltens bei einem Säugethier.

Wir sehen also anfangs lange, schmale Streifen, manchmal so lang, dass sie den Kern seiner ganzen Länge nach durchsetzen; häufiger kommt aber eine mehr oder weniger quere Lagerung der Reifen in dem in der Regel schwach ellipsoidischen Kern vor. Verdrehungen der Reifen sind nicht selten, wodurch Achterfiguren oder noch unregeỉmässigere Formen zu Stande kommen. Die beiden Schenkel des Reifens oder der Schlinge laufen anfangs ganz parallel mit einander, durch einen sehr engen Spalt von einander getrennt; sehr bald ändert sich aber dieses Verhalten, indem sie allmählich auseinander zu weichen, einen bogenförnigen Verlauf anzunehmen beginnen, so dass sich die Form des Gebildes allmählich einer Ringform nähert. Jetzt erkennt man auch aufs Deutlichste, dass die Chromosomen mindestens um die Hälfte dünner sind, als der chromatische Faden der mittelgrossen Spermatocyten; auch die Chromatineinlagerungen des Lininfadens präsentiren sich jetzt mehr unter dem Bilde unregelmässiger Schollen als unter dem regelmässiger Mikrosomen. - Hand in Hand mit der Umgestaltung der Reifen zu einem vollkommenen Ringe greift ein zweiter Vorgang Platz: die concentrische Verengerung des Ringes mit gleichzeitiger Verdickung des ihn bildenden Chromosomenpaares, eine Erscheinung, die der Verkürzung und Verdickung der Chromosomen bei der homoeotypischen Theilungsform entspricht. Wodurch die Verengerung des Ringes zu Stande kommt, lässt sich nicht sicher entscheiden, doch darf man aus der Thatsache, dass man die Chromatinkügelchen an Zahl allmählich abnehmen sieht, schliessen, 
dass der Vorgang durch den Austritt eines Theiles des Linins und durch die Verschmelzung der Chromatintheile der Chromosomen bewirkt wird.

Noch eine weitere Erscheinung lässt sich gleichzeitig feststellen: die Ringe wandern alle nach der Peripherie des Kerns und man findet sie zuletzt alle der Kernmembran auf der Innenseite flach aufgedrückt, während das Innere des Kernes ganz von den achromatischen Kernbestandtheilen eingenommen wird. Diese peripherische Verlagerung der Chromosomen hat auch M o o r e neuerdings (1895) bei Selachiern betont und seine Wahrnehmungen stehen mit den meinigen auch insofern in Uebereinstimmung, als auch er die Wanderung erst gegen das Ende dieser Periode, erst wenn die Ringe bereits in fertigem Zustande vorliegen, eintreten lässt. Vergl. S. 288 nThe ring chromosomes, when fully formed, become dispersed over the nuclear periphery."

Das Einschrumpfen der Ringe nimmt nun mehr und mehr zu, so dass wir zuletzt (Fig. 10) die meisten davon zu kleinen klumpigen Gebilden umgeformt sehen, an denen kaum mehr ein centrales Lumen wahrzunehmen ist.

All' die Veränderungen, die hier als zeitlich vor sich gehend geschildert wurden, lassen sich manchmal in räumlichem Nebeneinander an den Chromosomenringen ein und desselben Kerns beobachten. Die einzelnen Ringe desselben Kerns verbalten sich nämlich in dieser Beziehung ganz unabhängig von einander, zeigen gegen einander starke zeitliche Verschiebungen, so dass man z. B. in demselben Kern oft neben noch ganz schmalen, langen Schlingen schon ganz zusammengeschrumpfte, fast lumenlose Ringe antreffen kann. Nur die allerletzten Stadien, die Kerne derjenigen Zellen, die man unmittelbar neben den Mitosen als ihre letzten Vorstadien findet, zeigeu wieder ein gleichmässiges Verhalten, indem zuletzt alle Ringe früher oder später einen stark reducirten Zustand erreichen. Solche Kerne bieten ein recht typisches Aussehen dar: der Kern hat zuletzt noch unmittelbar vor dem Eintritt der Spindelbildung durch Aufnahme von Kernsaft beträchtlich an Ưmfang zugenommen, er stellt eine grosse, helle Blase dar; an der Innenseite der noch immer nachweisbaren Kernmembran vertheilen sich in ziemlich gleichen Abständen, weit auseinander gerückt, die nun zumeist bis zur Lumenlosigkeit zusammengeschrumpften kleinen klumpenförmigen 
Doppelchromosomen, ein Bild, das ich in Fig. 11 wiederzugeben bemüht war. Man erkennt daran auch die Gegenwart der Nucleolen, die sich bis unmittelbar zur Mitose unverändert erhalten.

Grosse Miihe habe ich auf die Frage verwendet, wie gross die Zahl der Cbromosomen sei. Auf den ersten Blick sollte man meinen, dass es ein Leichtes sei, die ringförmigen Chromosomen, besonders wenn sie bereits geschrumpft und dadurch von einander besser isolirt sind, zu zählen. Und doch sind meine dahinzielenden Bemühungen nicht von einem ganz sicheren, mich selbst ganz befriedigenden Ergebniss gekrönt worden. Die Schwierigkeit liegt hauptsächlich daran, dass die feinen Schnitte, die man zur Untersuchung benutzen muss, nur Fragmente der Kerne zeigen, an dickeren Schnitten dagegen, an denen vielleicht die betreffenden Kerne in unaufgeschnittenem Zustande vorliegen, ein Einblick in den Bau dieser letzteren wegen der Uebereinanderlagertung der Chromosomen, Nucleolen u. s. w. nicht möglich ist. An den gewöbnlichen feinen Schnitten wird man neben den schönen, geschlossenen Ringen immer auch noch Fragmente von Chromosomen vorfinden, oft mehrere nebeneinander, von denen man nicht weiss, ob sie aus einem oder mehreren Ringen abgetrennt sind, iiberdies bleibt man darüber immer im Ungewissen, ob der Kerndurchschnitt alle Ringe des Kerns enthält oder nur einen Theil davon. Auch die oben erwähnten Verwickelungen und Verdrehungen der Chromosomenschleifen kompliciren das Bild. Trotz dieser Schwierigkeiten schien es mir anfangs, als hätte ich in der Zahl 8 die gewünschte Ziffer gefunden; alle die Zählungen, die ich vorgenommen hatte, leiteten mich anfangs $\mathrm{zu}$ dieser Zahl hin; noch weiter bestärkt wurde ich in meinem Vertrauen zu dieser Zabl, als ich in einer ebenfalls den Rattenhoden behandelnden Arbeit M $00 \mathrm{r}$ e's (1893), die ich erst nachträglich kennen lernte, dieselbe Zahl angegeben fand. Indessen häuften sich im Fortgange meiner Untersuchungen mehr und mehr die Verdachtsmomente, dass die Zahl 8 vielleicht $\mathrm{zu}$ niedrig gegriffen sei, und schliesslich sah ich mich zur Zahl 12 hingedrängt, die dann bis zum Abschluss meiner Untersuchungen Stand gehalten hat; mit absoluter Sicherheit indessen könnte ich auch diese Zahl nicht vertreten. Auf alle Fälle dürfen wir annehmen, dass die Zahl der Ringehromosomen die Hälfte der Chromosomenzahl in den gewöhnlichen somatischen Zellen ausmacht. 
Ausser den Chromosomen findet man im Kern bis zuletzt ein oder zwei runde Kernkörperchen von mässiger Grösse. Man bekommt von ihnen sehr schöne differenzirte Färbungen mit der Doppelfärbung Safranin-Gentiana; lässt man den Alkohol bei der Differenzirung etwas stärker einwirken, so erscheinen die Chromosomen gerade nur schattenhaft angedeutet, in leicht röthlichem Ton, während die Nucleolen in röthlich violetter, satter Färbung lebhaft hervortreten. Auch sie zeigen zuletzt eine wandständige Lage; nicht selten findet man sie dicht nebeneinander. Finen weiteren Befund im Kernraum bilden kleinere Chromatinklümpchen in mässiger Zahl, gewissermaassen Abfälle des Chromatinfadens bei der Abgliederung der einzelnen Chromosomen daraus. Freilich ist hier die grösste Vorsicht geboten, damit man nicht etwa durch den Schnitt abgetrennte Theile der Chromosomen für derartige selbständige Chromatinreste hält. Ich habe alle Cautelen walten lassen, habe mich aber dabei von der Existenz dieser Chromatinfiagmente doch überzeugt. Vielleicht bilden sie die Vorläufer der "Centralspindelkörperchen".

Als letzter Inbaltshestandtheil der Kerne der grossen Spermatocyten ist eine in geringer Menge vorhandene, blasse, feinkörnige, sich mit Eosin, Erythrosin oder anderen sauren Anilinfarben leicht färbende Masse $\% u$ nennen, die theils zwischen den Chromosomen, theils auch im inneren Raum des Kerns bald fädig ausgesponnen, bald gerinnselartig angesammelt erscheint. Sie ist, wie gesagt, nur in sehr geringer Menge vorhanden.

Kehren wir auf einen Moment zu dem Zellkörper der Spermatocyten zurück. Es hart da noch ein Bestandtheil der Beschreibung. An Eisenhämatoxylinpräparaten wird man im Cytoplasma der Spermatocyten nur selten 1-2 intensiv schwarz gefärbte, sehr auffallende Kügelchen vermissen, die immer viel grösser sind, als dass man sie etwa mit Centrosomen verwechseln könnte; sie haben den Umfang kleinerer Nucleolen. Aber auch mit anderen Färbungen, so z. B. mit Magentaroth, kann man sie sehr deutlich darstellen. Es handelt sich hier um die ,chromatoiden Nebenkörper" Benda's. Benda spricht freilich nur von einem einzigen solchen Körper; auch lässt die kurze Mittheilung (1891), in der das Gebilde erwähnt wird, eine genauere Beschreibung desselben vermissen. B e n d a giebt nur soviel an, dass das Gebilde mit dem Centrosom und der Sphäre nichts zu thun hat, vielmehr 
wahrscheinlich ein aus dem Kern isolirtes Chromosom darstellt, ferner dass es sich anch in Mitosen erhält und auch in den neugebildeten Spermatiden nachzuweisen ist. Etwas ausführlicher ging kürzlich Niessing (1896, S. 120) auf das Gebilde ein; er findet es als einen ungefähr die Grösse des Nucleolus zeigenden rundlichen oder ellipsoidischen Körper im Zellkörper der Spermatocyten in unbeständiger Lage; eine feinere innere Struktur vermochte er daran nicht zu erkennen. Die Herkunft des Gebildes blieb räthselhaft. Also auch bei $\mathrm{Ni}$ es sing figurirt ein einziges chromatoides Nebenkörperchen in den Spermatocyten. Schon früher aber (1893) hat M o ore in den Spermatocyten der Ratte zwei Körperchen gesehen und auch abgebildet; er schildert sie als "small intensely chromatic extra-nuclear particles". Auch ich finde, ebenso wie Mo ore, dass das Gebilde in den Spermatocyten der Ratte weitaus am bäufigsten in der Zweizahl auftritt. Mit der Lage aber, die Moore in der seiner Arbeit einverleibten Abbildung den Körperchen zutheilt, kann ich mich nicht einverstanden erklären. Moore bildet sie in der Nähe des Kerns und zwar unweit von einander liegend ab. Ich finde, dass sie bei den grossen Spermatocyten nicht neben einander, sondern im Gegentheil weit auseinander, in die beiden Hälften der Zelle vertheilt, liegen, und zwar liegen sie nicht in der Nähe des Kerns, sondern mehr in die beiden Zellpole gerückt. Sie zeigen merkwürdigerweise oft eine regelmässige, symmetrische Lagerung, indem jedes davon in einem der Pole der länglichen Zelle liegt und zwar sehr hänfig gerade in der Achse der Zelle. Man findet manchmal eine ganze Reihe von Spermatocyten neben einander, in denen die beiden chromatoiden Nebenkörperchen diese in Fig. 9 vergegenwärtigte typische Lage erkennen lassen. Diese Regelmässigkeit der Lagerung kommt ihnen ubbrigens nur in den grossen Spermatocyten $z \mathfrak{u}$; in den kleinen und mittelgrossen, wo man sie oft schon nachweisen kann, freilich noch als etwas kleinere Körnchen und oft nur in der Einzahl, lassen sie einen typischen Sitz vermissen. In den Spermatogonien fehlen sie; sie müssen sich also in den kleinen Spermatocyten gebildet haben. Wie erfolgt aber ihre Bildung? Zwei Möglichkeiten sind hier in Betracht zu ziehen: sie können sich direkt aus dem Cytoplasma herausdifferenzirt haben oder sie können aus dem Kerne hervorgegangen sein, wie dies B e nd a annimmt. Ihr färberisehes Ver- 
halten weist entschieden auf den Kern hin und zwar weniger auf dessen Chromatintheile als auf die Nucleolen. Während der Mitose bleiben sie, wie das schon Benda (1892) bemerkt, erhalten, und werden dann unter Zunahme an Umfang in die Tochterzellen übernommen, und zwar nunmehr einzeln in jede Spermatide. Dort werden wir dem chromatoiden Nebenkörper wieder begegnen.

\section{Die Mitosen der Spermatocyten.}

Im Allgemeinen sind die Spermatocyten der Säuger wegen ihrer relativen Kleinheit keine besonders günstigen Specimina für das Stadium der feineren Einzelheiten der Mitose: Es mag dies als Entschuldigung dienen, wenn das vorliegende Kapitel etwas kurz ausgefallen ist, wenn es sich unter Vermeidung allgemein-histologischer Auseinandersetzungen nur auf eine bündige Beschreibung der Bilder beschränkt, unter denen uns die verschiedenen Stadien der Mitose an den Spermatocyten der Ratte entgegentreten. Auch vereinfacht sich meine Aufgabe durch die Möglichkeit eines Hinweises auf die ausführlichen Darstellungen, die kürzlich Mo o re (1895) und M eves (1896) von der Spermatocytentheilung bei Selachiern und bei Salamandra gegeben haben. Denn in der Hauptsache liegt die Sache auch bei Säugern nicht anders als bei diesen. Ich war geradezu frappirt, als ich die Abbildungen der Moore'schen Arbeit erblickte; sie könnten, wenigstens die meisten davon, ohne weiteres vorliegendem Aufsatze als Illustrationen beigegeben werden.

Natürlich sind hier unter ,Mitose" nur die Stadien von der Spindelbildung an gemeint, eigentlich gehören ja alle Formen der Spermatocyten, ja sogar schon die Uebergangsspermatogonien, in ihrer Eigenschaft als Spireme, in den Kreis der Mitose; indessen ist hier diese Beschränkung aus Gründen der Einfachheit des Ausdruckes geboten.

Auf S. 229 wurde bereits ausgeführt, dass wir eine zweimalige Theilung der Spermatocyten anzunehmen haben. Nach der ersten Theilung gelangt die Zelle zur vollkommenen Ruhe und stellt nun die v. Ebner'sche Zelle oder die Spermatocyte II. Ordnung dar. Es sind das (s. Fig. 5) verhältnissmässig grosse, eckige Zellen mit schönem, hellem, rundem Kern, der ein zierliches, lockeres Kerngerüst und an dessen Knotenpunkten eine Anzahl grösserer Chromatinschollen einschliesst; im Zellkörper 
erblickt man eine wohl abgegrenzte runde Sphäre von nur ein wenig kleinerem Umfang als die der grossen Spermatocyten, sowie einen nunmehr in der Einzahl vorbandenen chromatoiden Nebenkörper. Die Ruhepause dieser Zellen ist jedenfalls nur von kurzer Dauer, auch muss ibr Uebergang aus dem Ruhezustand in den der Mitose sehr rasch erfolgen; denn niemals ist es mir gelungen, die einleitenden Stadien der Mitose, d. b. die der Auflösung der Kernmembran und der Spindelbildung hier zu Gesicht zu bekommen. Aus der zweiten Theilung erst gehen die richtigen Spermatiden hervor. Diese stellen sich zunächst als Zellen mit auffallend kleinem Kern dar, doch nimmt dieser bald etwas an Umfang zu. Die ganze zweite Theilung muss einen sehr raschen Verlauf nehmen; bieraus kann man sich mit v. Ebner erklären, dass man oft E bner'sche Zellen mit Spermatiden untermischt findet, obne dass Vertreter der dazwischen gelegenen zwieiten Mitose zwischen ihnen oder auch nur in der Nähe zu finden wären. Die Theilung erscheint also an solchen Stellen vollkommen vollzogen, bevor sich eine zweite Generation von Ebner'schen Zellen zur Theilung angeschickt hätte.

In dem Verlauf des mitotischen Vorganges scheinen mir zwischen den beiden Mitosen, der ersten und der zweiten, keine principiellen Unterschiede zu bestehen; beide weichen etwas von den gewöhnlichen Typen der Mitose ab und schliessen sich mehr an die Form an, die Flem $\mathrm{ming}$ (1887) bei der Spermatocytentheilung von Salamandra als heterotypische Varietät beschrieben hat. Vor allem möchte ich hervorheben, dass in der Zabl der Chromosomen ein Unterschied nicht nachweisbar ist. In zwei Punkten weichen die beiden Theilungen von einander ab: erstens sind bei der zweiten Theilung die Chromosomen etwas kleiner, mehr körnchenartig, so dass man annehmen darf, dass die Gesammtmasse des Chromatins hier beträchtlich geringer ist als bei der ersten Theilung. Ein noch auffallenderer Unterschied kommt in der verschiedenen Menge des Cytoplasmas bei den beiden Mitosenformen zum Ausdruck; bei den kleinen Mitosen steht die Quantität des Cytoplasmas nicht nur absolut, sondern auch relativ, d. h. im Verhältniss zur Grösse der Spindel und der ganzen karyokinetıschen Figur weit hinter der bei der grossen Form zurück.

Wir hatten den Kern der grossen Spermatocyten verlassen 
als eine grosse Blase, die als Inhalt viel Kernsaft, eine Anzahl ringförmiger, wandständiger, relativ kleiner doppelwerthiger Chromosomen, einige kleine Kernkörperchen, und schliesslich zwischen den Chromosomen eine spärliche fädig-körnige achromatische Zwischenmasse aufwies. Neben dem Kern lag im Protoplasma die grosse Sphäre, in eine Rinden- und Markschicht geegliedert. Die beiden Centrosomen fanden wir nicht mehr in der Mitte der Sphäre gelegen, sondern der Kernwand angedrückt und im Begriffe, sich allmählich von einander zu entfernen.

Der Vorgang nun, der für den Beobachter die "Nitose" einleitet, ist die plötzliche Auflüsung der Kernmembran. Hierdurch muss sich natürlich ein grosser Theil des Kernsaftes in das Cytoplasma ergiessen und es mehr oder weniger durchtränken, und vielleicht kann man aus dieser Vermischung die plötzlich eintretende leicht granuläre Umwandlung und Aufhellung des Zellkörpers erklären.

Der Frage der Centralspindelbildung möchte ich ausweichen, da meine Präparate hierüber nichts Bestimmtes erkennen lassen. Nach den Beobachtungen von Moore an den Spermatocyten von Selachiern und denen von Hermann und Meves an denen von Salamandra darf man annehmen, dass sich zwischen den allmählich auseinanderweichenden Centrosomen eine kleine Centralspindel bildet, die, allmählich grösser werdend, in Folge der Wanderung der Centrosomen nach den Stellen der früheren Kernpole hin in den früheren Kernraum hineingelangt. Mir selbst ist es nicht gelungen, die Centralspindel in so frühen Stadien gut zu färben.

An dieser Stelle möchte ich nun den Faden meiner eigenen Beobachtungen wieder aufnehmen. Ich beginne mit einem Bilde - in Fig. 11 dargestellt -, dessen Verständniss mir anfangs einige Schwierigkeiten bereitete. Genau an der Stelle, wo früher der Kern lag, bemerkt man jetzt die zunächst noch etwas plumpe, bauchige Centralspindel; an ihren Polen gelingt es an der Hand der Eisenhämatoxylinfärbung leicht, die Centrosomen nachzuweisen als kugelförmige Gebilde, eines nur an jedem Pole. Es scheint aber, als ob die Centrosomen gegen fribher gewachsen wären. Es ist also die Spindel gewissermaassen hineingedrängt in den früheren Kernraum, eine Vorstellung, der man sich um so leichter hingeben kann, als die Chromosomenringe zuletzt Arehiv f. mikrosk. Anat. Bd. 51 
eine ganz wandständige Lage innehatten und das Innere des Kerns sich als ein hauptsächlich rom Kernsaft ausgefüllter Hohlraum darstellte. Von den beiden Spindelpolen sieht man eine schöne Polstrahlung ausgehen, einzelne dieser Strahlen, gewöhnlich etwas schärfer ausgeprägt, scheinen als "Zugfasern" an die Chromosomen heranzutreten und sich mit ihnen zu verbinden. Die Chromosomen liegen zunächst noch durchaus nicht alle in regelmässiger Stellung am Aequator der Spindel. Einige davon nehmen schon diese typische Lagerung: ein, aber immer finden sich noch welche, die frei im Cytoplasma liegen, gewissermaassen ihre frübere, ungezwungene Lagerung im Kern noch beibehaltend. Dadurch kommt jene Unregelmässigkeit des Bildes zu Stande, die für dieses "Umordnungsstadium" charakteristisch ist. Der Vorgang der Hinnöthigung der Chromosomen an die Centralspindel geht also nicht gleichzeitig an allen Chromosomenreifen vor sich; ja es kommt vor, dass man in einem Stadium, wo bereits alle Ringe am Spindeläquator sich zu einer schönen Aequatorialplatte an einander geordnet zeigen, seitlich von der Spindel, frei im Cytoplasma gelegen, noch ein renitentes Chromosom wahrnimmt. Auch läuft die Sache in einer anderen Beziehung nicht ganz glatt ab; die Ringe nehmen dabei oft recht unregelmässige Formen an, woraus man auf zwei Dinge schliessen kann: erstens, dass die Chromosomen bei ihrer Heranziehung an die Spindel wirklich einer mechanischen Einwirkung, nicht nur einem in bildlichem Sinn gemeinten, sondern einem wirklichen Zug unterworfen sein dürften; zweitens, dass sie von dehnbarer, zäher, aber doch elistischer Beschaffenbeit sein müssen. Beide Schlüsse stimmen überein mit den Beobachtungen von Me ves.

Zuletzt müssen natürlich aber alle Chromosomen dem Zwange nachgeben, und man hat nun das regelmässige Bild des ${ }_{n}$ Aequatorialplattenstadiums" oder Monasters vor sich, sofern die Zelle in der Richtung der Theilungsaxe getroffen ist; am Querschnittsbilde der Zelle liegt insofern eine Abweichung von dem gewöhnlichen Bilde dieses Stadiums vor, als die Chromosomen niemals die schöne, weit offene kranzförmige Anordnung erkennen lassen, die sie sonst bei dieser Betrachtung darzubieten pflegen; ein centrales Lumen fehlt ganz oder ist gerade nur andeutungsweise vorhanden. Es haften hier also die Chromosomen den Fäden 
der Centralspindel nicht nur oberflächlich an, sondern dringen auch zwisehen den Fäden in den inneren Raum der Spindel hinein.

Das Stadium der Aequatorialplatte bezeichnet wohl eine kleine relative Verzögerung in dem Fortgang der Mitose, denn man begegnet dieser Form auffallend häufig, am häufigsten von allen Mitosenformen. Fig. 12 vergegenwärtigt dieses Stadium. Die sehr regelmässige Spindel erscheint jetzt gegenüber ihrem frïheren Verhalten etwas in die Länge gestreckt; ihre Achse fällt in der Regel mit der Längsachse der auch auf dieser Stufe noch immer etwas länglichen Zelle zusammen, in der Regel, aber nicht immer, denn in seltenen Fällen sieht man sie schief oder gar quer zur Zellachse eingestellt, was man sich wohl so erklären kann, dass die schon in der Mitose begriffenen Zellen durch die Nachbarzellen comprimirt werden.

Die Spindelfasern treten sowohl an Eisenhämatoxylin- wie auch an anderweitigen (z. B. Hämalaun-Erythrosin-) Färbungen sehr deutlich als leicht körnige Streifen hervor und sind gar nicht so besonders zart; man zählt gewöhnlich 6-8 davon in jeder Spindelhälfte, doch bin ich weit davon entfernt, dies für die thatsächliche Zabl der Spindelfasern zu halten. Eine Unterscheidung von Centralspindel und Mantelfasern ist jetzt kaum mehr möglich; die ganze Spindel zeigt ein einheitlich streifiges Verhalten, und die Streifen scheinen mit den Chromosomen in der Mitte eine wirkliche Verschmelzung eingegangen zu sein. Ich möchte noch besonders betonen, dass anch die $Z_{\text {wischen- }}$ masse zwischen den Spindelfäden von einer besonderen Substanz gebildet sein muss; sie zeigt an Hämalaunfärbungen einen helleren, an Eisenhämatoxylinbildern einen ausgesprochen dunkleren Farbenton als das umgebende Cytoplasma; diesem Unstande ist zum grossen Theile das scharfe Hervortreten der Spindelfigur zuzuschreiben.

Die Chromosomen lassen in der Regel, sobald sie einmal mit der Spindel in Verbindung getreten sind, die Form von plumpen, kurzen Stäbchen erkennen von etwas verschiedener Grösse und oft auch Form. Manchmal sind es freilich eher kleine Spindeln, die an ihren zugespitzten Enden fast unmerklich in die mit ihnen verschmolzenen Spindelfäden übergehen. Dass diese Formen alle aus den Ringen durch concentrische Verengerung hervor- 
gegangen sind, ergiebt sich schon aus den Verhältnissen der früheren Phasen, aber man kann sich daron in den ersten Phasen der Mitose leicht von Nenem überzeugen, indem bei den oben geschilderten Zerrungen, die die Chromosomen bei ibrer Heranziehung an die Spindel zu erleiden haben, die schon früher fast ausnahmslos lumenlos gervordenen Ringe oft wieder etwas ausgedebnt werden, um dann zuletzt doch wieder zu scheinbar massiven Stäbchen zusammenzuschrumpfen.

Zählen lassen sich die Chromosomen auch auf dieser Stufe nicht; es ist dies sogar noch viel weniger möglich, als bei den grossen Spermatocyten, da sie hier so dicht gedrängt liegen, dass man ihre Grenzen gegen einander oft kaum wahrnimmt; besonders ist dies der Fall an den Eisenhämatoxylinpräparaten, wo ihr Complex oft nur unter dem Bilde eines knorrigen schwarzen Querbalkens erscheint.

An den Polen der Spindel bemerkt man an Eisenhämatoxylinpräparaten als ziemlich in die Angen springende schwarze Körper die Centrosomen, immer in der Einzahl um diese Zeit. Manchmal sieht man die Spindelfasern sich direkt mit dem Centrosoma verbinden, häufiger ist aber ein anderes Verhalten, das darin besteht, dass das Centrosoma von einem kleinen bellen Hofe umgeben ist, von dessen Rande erst sowohl die Spindelfasern wie auch die Polstrahlen ausgehen (s. Fig. 12). Die Polstrahlung tritt an gelungenen Präparaten, besonders von dem in Sublimat-Alkohol-Eisessig fixirten Material, scharf hervor. Die Fasern scheinen wie von einer feinkörnigen Substanz gebildet zu sein und sind nicht gerade fein zu nennen; sie stehen in cinigen Abständen von einander und verlaufen bald gestreckt, bald in bestimmter Weise leicht gebogen. In den Fig. 11, 12 u. 13 habe ich es versucht, die Polstrahlen, die ich je an einer Zelle durch sehr sorgfältige, oft wiederholte Beobachtung allmählich herausfinden konnte, darzustellen, wozu ich freilich bemerken muss, dass die Zeichnung sie etwas schärfer hervortreten lässt, als es in der Wirklichkeit der Fall war. Auf zwei Punkte möchte ich hier Gewicht legen: erstens, dass die Strahlen bestimmt bis zur Zellperipherie reichen, sich mit der etwas verdichteten Randschicht der Zelle verbindend, und zweitens, dass im Aequator der Zelle eine starke Ueberkreuzung der Fasern stattfindet, indem einige davon weit iiber die Mitte der Zelle hinausgehen, ja dank einem ein- 
wärts gebogenen Verlaufe oft fast bis zum entgegengesetzten Zellpol hinübergreifen. Ich konnte mich von dieser Thatsache an zahlreichen Exemplaren überzeugen. Aehnliche Bilder mit sich kreuzenden Polstrahlen sind schon an den versehiedensten Zellgattungen in der Litteratur veröffentlicht worden; ich verweise z. B. auf die Bilder, die van der Stricht (1894) von den Mitosen der Eizellen von Thysanozoon Brocchi und auf die, die v. Kostanecki (1896) von der Zelltheilung bei Physa fontinalis gab. Nicht mit Unrecht wurde von R. Fick (1897, S. 107) kürzlich geltend gemacht, dass dieses Verhalten mit den Vorstellungen, die sich M. Heidenhain auf Grund seines Spannungsgesetzes von der Mechauik der Mitose gebildet hat, in Widerspruch steht. Die über den Aequator hinausreichenden Fibrillen müssten bei der Annahme einer Zngwirkung sämmtlicher Polradien den kürzeren Fasern gegenüber geradezu antagonistisch wirken, ja das Auseinanderweichen der Tochterzellen geradezu unmöglich machen. Man müsste da schon zu der etwas gezwungenen Erklärung greifen, dass die bis zum Aequator inserirenden Fasern Zugfasern, die darïber hinausgehenden im Gegentheil Propulsionsfasern seien, die durch ihr Längenwachsthum die Scheidung der Mutterzelle bewirken.

Noch immer erkennt man in diesem Stadium den in der geschilderten Weise seitlich liegenden Sphärenrest, doch fällt er nun allmählich einer Auflösung anheim. Jetzt ist der Augenblick der Trennung der Chromosomenhälften gekommen: die Metakinese beginnt. Der erste Akt dieses Vorganges muss in raschem Tempo vor sich gehen, denn die Bilder, die man sehen kann, zeigen die Tochterchromosomen in der Regel schon weit anseinanderliegend; es muss eine Art Auseinanderschnellen hier im Spiele sein. Anch bei diesem Trennungsprocess bewährt sich die schon oben hervorgehobene plastische Beschaffenheit der Masse, ans der die Chromosomen bestehen; denn die Trennung, die allem Anscheine nach durch einen Querriss der Chromosomen erfolgt, gelingt nicht bei allen mit derselben Leichtigkeit. Nanche iiben einen gewissen passiven Widerstand aus, indem sie sich sehr in die Länge dehnen, bevor sie in der Mitte zerreissen, wodurch wieder recht unregelmüssige Bilder entstehen können.

Die vollkommen ausgebildeten Dyasterformen zeigen ein sehr typisches Verhalten, besonders dadurch, dass der zwischen 
den beiden Tochtersternen gelegene Theil der Spindel eine merkwürdig plumpe, bauchige Form erkennen lässt. Die seitlichen Fibrillen bilden stark convexe Bogen, seltener ist es, dass sie unter Bildung eines stumpfen Winkels an den Seiten eckig hervortreten. Die Spindel hat nun ein helleres Aussehen, da ibre Fibrillen durch das tonnenförmige Anschwellen des ganzen Gebildes stärker auseinandergespreitzt sind. Sehr oft zeigen die Fasern einen leicht welligen Verlauf, doch liegt hier der Verdacht eines Kunstproduktes nahe. Niemals fehlen zwischen den Spindelfäden einige durch Eisenhämatoxylin schwarz färbbare Körnchen, v. Kostan e cki's (1892) Centralspindelkörperchen, deren Herkunft nach der Ansicht Moore's und auch nach meiner eigenen in $\mathrm{Zn}$ sammenhang gebracht werden muss mit den auf S. 259 in dem noch ruhenden Kern beschriebenen Chromatinfragmenten. Mit Resten der Sphäre, wie v. Kostanecki vermuthet, haben diese Körnchen wohl nichts zu thun. Die Spindelfäden sind jetzt wegen ihrer lockeren Anordnung der Beobachtung ausgezeichnet zugänglich; man kann hierbei an ihnen ein leicht körniges Verhalten konstatiren. Die Tochterchromosomen stellen sich als ganz kleine Stäbchen, noch häufiger als rundliche Körnchen dar; sie scheinen miteinander fast regelmässig mehr oder weniger verklumpt zu sein. Die beiden Pole der Spindelfigur sind jetzt bedeutend abgeflachter als vorhin; sie werden nun auch allmählich etwas unscheinbarer.

Von Pol zu Pol gemessen, hat die Spindel auf dieser Stufe an Länge zugenommen, und zwar in grösserem Maasse als die Zelle selbst; dies ist nur dadurch möglich geworden, dass eine Wanderung der Spindelpole mit ihren Centrosomen nach der Oberfläche der Zelle hin erfolgt ist. Bei der zweiten Spermatocytentheilung, bei der die Menge des Cytoplasmas viel geringer ist als bei der ersten, findet man die Spindelpole mit ibren Centrosomen fast immer in der Nähe der Oberfläche oder sogar direkt auf der Oberfläche gelegen; häufig ist dies aber hier schon im Monasterstadium der Fall (Fig. 15). Diese oberflächliche Lage der Centrosomen ist eine bemerkenswerthe Thatsache, auf die ich später noch Bezug za nehmen haben werde. Ein „Polkegel " kann natürlich bei dieser Sachlage bei der zweiten Theilung jetzt nicht mehr vorhanden sein; aber anch bei der ersten, an Protoplasma reicheren Theilung vermissen wir eine solche; die Pol- 
strablung wird während der Metakinese überhaupt allmählich undeutlicher und scheint bald ganz zu schwinden.

Dies ist nun der Zeitpunki, wo die Durchschnürung des Zellleibes beginnt. Der Einschnitt erfolgt bei der Ratte symmetrisch ringsum an der ganzen Peripherie des Zelläquators, nicht einseitig, wie es bei Salamandra nach den Angaben von Flemming (1887 S. 421) und Meves (1896 S. 51$)$ der Fall ist. Die Furche schneidet allmählich circulär tiefer ein, was natürlich nicht ohne Einwirkung bleiben kann auf die plump aufgeblähte und dadurch sich dieser neuen Erscheinung sofort in den Weg stellende Spindel. Sie weicht vor der Trennungsfurche aus, indem sie im Aequator mehr und mehr zusammenschrumpft; bald seben wir sie schon in der Form eines gleichbreiten Stranges von einem Tochterkern zum andern ziehen (Fig. 13), indessen dringt die Furche noch weiter vor, und nun wird sie in der Mitte ganz schmal, sodass sie nun im Ganzen eine ausgesprochen Sanduhr- oder Doppelkegelform annehmen muss, das gerade Gegentheil ihrer früheren Gestalt. Nun, sollte man meinen, miisse bald der Riss in der Mitte erfolgen. Dem ist aber nicht so; zuletzt findet die Spindel ihre Widerstandskraft wieder: sie lässt die Trennungsfurche des Zellplasmas ganz durchschneiden, ja die beiden Tochterzellen sogar ein wenig auseinanderweichen, ohne dass sie zerreissen würde. Sie legt jetzt eine grosse Zähigkeit an den Tag, indem sich ihr sehr verdünnter äquatorialer Theil eine Zeit lang noch als Spindelbrïcke $^{u}$ (Fig. 14) zwischen den Tochterzellen erbält, oft auch noch zu einer Zeit, wo sich die Tochterkerne bereits so gut wie vollkommen reconstruirt baben. Die Spindelbrücke präsentirt sich als ein kleines spindelförmiges Gebilde; die Spindelform ist durch das niemals fehlende Flemming'sche Zwischenkörperchen, das in der Mitte der Bildung eine Anschwellung herrorruft, bedingt. Dieses Körperchen färbt sich in Eisenhämatoxylin äusserst lebhaft; allem Anscheine nach geht es aus den Mikrosomen der Spindelfäden hervor. Wir begegnen hier gewissermaassen der ersten Stufe jener Zähigkeit der Spindel, die uns bei Wirbellosen in so gesteigertem Maasse entgegentritt, und dort jene merkwürdigen Zellkoppeln (Zimmermann, Bolles Lee, v. Erlanger) und "echte Nebenkerne" entstehen lässt. Bei der Ratte geht die Bildung zuletzt spurlos unter. 
Die polaren Abschnitte der Spindel entziehen sich schon viel früher dem Blicke. Am frühesten schwindet das Stück zwischen Tochterkern und Centrosom. Zu einer Zeit, wo dieser Theil der Spindel kaum mehr gefürbt werden kann, inserirt noch mit breiter Basis an dem scheinbar verschmolzenen Complex von Tochterchromosomen der internucleäre Theil der Spindel, d. h. der Complex der "Verbindungsfasern". Nun beginnt der Reconstructionsvorgang der Tochterkerne, die Schaffung normaler Verhältnisse. Der Kern durchlänft hierbei durchaus nicht alle Stadien der gewöhnlichen „Anaphase", die Knäuelstadien werden übersprungen. Das erste ist, dass die Tochterchromosomen mit einander vollkommen, zu einem einheitlichen länglichen Klumpen verschmelzen, wobei aber die Gesammtform ihres Complexes zunächst unverändert bleibt. Hieran schliesst sich ein Vorgang, den Moore und Meves mit dem wie mir scheint nicht gerade glücklich gewählten Ausdruck, Vacuolenbildung" ( fluid vacuole“, M o o r e 1895 S. 291) kennzeichnen. Es handelt sich um nichts anderes als um die Bildung einer neuen Kernmembran und im Zusammenhange damit mit der Entstehung des den Tochterkern auszufüllenden Kernsaftes. Die Sache geht in folgender Weise vor sich. An der polaren Seite des Kerns bemerkt man eine der Chromosomenplatte sich halbmondförmig anlegende helle Stelle, die von wasserklarer Flüssigkeit erfüllt zu sein scheint und sich bald auch durch ein zartes Häutchen, die erste Anlage der Kernmembran, abgrenzt. Das Bläschen umwächst nun allmählich den Rand der Chromosomenplatte und breitet sich auch nach der äquatorialen Seite der Platte aus. Hier aber findet es seinem Wachsthum einen Riegel vorgeschoben durch die breite Insertionsstelle der Spindel. So behält das Bläschen anfangs die Form einer Niere, deren Hilus durch die Spindelinsertion ausgefüllt wird (Fig. 13). Dieser Zustand ist aber nicht von Dauer; das Hinderniss wird bald überwunden, indem sich die Blase zwischen die Chromosomenplatte und die Spindel hineindrängt und das Chromatin auf diese Weise ganz umwächst (Fig. 14).

Damit liegt bereits ein richtiger vollausgebildeter Tochterkern vor, mit dem Unterschied freilich gregen das spätere Verhalten, dass die Chromatinmasse noch in einen centralen Klumpen zusammengefasst ist, während der Kernsaft die Peripherie des 
Kerns einnimmt. Dieser junge Kern hat eine stark elliptische und zwar im Verhältniss zur früheren Theilungsachse quereliptische Gestalt, entsprechend der früheren Stellung des Tochtersterns; an der der Schwesterzelle zugekehrten Seite des Kerns, genauer an der neugebildeten Kernmembran dieser Seite, inserirt anfangs noch mit breiter Basis, dann aber allmählich ganz dünn werdend, die Spindel. Nun erfolgt aber etwas, was mir in seiner mechanischen Begründung nicht klar geworden ist. Die Insertion der Spindel, die anfangs streng median, d. b. an der Mitte der Breitseite des Kernes lag, wandert nun allmählich seitwärts gegen eine der Spitzen der Kernellipse hin; in Folge dessen zeigt nun die Spindel innerhalb der beiden einander gegenüber stehenden Tochterzellen sehr oft einen diagonalen (Fig. 14) oder seitlich verschobenen Verlauf. Offenbar hängt diese Verschiebung mit jenen terminalen Wanderungsvorgängen des Centrosomas und den Kern herum zusammen, die zuerst von M. H e i d e nhain bei den Leukocyten als Telokinese beschrieben und neuerdings von Meves (1896) bei den Spermatocyten des Salamanders wieder ausfïhrlich besprochen worden sind. Meine Erfahrungen hierüber sind sehr mangelhaft, da ich das Centrosoma in diesem Stadium nur selten zuverlässig färben konnte; indessen spricht alles dafür, dass hier ein in die Kategorie dieser Telokinese gehörender Erscheinungscomplex vorliegt.

Die letzten Stadien der Rekonstruktion. der Tochterzelle und ihres Kerns kennzeichnen sich vor allem durch den vollkommenen Schwund des an den Kern stossenden Theiles der Spindel. Im Kern splittert sich die zusammengebackene Chromosomenplatte zu einer regelmässigen Kernstruktur auf, es erfolgt eine gleichmässige Vertheilung von Kerngerïst und Kernsaft in dem von der allmählich schärfer hervortretenden Kernmembran begrenzten Raume ${ }^{1}$ ). Auch nimmt der bis dahin elliptische

1) Die geschilderten Erscheinungen bei der Rekonstruktion des Spernatidenkerns sprechen gewiss sehr überzeugend gegen die Anschauung von Schneider, Rawitz, Reinke, Rohde u. A, dass die sog. Kernmembran nur ein Verschmelzungsprodukt der Filarmasse des Cytoplasmas mit dem Liningerüst des Kerns sei. Die Membran taucht zu einer Zeit auf, wo die gesammte geformte Substanz des Kerns, Linin und Chromatin, zu einem Klumpen zusammengeballt, im Innern des Kerns liegt, von Kernsaft umgeben. Ich muss hier noch 
Kern allmählich eine kugelrunde Form an. Hat es sich um die zweite Theilung gehandelt, so findet man, dass sich der unmittelbar nach der Mitose sehr kleine Kern nun bald etwas aufbläht, womit der normale Zustand eines ruhenden Spermatidenkerns erreicht ist. Im Zellkörper tritt von Neuem die Sphäre in die Erscheinung.

Noch ein Punkt ist schliesslich zu erwähnen. Während der ganzen Theilung gelingt es, die chromatoiden Nebenkörper nachzuweisen; sie liegen im Cytoplasma, ansserhalb der mitotischen Figur, aber in unregelmässig wechselnder Anordnung, auch scheint manchmal ein vorübergehender Zerfall dieser Bildungen in mehrere Körnchen einzutreten. In den Tochterzellen aber tauchen die Gebilde immer wieder auf, und zwar in etwas gewachsenem Zustande, als ziemlich ansehnliche kugelförmige Gebilde, natürlich nunmehr in der Einzahl, je eines in jeder Spermatide. Ist zuletzt auch der letzte Rest der ${ }_{n}$ Spindelbrücke" geschwunden, so haben wir nun eine vollkommen zur Ruhe gelangte fertige Spermatide vor uns, die sich nun der Erfüllung ihrer Aufgabe, der Metamorphose zu einem Spermatozoon, widmen kann.

\section{Die Vorgänge an den Spermatiden.}

Die letzte Zellgeneration in den Samenkanälchen, die Spermatiden (S e m per und W. Voigt) oder Nematoblasten (Sertoli, Sraen und Masquelin), sind verhältnissmässig kleine Elemente; von Haus aus wohl rundlich, nehmen sie bei ihrer dicht zusammengedrängten Lage durch den gegenseitigen Druck bald eine eckige Form an und verlängern sich auch gewöhnlich etwas in der Richtung nach dem Lumen hin. Ihr Cytoplasma zeigt eine ganz helle, ausserordentlich feinkörnige Beschaffenheit; von einer radiären Faserung, wie überhaupt von einer fibrillären Struktur,

\footnotetext{
bemerken, dass das Auftreten der hellen, aus Kernsaft bestehenden „Vacuolen" nicht in allen Fïllen streng nach dem geschilderten Modus vor sich geht; die oben stehende Darstellung giebt nur das typische und häufigste Verhalten wieder. Es kann auch vorkommen, dass die Vacuole zuerst auf der aquatorialen Seite des Tochtersternes auftritt, un sich von hier aus nach der polaren Kernseite hin auszubreiten, oder dass sie gleichzeitig ringsum um den ganzen Tochterstern zur Anschauung kommt.
} 
habe ich nie was an ihnen bemerken können. Der Zellkontour markirt sich stets als recht scharfe, deutliche Linie, offenbar vermöge einer kleinen Verdichtung der oberflächlichsten Plasmalage. Der nach der letzten Theilung sich rasch rekonstruirende Kern stellt sich als kugelrundes oder nur leicht ellipsoidisches Bläschen dar von $7-9 \mu$ Durchmesser und erscheint von einer zarten Kernmembran begrenzt. Durch den Kernraum spannt sich ein feines, blasses, lockeres Gerüst aus mit weiten, ungleich grossen Maschen. Oft ist ein radiärer Typus des Gerüstes unverkennbar. In die Substanz der Gerüstbalken und ihrer Knotenpunkte finden wir in ungleicher Vertheilung Chromatintheile eingelagert, theils in Form kleinerer Mikrosomen, theils in der von gröberen Schollen. Im Allgemeinen ist der Kern als chromatinarm und überhaupt als strukturarm zu bezeichnen. Da ich mich vergeblich bemüht habe, durch Doppelfärbungen ein typisches Kernkörperchen im Kern der Spermatiden nachzuweisen, möchte ich annehmen, dass ein solches bier nicht mehr vorhanden ist.

Wenden wir nun unseren Blick vom Kern wieder zum Cytoplasma der jungen Spermatide, so sehen wir, dass dieses drei verschiedene Einschlüsse von freilich sehr verschiedenem Umfang aufweist. Diese sind: Sphäre, chromatoider Nebenkörper und Centrosomen.

Vor allem fesselt den Blick neben dem Kern die neugebildete Sphäre. Wir hatten sie zuletzt am Schlusse der Prophasen, im Muttersternstadium der zweiten Spermatocytentheilung gesehen; hier entzog sie sich spurlos dem Blicke, um während des ganzen ubrigen Verlaufes der Mitose unsichtbar zu bleiben. Ihr Wiederauftauchen in den Spermatiden erfolgt nicht ganz so rasch, wie in den $v$. Ebner'schen Zellen, so dass hier doch einiges über die Art und Weise, wie ihre Bildung vor sich geht, ermittelt werden konnte. Es zeigte sich erstens, dass sie auch hier obne jede Beziehung zu der Spindel in die Erscheinung tritt, zweitens, dass sie nicht auf einmal in ihrer vollen Grösse, Form und Einheitlichkeit auftaucht, sondern aus der Verschmelzung von kleinen Theilstücken entsteht. $\mathrm{Zu}$ einer Zeit, wo der Spermatidenkern noch auffallend klein ist, aber sich doch schon soweit regenerirt hat, dass er bereits ein Kerngeruist aufweist, gewahrt man an Hämalaun-Erythrosinpräparaten in der Nähe des Kerns zwei bis drei sehr kleine, unregelmässig geformte 
Klümpchen, die die charakteristische Sphärenfärbung zeigen. Darauf folgt gleich ein Stadium, wo die Sphäre schon als einheitliches, rundes Gebilde hervortritt. Man kann sich demnach den Vorgang so vorstellen, dass die specifische Sphärensubstanz, die während der zweiten Hälfte der Mitose gleichmässig über das ganze Gebiet des Cytoplasmas der sich theilenden Zelle vertheilt war, in den Tochterzellen sich rasch.wieder zusammenballt, zuerst za kleinen-Partikelchen, die aber sehr bald zu einem einheitlichen Gebilde mit einander verschmelzen.

In den fertigen Spermatiden zeigt sich die Sphäre wieder als regelmässig runder Körp̉er, gewöhnlich in direkter Berührung mit dem Kern, ohne aber zunächst so fest an ihn angedrückt zu sein, dass an einem von beiden, sei es am Kern oder der Sphäre, eine Abplattung oder dergl. wahrnehmbar wäre. Die Stelle, an der die Sphäre den Kern berührt, kann zunächst eine beliebige sein, $d$. $h$. sie kann sich ebenso gut auf der Kanalwandseite wie auf der Lumenseite des Kerus befinden. Gleichwohl ist durch jene Berührungsstelle bereits ein wichtiger Fixpunkt für die Anlage der einzelnen Glieder des späteren Spermatozoons gegeben: schon jetzt ist dadurch unweigerlich das vordere Ende des Spermatozoonkopfes bestimmt; und wenn wir in einer etwas späteren Phase die Sphäre immer an der Kanalwandseite des Kerns antreffen, so ist dies nicht in der Weise auszulegen, dass die Sphäre eine Wanderung um den Kern beschrieben hat, sondern so, dass sich der ganze Inhalt der Zelle, die Zelle als Ganzes, einheitlich in einer bestimmten Weise eingestellt hat, ohne dass eine Verschiebung der räumlichen Beziehungen von Kern und Sphäre eingetreten wäre. Der Durchmesser der Sphäre beträgt $2-2,5 \mu$; sie ist also nicht unbeträchtlich kleiner geworden, als sie in den grossen Spermatocyten wal $(4 \mu)$. Im Innern erscheint sie zunächst homogen, ohne Andentungen von Fibrillen oder Körnchen; nur an der Grenze des Gebildes sind manchmal an Eisenhämatoxylin-Präparaten schwarze Punkte sichtbar, die sich zu einem fast zusammenhängenden Rabmen verbinden können; indess an sonstigen Färbungen erscheint auch der Rand von allen derartigen Bildungen frei. Den Körnchen, die $\mathrm{N}$ iessing in der Spermatidensphäre beschreibt, muss ich auf Grund meiner Beobachtungen die Realität absprechen. Die Centralkörperchen scheinen zu dieser S̄phäre 
von Anfang an in keinen Beziehungen zu stehen, denn ich sehe sie von dem Momente an, wo ich sie überhaupt färben kann, unabhängig von der Sphäre an einer anderen Stelle der Zelle liegen. Auch von einer Trennung in Rinde und Mark ist zunächst nicht zu bemerken.

Die Sphäre ist in den Spermatirlen der Säuger bereits von vielen Forschern gesehen worden. Entdeckt hat sie allem Anscheine nach v. La Valette St. George beim Meerschweinchen. Merkel (1847), v. Brunn (1876) behandeln sie bereits; Rens on (1882) beschreibt sie beim Kaninchen (S. 327) und bildet sie bei der Ratte ab (Fig. 1-2), ebenso auch H. Brown. Ausführlichere Behandlung hat sie dann bei Benda und Niessing erfahren, auf deren Darstellungen wir bald näher einzugehen haben werden.

Ein zweites Gebilde im Cytoplasma der Spermatide ist der nchromatoide Nebenkörper ${ }^{\alpha} \quad$ Benda's (1891). Die beste Anschauung ron diesem Gebilde liefert die Eisonhämatoxylinmethode; der Nebenkörper nimmt damit eine tintenartige schwarze Färbung an, die er auch bei ausgedehnter Differenzirung, ähnlich wie ein Kernkörperchen, behauptet. Er tritt natürlich als schwarzer Fleck schon bei schwachen Vergrösserungen mit grosser Lebhaftigkeit hervor und fehlt in keiner Spermatide. Wo er zu fehlen scheint, ist er offenbar durch das Mikrotommesser weggeschnitten. In der überwiegenden Mehrzahl der Fälle stellt sich der Nebenkörper als ein streng kugelförmiges Gebilde dar, etwas kleiner als die Sphäre, stets in der Nähe des Kernes gelegen, doch kann er auch eine mehr längliche ellipsoidische Form aufweisen oder wie aus zwei in der Mitte verschmolzenen Kiigelchen zusammengesetzt sein. Niemals gelang es mir, Spuren einer inneren Differenzirung an dem chromatoiden Nebenkörper wahrzunehmen. An den Eisenhämatoxylinbildern, an denen er als schwarzer Klecks erscheint, könnte eine solche natürlich, auch wenn sie vorhanden wäre, nicht zur Geltung kommen, aber der Körper färbt sich auch mit anderen Farbstoffen, z. B. mit Gentiana in der Doppelfärbung Gentiana-Safranin oder mit Magentaroth, und hierbei erscheint er immer ganz homogen.

Die Durchforschung der Litératur bezüglich des chromatoiden Nebenkörpers ergab eine verhältnissmässig geringe Ausbeute. Dies mag einerseits daran liegen, dass das Körperchen durchaus nicht mit allen Färbungen dargestellt werden kann, andererseits auch daran, dass es nicht bei allen Säugethieren vorhanden zu sein scheint. v. B runn ist wohl als der Entdecker dieses Gebildes zu bezeichnen. In seiner 
Arbeit vom Jahre 1876 hält er bereits die zwei verschiedenen Einlagerungen des Cytoplasmas der Spermatiden, Sphäre und Nebenkörper auseinander, weniger in dem Text als in den Figuren $a-d$ der Tafel XXII. In diesen Abbildungen sind unverkennbar beide Dinge nebeneinander dargestellt, wenn auch wegen der zu kleinen Dimensionen der Zeichnungen etwas undeutlich: die Sphäre schon in ihrem Lunulastadium, der Nebenkörper in wechselndem Lageverhältniss da$\mathrm{zu}$, als rundes, schwarzes Körnchen.

Brown (1885) hat das Gebilde an der Hand der Goldmethode unzweifelhaft dargestellt. Dies geht aus seinen Figuren 12 und 22 sowie aus einem Satz auf S. 357 seiner Arbeit ${ }^{1}$ ) ohne weiteres hervor, indessen hat er es nicht genügend als etwas für sich Bestehendes erkannt; er hat es zusammengeworfen mit der Sphäre. Auch Hermann dürfte das Gebilde gesehen haben, allein auch in der Arbeit dieses Forschers fehlt noch die scharfe Unterscheidung der zwei differenten Plasmaeinschiüsse.

Bei Benda (1891) tritt uns mit aller Schärfe die Trennung der beiden Gebilde entgegen. „Bei den „neugebildeten Spermatocyten“, d. h. unseren Spermatiden, ,ist sofort . ... der chromatoide Nebenkörper sichtbar." Benda findet aber, dass dieser in den Spermatiden eine complicirte Natur erkennen lässt, „obgleich diese bei der Kleinheit des Objektes nicht so sicher zu stellen sei“. Er soll aus einem punktförmigen Körnchen und einem diesem mützenförmig aufliegenden helleren Theil bestehen. In dem Vortrag der VI. Versammlung der Anatomischen Gesellschaft (1892) heisst es daun, dass von den beiden Bestandtheilen des Nebenkörpers der eine ringförmig ist, der andere knöpfchenförmig. Ich kann mich dieser Darstellung durchaus nicht anschliessen; meine Erfahrung'en stehen zu denen Benda's nicht nur in Bezug auf die ángebliche Differenzierung des Nebenkörpers im Gegensatz, sondern vor Allem auch in Bezug auf dessen weitere Schicksale, wie das an einer späteren Stelle ausgeführt werden soll.

Erst Niessing (1896) schildert das Körperchen mit aller Ausführlichkeit, so wie es sich wirklich darstellt, nämlich als strukturloses Kügelchen, und da ich auch die weiteren Darstellungen, die Niessing davon giebt, im Ganzen bestätigen kann, so muss ich sagen, dass meiner Ansicht nach die Angelegenheit des chromatoiden Nebenkörpers zuerst durch Niessing in der Hauptsache in's Klare gebracht wurde.

Was man über die Herkunft des Gebildes sagen kann, ist bereits auf S. 259 angeführt, denn auch für den Nebenkörper der Spermatiden gilt ja Alles dort Gesagte, da sich ja dieser

1) Er beschreibt in den Spermatiden: „a small refracting granule, attached to the nucleus membrane at the point, from which the deve loppement of the body of the spermatozoon in about to begin." 
unzweifelhaft direkt aus dem chromatoiden Nebenkörper der Spermatocyten ableitet. Freilich ist dabei noch an die Möglichkeit zu denken, dass der Nebenkörper hier doch noch etwas mehr ist, als in den Spermatocyten, indem er hier entschieden einen etwas grösseren Umfang erkennen lässt, als dort, und man könnte speciell daran denken, dass etwa Theile der Nucleolen während der nacheinanderfolgenden zwei Mitosen in den Nebenkörper aufgenommen worden sind. Diese Möglichkeit liegt aus zwei Gründen nahe: erstens zeigt der Nebenkörper der Spermatiden in seinem färberischen Verbalten entschieden eine gewisse Annäherung an das Verhalten der Nucleolensubstanz, zweitens haben wir gesehen, dass die Nucleolen bei der Spermatocytenmitose verschwinden und dann im Spermatidenkern nicht mehr nachgewiesen werden können. Wäre es nicht möglich, dass ihr Verschwinden in innerem Zusammenhang steht mit dem Anwachsen des Nebenkörpers? Indess sind das nur Vermuthungen, für die ich einen vollgültigen Beweis zu erbringen nicht im Stande bin. Jedenfalls besteht das Gebilde nicht aus reinem Chromatin, weder aus dem gewöhnlichen Basichromatin, noch aus M. Heide nha in's Oxychromatin, denn sowohl die reinen Kernfarbstoffe wie Hämatoxylin, Thionin, Methylenblau, als auch die sauren Anilinfarbstoffe wie Eosin u. s. w. lassen es ungefärbt.

Der dritte Bestandtheil im Spermatidenkörper wird durch die Centralkörperchen dargestellt. Sie sollen unten bei der Besprechung der Bildung des Achsenfadens ausführlich behandelt werden; hier genüge es zunächst, sie genannt zu haben.

\section{Schicksale der Sphäre und des Kerns in den Spermatiden.}

Wir hatten die Spermatidensphäre zuletzt gekennzeichnet als eine im Inneren nicht weiter differenzirte Kngel, die dem Kern an irgend einer Stelle anliegt. Nicht lange indess verharrt sie in diesem Zustande; bald sehen wir wesentliche Umgestaltungen in ihr Platz greifen, die sie - um das Wesentlichste hier vorweg mitzutheilen - als den Mutterboden für die Bildung der Apperticulargebilde am vorderen Pol des Samenfadenkopfes erscheinen lassen. Diese Veränderungen haben schon in den Untersuchungen Merkel's und v. B r a n n's Berücksichtigung gefunden, 
besonders aber sind sie in den letzten Jahren ron Ballowitz, $\mathrm{B}$ enda und $\mathrm{Ni}$ essing genauer erforscht worden.

Ich möchte zunächst meine eigenen Befunde darlegen und dann erst anknüpfen an die Mittheilungen Anderer. Die deutlichsten Bilder von den zu beschreibenden Vorgängen erhielt ich durch die Magentarothfärbung, besonders nach der Fixirung im Sublimat-Platinchlorid-Eisessiggemisch. Die verschiedenen Phasen des Vorganges lassen sich sehr leicht an ein und demselben Präparate verfolgen; die Zusammenstellung der verschiedenen
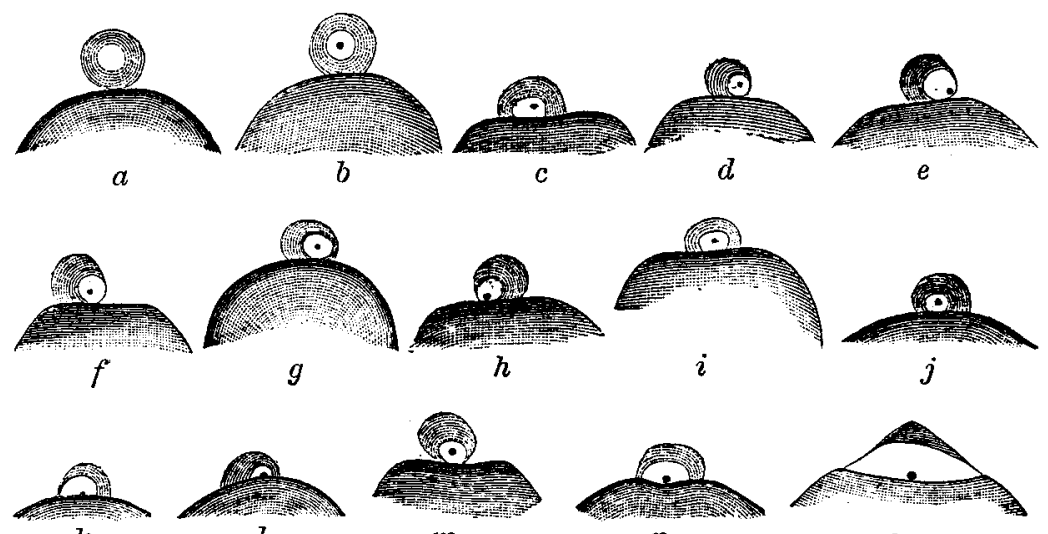

$m$

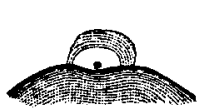

$n$

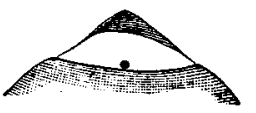

Sphäre der Spermatiden (Ratte), mit den ersten Stadien der Bildung. des homogenen Bläschens (spätere Kopfkappe) und des Akrosomas darin. Dieses in $a$ noch nicht sichtbar. In $o$ schon ausgesprochenes Lunulastadium des Sphärenrestes.

Phasen zu einem zusammenhängenden Vorgang gelingt auf's Leichteste.

Das erste was man sieht (s. Zeichnung $a$ der beistehenden Textfig.) ist, dass die anfangs homogene Kugel im Innern eine Differenzilung erfährt. In der Mitte des Gebildes tritt ein helles Bläschen, oder nach Bend a's Ausdruck (1892, S. 196) „eine zartwandige

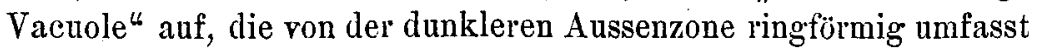
wird. Eine ähnliche Erscheinung hatten wir ja bereits bei der Sphäre der grossen Spermatocyten gesehen; indessen liegt hier doch etwas anderes vor. Dort handelte es sich bloss um eine verschwommen in die dunkle peripherische Zone übergehende centrale Aufhellung, hier dagegen ist ein wirkliches, scharf be- 
grenztes Bläschen im Spiele. Sehr bald (b) aber bemerkt man noch ein weiteres Detail. Genau in der Mitte des Bläschens erscheint ein kleines körnchenartig'es, rundliches Gebilde, das sich mit Magentaroth, Erythrosin und Fuchsin in intensivster Weise färbt, mit Eisenhämatoxylin dagegen bei der Ratte sich nicht deutlich darstellen lässt.

Was ist nun dieses centrale Korn, woraus und auf welche Weise ist es entstanden? Diese Frage hat kürzlich eine besondere Bedeutung gewonnen, indem $\mathrm{N}$ iessing (1896) die Meinuvg ausgesprochen hat, dass dieses Gebilde theilweise aus dem Centrosoma hervorgehe. Ni es sing kommt daher zu der Ansicht, die er als Hauptergebniss seiner Arbeit hinstellt, dass das Centrosoma des reifen Spermatozoons nicht, wie das allgemein angenommen wird, im Mittelstïck oder Verbindungstïck (Retzius) des Samenfadens enthalten sei, sondern vorn an der Spitze des Samenfadenkopfes sitze, denn das centrale Körnchen setzt sich später, wie das gleich vorausgeschickt werden soll, mit der Spitze in Verbindung.

Hier liegt meiner Ansicht nach ein verhängnissvoller Irrthum vor und es wird mir nicht schwer fallen, die Beweise für diese Behauptung beizubringen. Der erste und schwerwiegendste Beweis ist, dass man die Centrosomen anderswo in der Zelle nacliweisen kann, eine Thatsache, die eigentlich alle weiteren Beweise überflïssig macht.

Nun kommt aber weiter die färberische Reaktion des centralen Sphärengebildes in Betracht. Es zeigt, wie gesagt, bei der Ratte durchaus keine Affinität zu dem Eisenhämatoxylin, nur manchmal gelingt es, es damit zu färben. Dies steht also im Widerspruch mit allen unseren Erfahrungen über die tinctoriellen Eigenschaften der Centralkörper. M. H e i de n ha i u hat sogar die starke Färbbarkeit des Centrosomas in Eisenhämatoxylin in die Definition aufgenommen, die er von diesem Gebilde giebt, und ich muss mich in dieser Hinsicht auf Grund der Erfahrungen, die ich in letzter Zeit an den verschiedensten Zellgattungen gesammelt habe, mit voller Entschiedenheit Heiden$\mathrm{h}$ a in anschliessen. Wenn die Berechtigung der $\mathrm{He}$ iden hainschen Definition von mancher Seite angefochten wird, so liegt dies eben daran, dass einige Forscher unter Centrosom etwas anderes verstehen als $\mathrm{Heidenh}$ ain, namentlich rechnen manche $\mathrm{zu}$ 
dem "Centrosoma" etwas mehr hinzu als dieser, auch noch etwas von der Umgebung der Flemming-Heidenhainschen Centralkörper; diese letzteren sind Einschlüsse des Centrosomas für sie, Centralkörner, Centriolen. Dass aber die Centriolen für Eisenhämatoxylin eine besondere Affinität besitzen, giebt wobl heute jeder zu. - Nun zeigt aber unser Mediankörnchen in der Sphäre ein ganz anderes Verhalten. Schon nach ganz leichter Entfärbung, wenn sonst noch alles mögliche in der Zelle schwarz geblieben ist, sucht man vergebens nach dem centralen Gebilde. Es hat ganz andere Farbstoffneigungen: eine grosse Neigung zu Magentaroth, Fuchsin und besonders zu dem Erythrosin, uiberhaupt zu sauren Farbstoffen. Mit Erythrosin und Eosin verbindet es sich in so intensiver Weise, dass es manchmal schon bei der schwächsten Anwendung des Mittels, wenn sonst alles übrige kaum erst einen Hauch von Rosafärbung angenommen hat, leuchtend roth bemerkbar wird. Besonders kommt dies vor in einem etwas späteren Stadium, wenn sich das Gebilde schon mit dem Sameniadenkopf verbunden hat.

Die Entstebungsweise des Gebildes ist gan $z$ eigenartig. Nicht etwa im Anschluss an etwas schon Vorhandenes entsteht es, sondern plötzlich, wie durch einen Schöpfungsakt, tancht es in der bis dalin homogenen Sphäre auf, offenbar durch eine spontane Verdichtung, - Differenzirung ihrer Substanz. Ich muss mich vollkommen in Widerspruch setzen zu der Darstellung Niessing's, der das Gebilde aus dem Zusammenfluss von zahlreichen in der Sphäre gelegenen Körnchen ableitet. Solche Körnchen kommen im Innern der Sphäre typisch überhaupt nicht vor.

Auch mit der Schilderung Moores (1893) kann ich mich nicht einverstanden erklären. Moore spricht von einer Anz a h 1 von hellen Bläschen in der Sphäre, wovon jedes ein dunkles Körperchen in sich schliesse, und die erst durch ihre Verschmelzung schliesslich das einheitliche Bläschen bilden sollen. Auch Meves giebt eine ähnliche Entstehungsweise der Vakuole für Salamandra an. Bezüglich des Salamanders babe ich keine Erfahrungen, aber in Betreff der Ratte, auf die sich Moore's Darstellung bezieht, muss ich daran festhalten, dass jene Beschreibung unzutreffend ist, indem die "Vakuole" immer sofort als einheitliches Bläschen erscheint.

Aber wenn man nach all dem bezüglich der Nichtidentität 
des Körperchens mit einem Centrosoma noch Zweifel hegen würde, so müssten diese schwinden, wenn man die Spermatogenese beim Meerschweinchen heranzieht. Hier erscheint dasselbe Gebilde, das bei der Ratte sich als minimales Körnchen darstellt, als mäıhtige Kugel, so dass von vornherein an ein Centrosom nicht zu denken ist.

Die weiteren Vorgänge an der Sphäre und ibren Einschlüssen sind höchst merkwürdig und lassen sich eben nur von dem Standpunkte aus erklären, dass hier ganz specielle, keineswegs von einem allgemeinen Gesichtspunkte aus za beurtheilende Differenzirungen des Cytoplasmas der Spermatide im Spiele sind. - Zunächst erkennt man (siehe Textfigur $c-n$ ), dass sich die ganze Sphäre dem Kern (an der Stelle seines späteren vorderen Poles) etwas andruckt; hierdurch nimmt sie selbst eine leicht abgeplattete Form an, verursacht aber auch an der betreffenden Stelle des Kerns eine sanfte Abflachung. Das früher im Centrnm der Sphäre gelegene helle Bläschen kommt jetzt durch diese Abplattung der Sphäre mit dem Kern in direkte Berührung und verwächst sogar mit der Kernmembran. Der dunkle Theil der Sphäre umfasst lunulaartig das dem Kern angepresste Bläschen, ein Bild, das schon sehr oft (z. B. auf v. Brunn's Taf. XXII, Fig. $a-d$, bei Brown a. s. w.) bildlich dargestellt und beschrieben wurde. Indessen ist diese Lunula nur selten so ganz regelmässig beschaffen, wie sie fast immer abgebildet wird, gewöhnlich zeigt sie ein unsymmetrisches Verhalten, indem sie nach der einen Seite hin stärker gewölbt ist als nach der andern; es ist, als ob das helle Bläschen innerhalb der Sphäre eine kleine seitliche Verschiebung erfahren hätte, oder richtiger, als ob sich der Sphärenrest an dem Bläschen etwas seitlich verschoben hätte. Ein Blick auf die Figg. 22-24 wird genügen, um von diesem Verhalten, das sich nur sehr umständlich durch Worte vergegenwärtigen lässt, eine Vorstellung zu vermitteln.

In der Minderzahl der Fälle zeigt der Kern an der Berührungsstelle mit der Sphäre von Anfang an eine kleine concave Stelle oder sogar einen etwas tieferen Einschnitt (Textfig. $c, m, n, o$ ).

Was nun folgt, ist eine ziemlich rasche Vergrösserung des Bläschens (o); der Inhalt des Bläschens ist und bleibt dabei - abgesehen von dem centralen Körnchen - eine völlig struk- 
turlose, belle Flüssigkeit. Die Vergrösserung erfolgt anfangs sowohl nach der Breite wie auch nach der Seite der Convexität hin, so dass sich das Bläschen zunächst stark hervorwölbt, dann aber ansschliesslich in der Richtung der Breite, so dass allmählich ein grösseres Stück des Kerns von dem Bläschen wie von einer Miitze bedeckt erscheint; dem Wachsthum des Bläschens folgt auch streng die Abplattung des Kerns. Der "Sphärenrest“, wie man jetzt die „Lunula" bezeichnen kann, nimmt an dem Wachsthum nicht Theil und wird deshalb, da er um diese Zeit noch anscheinend mit dem Bläschen fest verwachsen ist, stark ausgcdehnt, das Bläschen jetrt wie ein schmaler Saum umfassend. Das centrale Körnchen sehen wir während dieser Vorgänge anfangs noch in der Mitte der Sphäre liegen; es plattet sich dabei oft zu einem kleinen querliegenden Stäbchen ab. Unerwartet aber stellt sich eine nene Erscheinung ein: das kleine Gebilde wird gleichsam an den Kern herangezogen und tritt mit der Kernmembran in dauernde Verbindung. Diese Verbindungsstelle bezeichnet die spätere Spitze des Samenfadenkopfes oder, ganz korrekt, die unmittelbar daran grenzende Partie, und das Körnchen kennzeichnet sich dadurch als die Anlage eines altbekannten Gebildes, des Spitzenknöpfehens ron Merkel. Niessing hat es, in Anlehnung an einen älteren Vorschlag Platner's, als $\mathrm{Mi}$ tos oma bezeichnet, weil es angeblich aus dem "Mitom" der Sphäre hervorgehe (?). Mir scheint aber dieser Namen absolut nichts Bezeichnendes an sich zu baben; will man sich daher eines griechischen Terminus technicus bedienen, ein Vorgehen, das ja rom Gesichtspunkt der Bequemlichkeit in der That geboten sein kann, so scheint mir das Wort "Akrosoma" weitaus den Vorzug zu verdienen. Im Momente der Verbindung stellt sich das "Akrosoma" - um diese neue sprachliche Schöpfung gleich zu benützen - immer als rundliches Körnchen dar, bald aber zeigt es die Tendenz, sich ein wenig in der Querrichtung abzuplatten.

Wir sehen jetzt also ein Bild, wie es die Textfigur $o$ und Figur 16 zur Ansicht bringen. Der vordere Kernpol erscheint wie abgeschnitten; auf die abgeflachte Partie legt sich das Bläschen in der Weise an, dass seine Wölbung der früheren Ausdehnung des Kerns an seinem vorderen Pol entspricht. Genau in der Mitte der Basis des Bläschens sitzt an der Kern- 
membran das knötchenartige Akrosoma; dem convexen Rande des Bläschens etwas unsymmetrisch angeschmiegt der halbmondförmige Sphärenrest. Frcilich begegnet man auch ab und zu Bildeln, die in manchen Punkten von diesem Bilde abweichen; so kann z. B. das Akrosoma mehr etwas seitlich verschoben liegen, nicht in der Mitte der Bläschenbasis, sondern einer der seitlichen Anheftungsstellen des Bläschens genähert (Fig. 24).

Ein etwas weiter vorgeschrittenes Stadium ist auf Fig. 20 vergegenwärtigt. Das Bläschen hat an Breite zugenommen; es beginnt nun in allem Ernst, den Kern zu umwachsen. Das Neue aber ist, dass der Kern, anstatt entsprechend der Ausdehnung des Bläschens weiter an Abplattung zuzunehmen, sich im Gegentheil auch da, wo er früher abgeplattet war, wieder abgerundet hat. Dies ist der Grund, warum das Bläschen jetzt nicht mehr stets so stark über den Kernkontur hinaus vorgebuchtet, sondern diesem oft schon sehr genähert erscheint. Es kann nun auch durch diese Annäherung mit dem Spitzenkörperchen wieder in Bertïhrung treten. Freilich treten dem Beobachter nicht nur auf diesem, sondern auch auf späteren Stadien Bilder entgegen, an denen die „Kernkappe", wie man nun schon das Bläschen bezeichnen darf, noch immer stark vorgewölbt erscheint.

Der Kern stellt sich auf dieser Stufe noch immer als rundes oder höchstens ganz leicht ellipsoidisches Bläschen dar; aber in seinem Inneren sind bereits gewisse Veränderungen vor sich gegangen, die hier Berücksichtigung erheischen. Freilich sind sie nach meinen Erfahrungen zunächst noch nicht so eingreifend, wie sie von mancher Seite geschildert worden sind. Ich finde vor allem eine kleine Aufhellung der Kernstruktur im centralen Theil des Kernraumes; die Gerüstsubstanz zieht sich mehr und mehr nach der Peripherie hin zurück, aber immer noch sieht man auch die Mitte des Kerns von einzelnen Balken durchzogen. Im Allgemeinen lässt sich eine Vereinfachung des Kerngerüstes nachweisen. Es liegt wohl eine Art von Verquellung des Kerns in seiner Mitte, eine centrale Ansammlnng ron Kernsaft ror; freilich ist diese Veränderung von Zelle zu Zelle sehr verschieden stark ausgesprochen, manchmal kanm angedentet. - Constanter und gewöhnlich auch anffallender ist folgende Erscheinung: im Bereich des von der „Kernkappe“ umwachsenen Theiles lässt die Kernmembran eine ziemlich starke Verdickung erkennen; 
sieht man genau zu, so erkennt man, dass diese Verdickung auf der Auflagerung einer gleichmässig dicken Lage von Chromatin auf der Innenseite der Membran beruht; es bildet sich eine "Chromatinkruste", 'eine sehr typische Erscheinung. Besonders deutlich lässt sich diese Kruste an Eisenhämatoxylinbildern erkennen, wo sie sich durch ihre schwarze Färbung manifestirt. An angeschnittenen Kernen wird sich die Kruste natürlich immer als dicke Grenzlinie darstellen, in strenger Beschränkung auf den von der Kernkappe bedeckten Theil des Kernkonturs, an dessen Rande wie abgeschnitten aufbörend. Hat man aber eine Gesammtansicht des Kerns vor sich, wie in Fig. 21, so erscheint das Gebiet der Chromatinkruste als eine dunkle, „vordere" Kernhälfte, die sich ron der hinteren helleren Kernabtheilung durch eine mehr oder weniger scharfe Linie, Rens on's ,strie équatoriale" (1882, S. 314) abgrenzt. Mit der Ausdehnung des Bläschens hält die Krustenbildnng genau Schritt.

Wir haben hier eine schon von Kölliker im Jahre 1856 (S. 265 und Taf. XIII, Fig. 6-9) abgebildete Erscheinung vor uns. Merkel (1874) bat sie dann eingehender untersucht und unter dem Namen „Gliederung des Kerns in zwei verschieden lichtbrechende Hemisphären" in die Literatur eingeführt. Ich halte aber diese Bezeichnung, die sich in der Literatur bald eingebürgert hat, nicht für ganz glücklich gewählt, denn die Gliederung ist, wie dargestellt, keine innere, das Kerngerüst lässt davon nichts erkennen, sie beruht vielmehr nur auf einer chromatischen Verdickung der Kernmembran. Auch ist die Erscheinung, wie wir sehen werden, bei der Ratte wenigstens, von vortubergehender Natur, sie kommt nur diesen frühen Stadien der Spermatogenese zu und schwindet bald. B a llowitz täuscht sich wohl, wenn er (1891, S. 284) die von ihm beschriebene spätere Trennung des reifen Samenfadenkopfes in ein „Vorderstück" und „Hinterstück" auf diese Kölliker-Merkel'sche Erscheinung zurückführt; sie hat mit ihr nichts zu thun. Brown scheint die Sache richtig erkannt zu haben, er schildert die Erscheinung folgendermaassen (S. 357): ,the nuclear membrane over the outer hemisphere of the nucleus becomes slighthy thickened."

In diesem Stadium beginnt nun der noch immer runde Kern aus dem mittleren Theil der Zelle herauszuriicken, und 
zwar nach deren der Kanalwand zugekehrtem Pol hin. Es ist um diese Zeit bereits immer eine strenge Orientirung der in der Spermatide enthaltenen Theile erfolgt. Der Sphärenrest mit der Kopfkappe liegt stets an dem der Kanalwand zugewandten Kernpol; der chromatoide Nebenkern, der noch vor kurzem keine konstante Lagerung erkennen liess, findet sich jetzt immer am hinteren Kernpol, in der Nähe der nun stets bereits angelegten Geissel. Es ist nicht leicht, sich über die mechanischen Momente, die diese regelmässige Orientirung hervorbringen, eine befriedigende Vorstellung zu bilden. Man bekommt den Eindruck, als wäre eine gewisse Strömung im Cytoplasma vorhanden in der Richtung von dem Kanalwandpol nach dem Lumenpol hin, wodurch der frei im Cytoplasma liegende chromatoide Nebenkörper gegen den binteren Zellpol hin geschwemmt wird; freilich miisste man da noch ein zweites Moment: die Attraktionskraft des hinteren Kernpoles auf den Nebenkörper heranziehen, denn bei der alleinigen Wirkung jener Strömung mïsste der chromatoide Nebenkörper in den distalsten Punkt des Protoplasmalappens gelangen.

Jene hypothetische Plasmaströmung würde uns nicht nur die allmäbliche Verlagerung des Kerns in einen der Zellpole, sondern auch noch eine weitere Erscheinung, die jetzt Platz greift, erklären: die Ablösung des Sphärenrestes von der Kopfblase, seine Wanderung in den als Lappen in das Lumen hineinbängenden Theil der Zelle. Durch Vergleichung verschiedener Zellen vermag man diesen Vorgang durch alle Stadien hindurch zu verfolgen. Zunächst findet man die Sphäre noch in unmittelbarer Nähe der Blase, vielleicht sogar noch in Beribrung damit, aber schon wieder zu ihrer früheren, rundlichen Form concentrirt (Fig. 20). Ein weiteres Stadium zeigt sie als blasse Kugel seitlich neben dem Kern, schon in einiger Entfernung von der Kopfblase gelegen; noch später, wenn sich der Kern ganz in den proximalen Zellpol zurückgezogen hat, ja aus diesem sogar theilweise hervorgetreten ist, liegt dic Sphäre in dem lappenartigen hinteren Theil der Zelle, vom Kern immer weiter wegrückend, und hier lässt sie sich färberisch so lange nachweisen, bis das Protoplasma überhaupt noch eine zusammenhängende Masse darstellt. Zuletzt geht dann der Sphärenrest mit diesem Protoplasmalappen zu Grunde, ohne sich weiter aktiv bethätigt 
zu haben. An der Bildnng der Schwanzes hat die Sphäre bestimmt keinen Antheil. Ihre Bestimmung besteht lediglich darin, dem Spitzenkörperchen als Mutterboden zu dienen; nachdem sie dieser ihrer Aufgabe gerecht geworden, wird sie als unnützer Ballast mit dem ebenfalls dem Untergang geweihten Zellplasma ausgestossen.

Eine richtige Erkenntniss der geschilderten Vorgänge - es handelt sich in der Hauptsache um Bekanntes - ist erst sehr allmählich erzielt worden. Merkel beschrieb als erster im Jahre 1874 den "Spitzenknopf" und machte auch schon über seine Entstehung einige Angaben. An der Stelle, wo das Gebilde auftreten soll, sah er, bevor dieses noch da ist, eine dunkle Protoplasmaanhäufung, die nach dem Erscheinen des Spitzenknopfes nicht mehr sichtbar ist; allem Anscheine nach geht dieser also aus der Anhäufung hervor. Merkel fasst daher schon ganz richtig den Spitzenknopf als ein Protoplasmagebilde, als ein Derivat der Sphäre - denn diese ist doch ohne Frage mit der "Protoplasmaanhäufunga" gemeint - auf. Was ihm noch entgangen war, das ist die Thatsache, dass der dunkle Protoplasmakörper nicht sogleich vollkommen schwindet, sondern auch noch später eine Zeit lang nachweisbar ist, zunächst als Lunula am vorderen Pol, dann als Sphärenrest im Protoplasmalappen; er geht also nicht in seiner Gesammtheit in die Bildung des Spitzenknopfes auf, sondern lässt diese durch Differenzirung und Ausscheidung aus sich hervorgehen. Die Kernkappe kennt Merkel ebenfalls schon; er führt sie auf eine partielle Ablösung der Kernmembran zurück.

Die Persistenz der "Sphäre" eine Zeit lang nach dem Auftreten des Merkel'schen Spitzenknopfes hat r. Brunn (1874) erkannt. Freilich sollte diese Entdeckung der Anlass zu einer irrthümlichen Anschauung für v. Brunn werden, zu der Folgerung, dass sich demnach "der Spitzenlsnopf ohne Betheiligung des Protoplasmas aus dem Kern bilden muss" (S. 586), wobei besonders das Kernkörperchen in Verdacht genommen wird. Während so $\mathrm{v}$. B run die von Merkel bereits richtig angegebene protoplasmatische Herkunft des Akrosomas leugnet, weist er zuerst gegen Merkel richtig darauf hin, dass die Kopflsappe aus dem Protoplasma entsteht. Freilich hängt er hier wieder seiner Darstellung einen kleinen Irrthum an, indem er die Kopfkappe als ein vergängliches Gebilde hinstellt; sie soll sich, wenn sie die Hälfte des Kerns umwachsen hat, von ihm loslösen. Ihre Persistenz auch im reifen Spermatozoon sowie ihr allgemeines Vorkommen haben erst Fürst, Jensen und Ballowitz (1891, S. 278) nachgewiesen.

Renson (1882) hält das Spitzenknöpfchen (bouton terminal) mit v. Brunn gleichfalls für ein Kernprodukt, die Kopfkappe aber mit Merkel für die abgelöste Kernmembran. Die Endschicksale des Sphärenrestes schildert Renson sehr zutreffend. S. 328 giebt er an, 
dass auch nach dem Hineinrücken des Kerns in den vorderen Zellpol das „corpuscule accessoire" (Sphärenrest) noch zu sehen ist, entweder seitlich neben dem Kern oder schon hinten im Protoplasmalappen; später schwindet er spurlos. In Fig. 27 bildet Renson die Lunula und den Spitzenknopf sehr naturgetreu ab; die Kopfkappe ist in den Figuren $27 d, e, f, g$ recht treffend zur Ansicht gebracht, doch hält sie Renson im Text noch für ein vergängliches Gebilde.

H. Brown (1885) giebt recht treue Abbildungen des Lunulastadiums in den Figuren 14 und 15 seiner Arbeit und sagt richtig von der "clear cap" (Kernkappe), dass sie „... seems to be derived from the accessory corpuscule". Die Endschicksale des Sphärenrestes werden gleichfalls im Ganzen zutreffend geschildert.

Wir übergehen eine Reihe von Autoren, die über den in Rede stehenden Punkt nichts Wesentliches beigebracht haben und halten gleich bei Benda, der in den Jahren 1891 und 1892 den fraglichen Verhältnissen besondere Beachtung geschenkt hat. Benda geht bei der Ratte von dem Stadium aus, wo der Sphärenrest bereits als Lunula dem Bläschen, das er "Vakuole" nennt, angeschmiegt liegt; in der Mitte der Vakuole erscheint ein sehr kleines, intensiv gefärbtes Kügelchen. In der Folge legt sich die Vakuole dem Kern unter Abplattung an, wobei das stark gefärbte Körperchen unter Bildung des Spitzenknopfes mit der Kernperipherie in Verbindung tritt, der Sphärenrest dagegen sich von der Vakuole ablöst, um in den distalen Zelltheil zu rücken. Die Vakuole gestaltet sich zur Kopfkappe. Man sieht also : etwas völlig neues, etwas, was nicht schon von anderen Forschern gesehen worden wäre, ist in Benda's Darstellung eigentlich nicht enthalten; gleichwohl stellt die Darstellung insofern einen wesentlichen Fortschritt in der Erkenntniss dieser Dinge dar, als sie zuerst den ganzen Vorgang in seinem Zusammenhange richtig, ohne wesentlichere Irrthümer darstellt. Unzutreffend ist nur die Angabe, dass alle diese Vorgänge, die Abplattung der Vakuole u. s. w. erst „im zweiten Stadium, beim Eintritt der Copulation mit der Fusszelle" erfolgen. Nach meinen Beobachtungen geht dies Alles schon lange vor der Copulation vor sich; jedenfalls ist diese für die Vorgänge der Spitzenknopfbildung: ganz gleichgültig. Benda scheint, wie später Niessing, den Spitzenknopf für das Centrosoma gehalten zu haben; ganz klar ist dies bei ihm freilich nicht ausgesprochen, aber der letzte, etwas unklar gehaltene Passus seines Vortrages lässt diese Ansicht unverkennbar durchblicken, eine Ansicht, die wir auf's entschiedenste bekämpfen müssen. Der Vortrag Benda's in der Anatomischen Gesellschaft vom Jahre 1892 ergänzt die referirten Mittheilungen durch die Darstellnng des ersten Auftretens des hellen Bläschens im „Archiplasma" und des kleinen Körnchens darin, sowie durch die bestinmte Angabe, dass der Sphärenrest mit der Spermatide zu Grunde geht.

Die Darstellung, die Moore (1893 S. 686) von den einschlägigen Verhältnissen bei der Ratte giebt, ist ein Gemenge von Richti- 
Richtigern und Unrichtigem. Die Angabe von der Entstehung des Bläschens in der Sphäre aus dem Zusammenfluss mehrerer kleiner Vakuolen muss ich auf Grund meiner Erfahrungen als unzutreffend bezeichnen. Die Bildung des Spitzenknopfes wird richtig geschildert. Unrichtig ist aber wieder die Angabe, dass das Bläschen verschwindet; die richtige Entstehungsweise der „Kopfkappe“ war Moore unbekannt geblieben.

Wir gelangen damit zu dem letzten Forscher, mit dessen Angaben wir uns zu beschäftigen haben, zu Niessing (1896). Da sich aber die Ausführungen Niessing's hauptsächlich auf das Meerschweinchen beziehen, so möchte ich auf seine Angaben in Verbindung. mit einigen Beobachtungen eingehen, die ich an den sich zu Spermatozoen umgestaltenden Spermatiden dieses Thieres gemacht habe.

Ein hervorragend günstiges Objekt zum Studium der Bildungsweise der Appendiculargebilde am vorderen Pol des Kopfes ist der Hoden des Meerschweinchens, indem hier diese eine ausserordentliche Entwickelung zeigen. Beginnen wir mit der eben aus der Spermatocytentheilung hervorgegangenen Spermatide (Fig. 30). Betrachtet man diese, so fällt sofort neben dem runden Kern die Sphäre auf, als streng kugelförmiger Körper; sie ist um ein Geringes grösser als das entsprechende Gebilde der Ratte. An sauber hergestellten Eisenhämatoxylinpräparaten sehe ich sie im Innern zumeist homogen, nicht gekörnt, wie sie $\mathrm{N}$ i essing findet; ein Randstratum von ungleich grossen Körnern scheint hier dagegen in der That konstant zu sein, wodurch die Sphäre saumartig umfasst erscheint. Ebenso wie den Niessingschen Körnern, muss ich mich auch den anderen Einzelheiten gegenüber, die Niessing in der Sphäre beschreibt (S. 121) ablehnend verhalten; weder von Centrosomen, die durch eine "Centrodesmose" mit einander verbunden seien, noch aber von den nzarten Fibrillenstrahlen", die von den Centralkörpern aus nach der Peripherie der Sphäre ziehen sollen, vermag ich an meinen Präparaten etwas zu sehen; höchst wahrscheinlich liegen hier die Centrosomen ausserhalb der Sphäre irgendwo im Cytoplasma, doch ist es mir nicht gelungen, sie hier in den Spermatiden darzustellen.

Die Veränderungen, die nun in der Sphäre Platz greifen, schliessen sich in ihren ersten Stadien aufs Engste an die entsprechenden Vorgänge in der Spermatidensphäre der Ratte an. Mitten in der Sphäre (Fig. 31) taucht plötzlich ein kleines rundes Bläschen auf, und in dessen Mitte ein anfangs ganz minimales 
Akrosoma, das hier allerdings - abweichend von dem bei der Ratte bestehenden Verhalten - von vornherein eine grosse Neigung zur Schwarzfärbung bei der Eisenhämatoxylinmethode zeigt. Das Bläschen zeigt anfangs eine streng centrale Lage, wandert aber sehr rasch an den dem Kern angrenzenden Rand der Sphäre heran (Fig. 32), wobei es mit dem Kern in Berührung tritt. Auch hier scheint mir das Akrosoma ohne Anschluss an schon vorhandene Körnchen oder dergleichen in die Erscheinung zu treten. Meine Erfahrungen stehen in dieser Beziehung in vollem Widerspruch zu den Angaben $\mathrm{N}$ iessing's. Nach diesem Forscher vollzieht sich die Bildung des Akrosomas in der Weise, dass die Körnchen, mit denen seinen Beobachtungen ge-

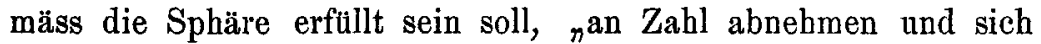
durch Verschmelzung mit einander zu wenigen grösseren vereinigen. Je geringer ihre Zahl, desto grösser erscheint ihr Volumen, bis sie schliesslich $\mathrm{zu}$ einem 'grossen Korn zusammengeflossen sind." Ich muss demgegenüber nochmals betonen, dass nach meinen Befunden das Akrosoma von vornherein als einheitliches, sehr kleines Körnchen auftaucht und dann durch selbstständiges Wachsthum und nicht durch Verschmelzung mit anderen Körnchen allmählich sein späteres Volumen erreicht. $\mathrm{N}$ i e s s in g's Angaben und ebenso auch seine Zeichnungen rufen die Vermuthung in mir hervor, dass diesem Forscher keine tadellosen Eisenhämatoxylinpräparate vorgelegen haben. Auch seiner Angabe, dass sich das helle Bläschen durch Zusammenfliessen mebrerer kleiner Vakuolen entwickelt, muss ich widersprechen.

Die weiteren Vorgänge sind auf den Figuren $33-39$ vergegenwärtigt. Anders als bei der Ratte und bei den meisten übrigen Säugern sehen wir, dass das ursprünglich so unscheinbar angelegte Akrosoma ein rasches und kolossales Wachsthum erfährt, es gestaltet sich sehr bald zu einer umfangreichen Kugel (Fig. 33 u. 34), die von dem ebenfalls entsprechend vergrösserten, mit dem Kern verwachsenen Bläschen saumartig umfasst wird. Wenn die Kugel eine bestimmte Grösse erreicht hat, dann fängt sie an (s. auch B all owitz 1891 S. 207), eine halbmondförmig abgeplattete Form anzunehmen (Fig. 36 u. 37). Mittlerweile hat das Bläschen seinen Umwachsungsprocess vollzogen, indem es sich um den grössten Theil des Kerns gestülpt hat; durch diese Ausbreitung wird das Bläschen futr das grosse Akrosoma ge- 
wissermaassen zu eng, der halbmondförmige Körper füllt jetzt daher das Bläschen am vorderen Kernpol prall ans, so dass sich die Konturen beider decken und es den Anschein gewinnt, als wäre zwischen Akrosoma und Bläschen - das wir jetzt schon als Kopfkappe bezeichnen dürfen - eine vollkommene Verwachsung eingetreten. Weniger innig scheint die Verbindung: zu sein zwischen Akrosoma und Kern; gewöhnlich lässt sich eine schmale helle Spalte zwischen beiden nachweisen. Die Substanz des Akrosomas färbt sich mit Eisenhämatoxylin bei der gewöhnlichen Anwendungsweise noch immer tief schwarz; setzt man aber die Differenzirung nur um ein Geringes über das gewöhnliche Maass hinaus fort, so bekommt man merkwürdige Bilder, indem eine peripherische Zone des Akrosomas den Farbstoff abgiebt, während der Kern des Gebildes ibn festhält: Vielleicht liegt der Erscheinung eine Verschiedenheit in der Consistenz der centralen und peripherischen Partieen des Gebildes zu Grunde; im Allgemeinen findet man ja bei der Eisenhämatoxylinfärbung, dass dicht gebaute, kompaktere Körper das Hämatoxylin stärker fesseln, als weniger consistente. Ein durch färberische Differenzirung in zwei Schichten getheiltes Akrosoma zeigt die Fig. 35.

Durch das kolossale Anwachsen des Akrosomas tritt der kleine Sphärenrest sehr in den Hintergrund. $\mathrm{Er}$ gestaltet sich zunächst in Folge der Ausdehnung der Blase, mit der er verwachsen ist, ebenso wie bei der Ratte, zu einem halbmondförmigen, blassen Körper, der nicht gerade in der Mitte über der Wölbung des Akrosomas und der Kopfkappe seine Lage hat, sondern diesem Gebilde seitlich, asymmetrisch angeschmiegt liegt. Diese asymmetrische Lage nimmt in der Folge noch zu; das Halbmöndchen gleitet an der Wölbung des Akrosomas seitlich mehr und mehr herunter; man findet es (Fig. 36 u. 37), wenn das Akrosoma halbmondförmig geworden ist, an einem der seitlichen Spitzen dieses Gebildes. Weiterhin wird dann dem Sphärenrest dasselbe Schicksal zu Theil, wie bei der Ratte: er löst sich vollkommen von der Kopfkappe ab und man findet ihn dann sehr bald hinten, in dem beim Meerschweinchen etwas kürzeren, plumpen Protoplasmalappen, als stark färbbares, wieder zu seiner früheren rundlichen Form zurüekgekehrtes Gebilde, bis er mit diesem Protoplasma untergeht.

Mittlerweile hat das Akrosoma nicht aufgehört zu wachsen; 
zunächst behält es noch - unter beträchtlicher Zunahme an Umfang - seine Halbmondform bei; nachdem aber die Sphäre abgestossen ist, ändert es seine Form plötzlich und zeigt eine mehr oder weniger regelmässige dreieckige Gestalt (Fig. 38); an den beiden dem Kern zugewandten Winkeln des Dreiecks scheint die Kopfkappe zu inseriren. Mit dem Kern scheint das grosse Gebilde noch immer nicht in organischer Verbindung zu stehen, noch immer ist es bloss durch die Kopfkappe an ihn gebunden. Auf der nächsten Stufe zieht sich das Akrosoma stark in die Länge, del frei hervortretende Winkel des Dreiecks ragt jetzt meist zipfelförmig hervor; es ist jetzt grösser geworden, als der Kern selbst und tritt an Eisenhämatoxylinbildern höchst energisch hervor, da es noch immer die gleiche starke Färbbarkeit in Hämatoxylin zeigt. Aber von jetzt ab scheint wieder allmählich eine Reduktion des Gebildes einzutreten; es wird jetzt wieder etwas kleiner, kleiner als der Kern und rertauscht seine schmale Zipfelform mit einer plumperen, kürzeren Mitraform (Fig. 39). Eine weitere, sehr auffallende Erscheinung ist, dass sich das Akrosoma von diesem Zeitpunkt ab mit Eisenhämatoxylin nicht mehr so lebhaft fürbt; statt der fruheren tiefschwarzen Färbung zeigt es jetzt einen dunkelgranen Ton. An den Kern ist das Akrosoma noch immer bloss durch die Kopfkappe bebefestigt, aber diese Verbindung ist um so fester, als die Kopfkappe jetzt bereits in ihrer ganzen Ausdehnung - natïrlich das. das Akrosoma bedeckende Stïck abgerechnet - mit der Oberfläche des Kerns in so innige Verwachsung getreten ist, dass es im Bereich des Kerns oft gar nicht mehr als selbstständige Membran zur Geltung kommt, vielmehr nur als eine Verdickung des Kernkonturs erscheint. (In der Fig. 39 war die Verwachsung noch nicht erfolgt.) Dagegen wird die Kopfkappe im Bereich des Akrosomas ron Neuem sichtbar, sie hebt sich jetzt an dessen ganzer Peripherie als heller Saum ab. Dieses abermalige Hervortreten der Kopfkappe beruht meiner Ansicht nach nicht auf einer Ablösung dieser von der Oberfläche des Akrosomas, sondern auf einer starken Verdickung der nach wie vor mit dem. Akrosoma fest verwachsenen Haut.

Von diesem letzteren Bilde ist $z u$ dem Bilde des ausgereiften Spermatozoons des Meerschweinchens (Fig. 40) nur noch ein kleiner Schritt. Das Akrosoma stellt sich nun als eine breite 
halbmondförmige, über den vorderen Pol des Kerns gestülpte Mütze dar, freilich nur bei der Flächenbetrachtung des Samenfadenkopfes, bei der seitlichen Betrachtung erscheint es als schmaler spiessförmiger Fortsatz des Kopfes, da das ganze Gebilde blattartig beschaffen, stark abgeplattet ist. Die Kopfkappe erscheint mit der Oberfläche des Kopfes vollkommen verwachsen; sie gelangt bloss als "dunkle, scharfgezogene Randbegrenzung ${ }^{\text {" }}$ (B a 110 witz) des Kopfes zum Ausdruck. Zwischen der vorderen Peripherie des Kopfes und der Aushöhlung des Akrosomas findet sich noch immer ein schmaler, sichelförmiger Spaltraum, nur scheint er jetzt nicht mehr, wie früher, von einer wasserhellen Flüssigkeit, sondern von einer blassen Substanz ausgeftillt zu sein, einer Kittsubstanz, die zur Sicherung der Verbindung zwischen Kopf und Akrosoma dient. Man kann das Auftreten dieser Zwischenmasse von Schritt zu Schritt verfolgen in den letzten Reifestadien des Spermatozoenkopfes; fraglich bleibt nur, ob sie ein Produkt des Kopfes oder des Akrosomas, also ein Kern- oder ein Cytoplasmaderivat ist. Die Färbbarkeit des Akrosomas in Eisenhämatoxylin ist noch weiter zurtickgegangen, dabei zeigt das Akrosoma ein eigenartiges Verhalten bei dieser Färbung: in seinem vordersten Abschnitt färbt es sich am lebhaftesten; von hier nach hinten verliert sich die Färbung allmählich völlig; ganz hinten aber, an der hinteren Grenze des Akrosomas stellt sich wieder saumartig ein dunkler Farbenton ein, wodurch das Akrosoma gegen den obenerwähnten Zwischenstreifen scharf abgegrenzt erscheint.

Der riesige helmförmige Anhang am vorderen Ende des Samenfadenkopfes des Meerschweinchens ist also nichts anderes, als das Homologon des kleinen Spitzenknöpfehens anderer Säugethiere, des Gebildes, das Jensen (1887) bei der Ratte als Hakenstäbchen beschrieben hat. Wir haben es nicht mit einer besonderen, nur dem Meerschweinchen zukommendeu Bildung, sondern nur mit der auffallend mächtigen Entwickelung eines, wie es scheint, bei jedem Säuger vorkommenden Gebildes, des Akrosomas zu thun. Dies erkannt und klar ausgesprochen $\mathrm{zu}$ haben, ist das Verdienst von B allowitz (1891, S. 208). 
Doch kehren wir zu unserem eigentlichen Untersuchungsobjekt, der Ratte, zurück. Wir hatten die Spermatiden verlassen, nachdem sich der Sphärenrest abgetrennt hat von der Kopfkappe. Die weiteren Vorgänge werden dadurch eingeleitet, dass der Kern in den vorderen, der Kanalwand zugekehrten Pol der Zelle rückt und zwar so weit, bis er an diesem Pol nackt ans der Zelle hervorragt, so dass das Cytoplasma schliesslich nur als lappenförmiger Anhang seiner hinteren Peripherie angefügt ist. Hand in Hand damit nimmt der Kern allmählich eine ellipsoidische Gestalt an (Fig. 25). Auch vollzieht sich im Innern des Kerns eine kleine Veränderung, indem das Gerüstwerk einfacher wird, offenbar durch Aufüsung der feineren Structuren. Was noch von dem Gerüst übrig bleibt, schliesst sich mehr und mehr an die innere Fläche der Kernmembran an, der Centraltheil des Kernraumes erscheint jetzt entweder ganz homogen oder nur von sehr spärlichen chromatinármen Gerüstfäden durchzogen. Die oben beschriebene Kruste im Bereich der vorderen, von der Kopfkappe bedeckten Kernhälfte tritt allmählich zurück. Mit der zunehmenden Verlängerung des Kerns werden alle diese Veränderungen viel ausgesprochener. Die vielen kleinen Chromatinbrocken, die wir früher in das Kerngerüst eingebettet sahen, schwinden jetzt zum grossen Theil, die übrig bleibenden fliessen zu 4-5 tropfenartigen, an der Kernmembran liegenden Gebilden zusammen, die noch immer in einem sehr feinen Lininnetzwerk suspendirt erscheinen.

Mit der Verlängerung des Kerns gelangt auch die Asymmetrie des späteren Samenfadenkopfes mehr und mehr zum Ausdruck. Sie prägt sich vor allem aus in der besonderen Insertionsweise der Kopfkappe. Diese ist nicht symmetrisch über den vorderen Pol gestiulpt, sondern reicht auf der einen Seite beträchtlich tiefer hinunter, als auf der anderen, dadurch schon die beiden Seiten des Kerns anzeigend, die in der Folge zur convexen und concaven Seite des Samenfadenkopfes werden sollen. Das Akrosoma ist jetzt höchst unscheinbar geworden; es ist ein winziges, abgeplattetes Gebilde, das nur an der Hand der Erythrosinfärbung etwas lebhafter hervortritt, indem es dabei oft eine intensiv rothe Färbung annimmt, besonders an Eisenhämatoxylinpräparaten. Der hintere Pol des Kerns vertauscht seine abgerundete Form mit einer wie querabgeschnittenen, wo- 
durch sie eine Basalflüche erhält. Oft ist diese Basalfläche von Anfang an nicht senkrecht zur Längsichse des Kerns gestellt, sondern etwas schief, worin schon eine weitere Annäherung an die spätere Form gegeben ist. Die Seite des stumpfen Winkels entspricht natïrlich der späteren concaven Seite; an ibr erstreckt sich die Kernkappe nur wenig berunter; auf der Seite des spitzen Winkels, der späteren convexen Seite dagegen sehen wir die Kernkappe fast zur Basalfäche des Kerns herunterziehen. Die schiefe Basalfäche hat sich in solcher Weise angelegt, dass die Anheftungsstelle der Centrosomen und des̉ Acbsenfadens nicht in ibren Mittelpunkt zu liegen kommt, sondern mebr nach der Seite des stumpfen Winkels gerückt ist, nach der Seite, an der die Kopfkappe weniger tief hinunterreicht.

Fig. 26 u. 27 unterscheiden sich von diesem Bilde bloss durch die Zunahme des Kopfes an Länge. Dies ist nun das Stadium, wo die Spermatide in den Fortsatz der Fusszelle aufgenommen wird. Als völlig neue Erscheinung erkennen wir in einem weiteren Stadium (Fig. 28) die schon ziemlich weit vorgeschrittene Umkrümmung des vorderen Kernpoles. Das vordere Ende spitzt sich jetzt allmählich hakenförmig zu. An der Endspitze des verdünnten Theiles oder etwas unter dem Ende am Anfang der concaven Seite bemerkt man noch immer das Akrosoma als kleines, mit Erythrosin hellroth gefärbtes Gebilde. Die Kopfkappe ist noch immer sehr deutlich sichtbar, oft erscheint sie sogar noch mehr wie früher bauschig vom Kern abgehoben. Sie schlägt sich uiber beide Seiten des Kerns, doch nicht in gleicher Ansdehnung; auf der concaven Seite bloss im Bereich des oberen Drittels, auf der convexen dagegen fast bis zur Grundfläche herunter. - Die Homogenisirung des Kopfes hat noch zugenommen, doch vermag man mit dem Eisenhämatoxylinverfahren noch immer 2-3 schwarze Klumpen und eine peripherisch gelegene, ansserordentlich feine Granulirung nachzuweisen. Mit den gewöhnlichen Kernfarbstoffen ist der Kopf jetzt nicht mehr so leicht darstellbar.

In Fig. 29 sehen wir schliesslich ein Stadium, das dem ganz fertigen Zustande schon sehr nahe kommt. Die charakteristische Hakenform ist nunmehr vollkommen ausgeprägt, der Samenfadenkopf - als solchen kann man den früheren Kern jetzt schon bezeichnen - ist etwas kleiner und zugleich schlanker, 
zierlicher geworden. Eincs unterscheidet nur noch dieses Bild vom definitiven Zustande: das Verhalten der Kernkappe. Sie hebt sich noch immer frei vom Kopfe ab and ragt namentlich über die Spitze des Kopfes ein Stückchen hervor, den Retzius'schen (1881) "Spiess" bildend. Das Akrosoma entzieht sich anf diesem Stadium schon der Darstellung auf färberischerem Wege; dass es auch im reifen Spermatozoon da ist, wissen wir aus den Untersuchungen von Jensen (1887), auf die hier hingewiesen sein mag.

In dem ausgereiften Spermatozoon wird die Kopfkappe sehr unscheinbar und ist bloss an der Hand einer sehr minutiösen Untersuchung des Samenfadens, wie sie uns zuerst von Jensen in seiner so hervorragenden Arbeit (1887), dann auch von Ballowitz gegeben wurde, zu erkennen. Jensen schildert sie (S. 403) bei der Ratte als eine durchsichtige, vorn spitz auslaufende Röhre von offenbar sehr f'ester Beschaffenheit. Nach hinten zu umgiebt die Kopfkappe den Samenfadenkopf oft bis zu seiner Grundflicbe. Doch ist dies das seltenere Verhalten, in der Regel hört sie schon etwas ror dem hinteren Kopfpol mit einer schrägen, deutlich erkennbaren Linie auf. Vor Jensen hat übrigens schon Helmann (1879) die Kappe bei der Ratte abgebildet. Das Akrosoma an den ausgereiften Spernatozoen der Ratte hat Jensen entdeckt: es liegt hier nicht mehr streng an der Spitze des Samenfadenkopfes, sondern als minimales stäbchenförmiges Gebilde (,Hakenstäbchen") etwas nach der concaven Seite hin davon. Jensen giebt an, dass es noch fester als mit dem Samenfadenkopfe mit der Kopfkappe verbunden ist. Ich möchte im Anschluss an diese Angabe bemerken, dass beim Hunde das Akrosoma mit dem Kopfe überhaupt nicht in Verbindung steht, sondern an der Innenseite der nach vorn ausgezogenen Spitze der Kopfikappe, des Spiesses, befestigt ist.

Der Kopf des ausgereiften Spermatozoons zeigt noch mehrere andere Einzelheiten, auf die ich hier indess nicht eingehen möchte. Die letzten Differenzierungen des Kopfes lagen ausserhalb des Bereichs meiner Untersuchungen, bei denen es ja hauptsächlich darauf ankam, z⿺ erforschen, aus welchen Theilen der Spermatiden die Bestandtheile des ausgereiften Samenfadens hervorgehen. Der Hauptheil des Samenfadenkopfes ist also ein Kerngebilde, die accessorischen Theile vorn an der Spitze des Kopfes sowie auch die Kopfblase sind dagegen Protoplasmaderivate. Es ist wichtig zu wissen, dass gerade der Theil des Samenfadenkopfes, der bei der Befruchtung zuerst in das Ei hineindringt, umgewandeltes Cytoplasma ist.

Archiv f. mikrosk. Anat. Bd. or 


\section{Die Bildung des Schwanzes.}

Die erste Anlage des Schwanzes gehört einer viel früheren Phase an, als vielfach angenommen wird. $\nabla$. Ebner z. B. in seiner Arbeit aus dem Jahre 1888 lässt den Schwanz erst entstehen, nachdem die Spermatide mit der Fusszelle bereits in Verbindung getreten ist, zu einer Zeit also, wo der Kern längst schon ganz oval geworden und in den einen Zellpol verlagert ist. Er meint, dass eben diese Verbindung eine Vorbedingung sei für die Bildung des Achsenfadens. Indess lagen schon zur Zeit der Veröffentlichung der $\nabla$. E bne r'schen Arbeit dahingehende Aeusserungen vor, dass oft schon an den freiliegenden, rundkernigen Spermatiden die ersten Spuren eines Schwanzes nachweisbar sind. So bemerkt Helman (1879), dass der Schwanz schon bei Rundzellen von bedeutender Länge sein kann. Renson (1882) legt ebenfalls Gewicht darauf, dass man oft Schwänze beobachtet, bevor am Kern Veränderungen erkennbar wären; v. Brunn (1887) beschreibt gleichfalls an den freien Spermatiden schon recht lange Fäden. Seitdem häuften sich die Beobachtungen, die unwiderleglich zeigen, dass die "Copulation" für die Anlage des Schwanzes durchaus nicht nothwendig sei, dass man vielmehr diesen stets schon angelegt finde, wenn die Spermatide mit der Stützzelle in Copulation tritt.

Indess muss ich auf Grund meiner Untersuchungen sagen, dass die allerersten Stadien der Schwanzbildung bei Säugern bisher von keinem einzigen Forscher gesehen wurden, auch von den genannten nicht. Denn auch die allerletzten Erforscher dieses Gegenstandes, wie Benda, Hermann, Niessing zeichnen als erste Stadien der Entstehung des Schwanzes Bilder, an denen man den Schwanz in Verbindung mit dem Kern sieht, und ähnlich lautet auch die Beschreibung, die sie von diesen Vorgängen geben. So schildert z. B. Niessing S. 125 das erste Auftreten des Schwanzfadens beim Meerschweinchen folgendermaassen: „Am hinteren Kernpol ist ein feines kurzes Fädchen zu bemerken, das an der Kernmembran seinen Ursprung nimmt." Aus diesem Befunde müsse man schliessen, dass der Achsenfaden aus Bestandtheilen des Kerngerüstes hervorgehe. Und ebenso heisst es auf S. 120, $n$ der Achsenfaden entspringt also direkt aus dem Kern ${ }^{\prime}$, ferner auf S. 135 in Betreff der Ratte und Mans ${ }_{n} \ldots .$. der 
als dünnes Fädchen aus dem hinteren Kernpol hervorwachsende Achsenfaden."

Ich habe dagegen gefunden, dass dem Stadium, das der Ni essing'schen Beschreibung zu Grunde liegt, ein Stadium vorausgeht, in dem der schon angelegte Achsenfaden unabhängig rom Kern frei im Zellprotoplasma liegt, in Verbindung aber mit etwas Anderem, nämlich mit den Centrosomen. Erst durch Heranwanderung. der Centrosomen und des Achsenfadens an den Kern und durch ibre Anlöthung daran wird das bisher als jüngstes aufgefasste Stadium erreicht. Ich will aber gleich berrorheben, dass sich die mitzutheilenden Beobachtungen lediglich auf die Ratte beziehen; bei anderen Säugern ist es mir bisher nicht gelungen, Präparate zu erhalten, die diese feinen Verhältnisse mit del erforderlichen Klarheit znr Ansicht bringen würden. Dạss die Sache aber auch anderswo principiell nicht anders liegt, ist im böchsten Grade wahrscheinlich.

Gehen wir zurück zur Spermatide, die unlängst erst aus der zweiten Spermatocytentheilung hervorgegangen ist, aber schon einen völlig rekonstruirten Kern zeigt. Wir sagten, dass in diesen Zellen neben dem Kern im Cytoplasma drei Dinge die Aufmerksamkeit fesseln. Zwei davon, die Sphäre und den chromatoiden Nebenkölper haben wir bereits abgehandelt; das dritte Gebilde soll jetzt seine Schilderung finden.

Betrachtet man sehr aufmerksam an gelungenen Eisenhämatoxylinpräparaten die Peripherie der Zelle, so bemerkt man (s. z. B. Fig. 16) an ihrer Oberfläche an einer bestimmten Stelle zwei schwarze runde Körncben. In den ersten Stadien der Spermatiden, d. h. unmittelbar nachdem sie aus der zweiten Spermatocytentheilung hervorgegangen sind, ist es sehr schwer, sie nachzuweisen, offenbar aus dem Grunde, weil sie sehr klein und unscheinbar sind; wenn sich aber der Kern zu seiner vollen Grösse entwickelt, die Sphäre sich von Neuem herausgebildet hat, nehmen auch die Körnchen an Umfang zu und treten etwas lebhafter hervor. Jetzt erkennt man auch, dass von den beiden Körnchen eines um ein geringes grösser ist als das andere.

Die beiden Körnchen stellen nun ohne Frage die Centrosomen der Spermatide dar. Die oberflächliche Lage, die sie zeigen, ist zwar auf den ersten Blick eigenartig, sie wird aber verständlicher, wenn man sich dessen erinnert, dass bei der zweiten 
Spermatocytentheilung die beiden Spindelpole mit ibren "Polkörperchen" wegen der geringen Menge des Cytoplasmas bejeits eine ganz oberflächliche Lage batten; so braucht denn nach der Vollendung der Mitose und der Zelltheilung das Centrosom der Tochterzelle bloss an Ort und Stelle zu bleiben, um jene Lagerung zu zeigen, die die beiden Körnchen in den Spermatiden aufweisen. Wann die Verdoppelung des bei der Spermatocytenmitose immer einfach gefundenen Centrosomas erfolgt, vermag ich nicht anzugeben; offenbar während der Anaphasen der Mitose.

Ueber alle Diskussion erhaben würde natïrlich die Centrosomennatur der Körnchen stehen, wenn es mir gelungen wäre, sie continuirlich von den Polkörperchen der Mitose her in die Spermatide zu verfolgen. Das ist mir leider nicht gelungen und ich gebe zu, dass meine Untersuchungen hier eine kleine Lücke zeigen. Diese Lücke wird nun aber zum Glück auf ein Minimum reducirt durch den Umstand, dass Meves in einer nach Abschluss meiner Untersuchungen veröffentlichten vorläufigen Mittheilung: (1897) in den Spermatiden von Salamandra eine ganz ähnliche oberflächliche Lage der Centrosomen beschreibt, wobei es ihn gelungen ist, sie continuirlich ron den Centrosomen der Sperma tocyten abzuleiten. Angesichts der fast in allen Stücken bestehenden grossen Analogie zwischen den einschlägigen Verhältnissen bei Salamandra und der Ratte darf man die Beobachtungen von Meves als entscheidenden Beweis für die Centrosomennatur der beiden Körnchen bei der Ratte heranziehen.

Aber: was sollten diese constanten und in ihrer Lagerung so typischen Bildungen sonst auch sein? Die einzige Möglichkeit, die uberhaupt in Betracht kommen könnte, und die ich mir in der That auch vorgelegt habe, wäre die, dass hier Dinge vorliegen, die genetisch mit dem Flemming'schen Zwischenkörperchen zusammenhängen. Diese Möglichkeit muss aber von der Hand gewiesen werden, wenn man sich erinnert, dass das Zwischenkörperchen nach Abschluss der zweiten Spermatocytenmitose schliesslich eine ganz extracelluläre Lage einnimmt; es liegt eingeschlossen in den Sphaerenrest, der sich von einer Spermatide brückenartig zur andern hinüberspannt, nurmebr in ziemlich loser Verbindung mit diesen. Die ganze Spindelbrücke gehört ihrem ganzen Habitus nach nicht mehr zur Zelle, sondern ist sammt dem Zwischenkörperchen darin als ein eliminirtes, dem 
Untergang geweihtes Organ aufzufassen. Aus diesem frei zwischen den Zellen gelegenen Gebilde miisste also das Zwischenkörperchen wieder in die Spermatide von aussen her hineinwandern, eine Annahme, die selbst den bescheidensten Anforderungen in Bezug anf Wahrscheinlichkeit nicht gerecht wird." Dann kommt noch hinzu, dass die grossartig aktive, kinetische Funktion, die die beiden oberflächlichen Körnchen in der Spermatide bei den weiteren Vorgängen, wie wil sehen werden, zeigen, bei einem Zwischenkörperchen etwas völlig Neues und Unerbörtes wäre; nirgends sonst kommt dem Zwischenkörperchen eine solche Rolle zu, weder im Thierreich, wo es überhaupt ein sebr rudimentäres Gebilde darstellt, noch aber im Pflanzenreich, wo es ja bekanntlich lediglich zur Bildung der Zellbaut dient.

Gerade diese weiteren Vorgänge scbliessen, wie wir sehen werden, die iiberzeugendsten Argumente für die Centrosomennatur der fraglichen Körnchen in sich, besonders der Umstand, auf den ich schon jetzt hinweisen möchte, dass die Körnchen zuletzt zu dauerndem Aufenthalte als "Endknöpfehen" in das Mittelstiick des reifen Samenfadens aufgenommen werden, in dasjenige Stäck also, von dem wir bei dem Befruchtungsvorgang die Wirkungen ausgehen sehen, die überall sonst an das Centrosoma geknïpft sind.

Es wären nun noch über die Lage der Centrosomen einige weitere Einzelheiten mitzutheilen. Die beiden Körnchen liegen in allen typischen Fällen genau auf der Oberfläche der Zelle, in einer Linie mit deren Grenzkontur, dicht nebeneinander. Meves giebt in seiner vorlänfigen Mittheilung für Salamandra eine abweichende Lagerung der beiden Centrosomen an, indem die sie verbindende Linie senkrecht auf die Oberfläche stehen und demnach also nur eines von den beiden Körperchen eine streng oberflächliche Lage besitzen soll. Darin würde sich also ein kleiner Unterschied zwischen Ratte und Salamandra aussprechen.

Es fragt sich weiterhin: zeigt die Stelle der Zelloberfläche, an der die Centrosomen liegen, eine Gesetzmässigkeit, d.h. steht sie in konstantem räumlichen Verhältniss zu den beiden Polen der Zelle oder nicht? Nach sorgfältiger Prüfung dieser Frage kann ich sie bejahen. Auffallend häufig findet man die beiden Körnchen ungefähr an der Mitte einer der Langseiten der zumeist leicht länglichen Spermatide. $\mathrm{Da}$ es aber auch Spermatiden von mehr 
rundlicher Form giebt, an denen also eine derartige Lagebestimmung: der Centrosomen nicht möglich ist, so ist eine zweite Lagebeziehung dieser wichtiger und zuverlässiger: die Beziehung zu der Sphäre. Bezeichnet man den Kernpol, dem die Sphäre anliegt, als den vorderen, den ihm gegenüberliegenden als den hinteren, so liegen die Centrosomen ungefähr entsprechend der Mitte zwischen den diesen beiden Polen entsprechenden Stellen der Zellperipherie, oft allerdings etwas weiter nach vorn oder nach hinten gerückt.

In einem kleinen Bruchtheil der Fälle findet man die Centrosomen von vornherein nicht ganz auf der Oberfläche liegen, sondern etwas darunter, schon in das Cytoplasma eingebettet; in solchem Falle fehlt niemals ein kleiner heller Hof um sie herum.

Die beiden Centrosomen bilden nun den Ausgangspunkt für die Bildung des Eimer'schen (1874) Achsenfadens. Aus ibnen wächst das Fädchen hervor, anfangs so unscheinbar, dass nur die sorgfältigste Beobachtung seine Spur zu erkennen vermag, dann aber etwas deutlicher hervortretend. Man sieht zuerst zwischen den beiden Körnchen eine minimale dunkle Verbindungsmasse auftreten; diese setzt sich dann auf der Seite des kleineren Körnchens tiber die Centrosomen hinaus fort, sich auf der Oberfläche der Zelle hinschiebend. Die Fädchenanlage präsentirt sich zunächst als eine kurze, lineare Verdickung der Zelloberfläche. Dass aber nicht etwa thatsächlich eine solche im Spiele ist, d. h, dass es sich nicht um eine "Herausdifferenzirung ${ }^{*}$ aus den oberflächlichsten Lagen des Zellplasmas handelt, ergiebt sich daraus, dass es Fälle giebt, in denen das Fädchen von vornherein eine mehr freie, ubber die Zelloberfläche hinausragende Lage aufweist. Das Fädchen wächst wirklich aus den Centrosomen hervor, als ein Ausscheidungsprodukt dieser; das Protoplasma ist für seine Entstehung meiner Ansicht nach nur insoweit wichtig, als es an die Centrosomen die Stoffe abgiebt, die sie zur Hervorbringung des Achsenfadens brauchen. Die Centrosomen müssen demnach mit der Fähigkeit der Assimilation ausgestattet gedacht werden, eine Forderung, die ja auch den Anschanungen M. Heidenhain's entspricht. Um Missverständnissen vorzubeugen, will ich nochmals hervorheben, dass daran nicht zu denken ist, dass sich die Substanz der schwarzen Körnchen unverändert in 
den Faden fortsetze; der Faden wird von einer ganz anderen, blasseren Substanz gebildet, es kann sich nur um eine Art von Ausscheidungsprodukt der Centrosomen handeln.

Dass das Fädchen sich zunächst an der Oberfläche hinzieht und nicht gleich frei aus der Zelle heraushängt, muss selbstverständlich erscheinen, wenn man bedenkt, dass die Spermatiden in jener frühen Epoche dicht gedrängt beisammen liegen; es ist also für das Fädchen, wenn es sich nicht einwärts in die Zelle entwickeln soll, die tangentiale Lage iiberhaupt die einzig mögliche. Wenn Meves für Salamandra angiebt, dass dort das Fädchen von vornherein geisselartig aus der Zelle hervorragt, so hängt dies eben mit der lockereren Anordnung der Spermatiden bei Salamandra zusammen. - Das Fädchen ist anfangs, wie gesagt, ganz kurz, nicht sehr scharf begrenzt.

$\mathrm{Da}$ das Fädchen von einem Punkte der Oberfläche aus den Zellkontur entlang wächst, so sind natürlich zwei Wachsthumsrichtungen denkbar: es kann nach dem vorderen (Fig. 20) oder dem hinteren Zellpol bin (Fig. 16) wachsen. Beides kann vorkommen, wie ich mich durch sehr sorgfältige Untersuchungen an solchen Zellen, wo nebst dem Fädehen noch als Orientierungspunkt die Sphäre sichtbar war, überzeugen konnte. Natürlich ist die Wachsthumsrichtnng schon durch das gegenseitige Lageverhältniss der beiden Centrosomen in voraus bestimmt, da ja das Fädchen, wie erwähnt, immer auf der Seite des kleineren Körnchens hervorwächst.

Gleich nach der ersten Anlage des Achsenfadens zeigen die Centrosomen eine zweite Erscheinung: sie treten eine Wanderung an, indem sie von der Oberfläche der Zelle durch das Cytoplasma hindurch in der Regel auf dem kürzesten Wege zum hinteren Kernpol hinschreiten, um sich mit ihm zu verbinden. Es ist dies ein ganz merkwürdiger Vorgang, der irgendwie mechanisch begründet sein muss. Vielleicht sind, wenn auch unsichtbar, Reste der früheren Zugfasern, d.h. derjenigen Spindelfasern, die die Centrosomen mit dem Kern verbanden, vorhanden, und vielleicht ist es die Contraction dieser, die die Annäherung der Centrosomen an eine bestimmte Stelle des Kerns bewirkt. Eine solche Hypothese schwebt freilich deshalb ganz in der Luft, 'weil es nicht gelingt, dergleichen Fäden in den Spermatiden nachzuweisen. Es können aber vielleicht noch viel komplicirtere Kräfte 
im Spiele sein, etwa eine spontane, antomatische Bewegung der Centrosomen selbst, in Verbindung mit chemotaktischen Einwirkungen, die die Richtung ihrer Wanderung bestimmen.

Die Art und Weise, wie das Centrosom an die betreffende Stelle am hinteren Kernpol hingelangt, wird der Leser aus der Vergleichung der Figg. 16-24 leicht erkennen. Man kann typische und atypische Fälle unterscheiden. In den typischen Fällen wandern die Centrosomen auf dem nächsten Wege zu der Kernmembran hin, das Fädchen je nach seiner Lage entweder nach sich hinziehend oder vor sich herschiebend; im ersteren Falle-d. h. wenn das Fädchen in der Richtung des hinteren Zellpols hervorgewachsen war - wird sich die definitive Einstellung des Fadens rascher und einfacher vollziehen können als im letzteren Falle, d. h. wenn sich der Faden in der Richtung des vorderen Zellpoles angelegt hatte, in welchem Falle der Faden früher oder später noch um das grössere Centrosoma herum eine Drehung um $180^{\circ}$ beschreiben muss. Aber es giebt auch viele atypische Fälle, wo einerseits die Centrosomen bei ihrer Hinwanderung zum hinteren Kernpol Umwege zu beschreiben scheinen, andererseits die Stellung des Fädchens zu den Centrosomen eine derartige ist, dass man annehmen muss, dass es um die Centrosomen herum während des Vorganges der Hinwandernng unnöthige Rotationen beschreibt. In allen Fällen aber bietet das frei im Zellplasma liegende Centrosomenpärchen mit dem kometenschwanzartig daran hängenden Achsenfaden ein sehr charakteristisches und zierliches Bild. Es ist bei der Ratte an richtig hergestellten Eisenhaematoxylinpräparaten gar nicht so schwer, Spermatiden zu finden, in denen man die Centrosomen sammt dem Fädchen gerade in der Wanderung begriffen sieht; auf Schritt und Tritt begegnet man, sobald man einmal auf die Sache aufmerksam geworden ist, entsprechenden Zellen, natürlich starke Immersionen und aufmerksame Beobachtung vorausgesetrt. Es ist mir geradezu ein Räthsel, wie so' diese zierlichen "Kometenbilder" der Aufmerksamkeit Niessing's entgangen sind, welcher Forscher doch auch den Rattenhoden untersucht und durchweg das Eisenhämatoxylinverfahren benütrt hat.

Der Wanderungsvorgang vollzieht sich schon in sebr frithen Stadien der Spermatiden, lange schon bevor der Kern eine längliche Form angenommen hat; ich habe die Centrosomen schon 
mit eiuem Fädchen ausgestattet im Innern des Zellplasmas liegen sehen, bevor noch Bläschen und Akrosoma in der Sphäre in die Erscheinung getreten sind. Die Verbindung der Centrosomen mit dem Kern erfolgt freilich in der Regel zu einer Zeit, da die Entwicklung der Kopfkappe bereits ziemlich vorgeschritten ist, aber doch noch immer im Rundkernstadium der Spermatide.

Die Verbindung'sstelle der Centrosomen mit dem Kern kennzeichnet dessen hinteren Pol, aber diese Stelle liegt bei der Ratte dem durch die Anheftung des Akrosomas an die Kernmembran gekennzeichneten vorderen Kernpol nicht streng gegenüber; verbindet man die beiden Punkte mit einander, so wird der Kern in zwei etwas ungleiche Hälften getheilt. Es ist also hierdurch schon die spätere asymmetrische Form des Samenfadenkopfes vorgezeichnet. Rundkernige Spermatiden mit einem scheinbar schon vom Kern entspringenden Achsenfädchen, d.h. Spermatiden, bei denen sich die Centrosomen bereits mit dem Kern in Verbindung gesetzt haben, gehören zu den gewöhnlichsten Beobachtungen; es sind das die altbekannten Formen, die man bisher, selbst den letzten Forscher, Niessing, eingeschlossen, für die ersten Stadien der Achsenfadenbildung gehalten hat.

Von den beiden Centrosomen verbindet sich nur das grössere direkt mit der Kernmembran, das kleinere bleibt immer durch einen deutlich wahrnehmbaren Zwischenraum davon getrennt. Die Verlöthung des grösseren Körnchens mit der Kernmembran muss zunächst eine selrr inuige sein; man bekommt den Eindruck, als würde es der Membran nicht nur äusserlich ankleben, sondern in sie geradezu aufgenommen sein, indem das Körnchen eine nicht nur nach aussen sondern auch nach dem Kerninnern hin hervorragende Anschwellung der Kernmembran zu bilden scheint. Wir werden aber sehen, dass dies nur ein vorübergehendes Verhalten ist, indem das Körnchen aus der Membran bald wieder ausgeschaltet wird.

In unmittelbarer Nähe der Einpflanzungsstelle des Achsen. fadens findet man jetzt immer den chromatoiden Nebenkörper, der irgendwie, sei es durch aktive Wanderung, sei es durch irgendwelche Strömungen oder Plasmaumlagerungen in der Zelle, an die betreffende Stelle hingelangt ist.

Der Befund, der im Vorstehenden mitgetheilt wurde, enthüllt zuerst die wahre Entstehungsweise der Geissel bei einem Säuger; für den Gesammtkreis der. Wirbelthiere stellt er aber durchaus nicht den 
ersten Nachweis dieses wichtigen Sachverhaltes dar. Derjenige Forscher, der zuerst die Entstehung des Achsenfadens aus dem Centrosoma bei einem Wirbelthier (Selachier) erkannt hat, ist unstreitig J. E. S. Moore (1896). Freilich lässt die Beschreibung, die er von diesen Verhältnissen giebt, an Klarheit viel zu wünschen übrig; speciell lässt der Autor den Leser etwas im Ungewissen, ob das Fädchen aus dem Centrosoma oder der Sphäre hervorgehe. Aber die Abbildungen, so z. B. Fig. 80 und 81 sprechen unverkennbar in ersterem Sinne. Wenn ich den etwas unklar gefassten Text richtig verstehe, so beschreibt M o ore (S. 294) den Vorgang folgendermassen: Nach der letzten Reifetheilung der Spermatocyten beschreibt die Spermatidensphäre, die hier auch die Centrosomen in sich schliessen soll, eine Wanderung von der polaren Seite des Kerns in der Richtung nach dessen aequatorialer Seite hin, aber ungefähr auf halbem Wege bleibt die Sphäre in der Nähe der Oberfläche stehen, die beiden Centrosomen rücken ganz an den äusseren Rand der Sphäre hinaus, und von dieser Stelle der Sphäre her (das "from this" der Moore'schen Beschreibung kann wohl nur auf das vorangehende ,outer archiplasmic surface" bezogen werden) wächst ein feiner protoplasmatischer Faden zur Zellperipherie hin und darüber hinaus. Von dieser Beschreibung weichen meine Befunde hauptsächlich in zwei Punkten ab: 1. finde ich die Centrosomen von Anfang: an ausserhalb der "Sphäre" gelegen, 2. wächst das Fädchen nicht aus der Sphäre heraus, sondern aus den unabhängig von der Sphäre geelegenen Centrosomen. Auch die weiteren Angaben Moore's müssen Zweifel hervorrufen, besonders die Angabe, dass der abgelöste und in den hinteren Plasmalappen wandernde Sphärenrest bei Selachiern nicht untergehe, sondern gemeinsam mit einem zweiten Körper, den Verf. „Nebenkern" nennt, und der offenbar mit unserem „chromatoiden Nebenkörper" identisch ist, die protoplasmatischen Hüllen des Achsenfadens im Bereich des Mittelstückes bilde. Bei der Ratte geht der Sphärenrest bestimmt spurlos unter.

Viel entschiedener hat sich Bühler (1895) für den Ursprung: der Geissel aus dem Centrosoma bei Bufo ausgesprochen. Indessen scheinen mir die Angaben Bühler's sowohl nach dem, was ich selbst bei der Ratte gesehen habe, wie auch namentlich nach den Erfahrungen von $\mathrm{Meves}$ an einem anderen Amphibium, an Salamandra, sehr der Nachprüfung $z u$ bedürfen. In den Spermatiden findet $B u ̈ h l e r$ die Attractionssphäre flach dem Kern aufliegend; sie soll ein oder zwei Centralkörper in sich schliessen. Ist der Kern zur annähernd homogenen Kugel geworden, so wird das Centrosoma (wenn es zwei sind, das grössere) in die Kernmembran aufgenommen. Aus diesem Centrosoma soll nun das Fädchen hervorgehen, aber was sehr befremdend ist, nicht, wie etwa bei der Ratte, durch Hervorwachsen einer substantiell von dem Centrosoma verschiedenen Masse, sondern durch direkte Verlängerung des Centrosoms. Noch weniger vertrauenerweckend ist die Angabe, dass aus dieser Bildungsweise gerade das Mittel- 
stück ausgeschlossen sein soll. Das sich zuerst zu einem stäbchen- oder lancettförmigen Gebilde, dann erst zu einem Faden verlängernde Centrosom soll nur zu dem Haupt- und Endstück der Geissel werden, während gerade das Mittelstück eine ganz andere Herkunft hat, indem es aus einer kugelförmigen Vorstülpung des Kerns an der Ansatzstelle des Centrosoms hervorgeht.

Die wichtigste Mittheilung, über die ich hier zu berichten habe, ist die von Meves (1897) ${ }^{1}$ ). Sie führt den überzeugenden Nachweis der Herkunft des Achsenfadens aus dem Centrosoma bei Salamandra. In den jungen Spermatiden dieses Thieres findet Meves die Centrosomen an der Zellwand liegrend; ihre Verbindungslinie steht senkrecht zu dieser. Die Bildung des Samenfadens beginnt damit, dass von dem einen mehr peripher gelegenen Centralkörper ein feines Fädchen auswächst, das die erste Anlage des Achsenfadens darstellt. Weiterhin werden die Centralkörper mit dem Achsenfaden gegen das Centrum der Zelle hin verlagert. In der Folge verwandelt sich der mehr peripher gelegene Centralkörper in ein Scheibchen, später in einen Ring, wobei er um das Doppelte seiner früheren Grösse anwächst, das mehr central gelegene zu einem kurzen, dicken, leicht gekrümmten Stäbchen. Dieses Stäbchen lagert sich nun dem Kern an seinem hinteren Pol unter Abplatcung an und treibt eine kugelförmige Vorwölbung ins Innere des Kerns binein, die sich dann zu einem cylindrischen Körper umformt, der zunächst noch relativ kurz ist, aber bald länger wird. Daraus geht in der Folge die vordere Partie des Mittelstückes des reifen Samenfadens hervor. Die hintere Partie desselben wird durch sehr complicirte Umwandlungen aus dem „ringförmigen Körper", d. h. dem peripherischen Centrosom gebildet.

Die Thatsache, dass das Centrosom der Ausgangspunkt bei der Bildung des mit so lebhafter Beweglichkeit ansgestatteten Achsenfadens ist, hat nach allem, was wir über das Centrosoma wissen, nichts Deberraschendes an sich. Sie bildet nur einen weiteren, sehr überzeugenden Beitrag zur Anschauung, dass das Centrosoma der Bewegungsmittelpunkt, das kinetische Centralorgan der Zelle ist.

An den Nachweis der Herkunft des Achsenfadens aus den Centrosomen knüpft sich gleich die Frage: haben die Centro-

1) Ich möchte hier nochmals hervorheben, dass meine eigenen Untersuchungen durch die Mittheilung von Meves durchaus nicht beeinflusst waren; ich habe die vorläufige Mittheilung dieses Forschers erst erhalten, nachdem ich meine Untersuchungen bereits abgeschlossen hatte. 
somen für den Samenfaden bloss eine genetische Bedeutung, oder erhalten sie sich auch im reifen Spermatozoon?

Die Eisenhämatoxylinmethode gestattet, diese Frage auf die leichteste und sicherste Weise zu beantworten. Die Antwort lautet: die Centrosomen sind auch im ausgereiften Spermatozoon vorhanden, und zwar in Form der Jen sen'schen Endknöpfchen, bei der Ratte in nur sehr wenig veränderter Gestalt.

Untersucht man die Gegend des "Verbindungsstückes" des ausgereiften Samenfadens der Ratte an Eisenhämatoxylinpräparaten, so sieht man zunächst, dass der Achsenfaden sich an dem bekanntlich stark abgeschrägten Hinterrand des Samenfadenkopfes nicht median inserirt, sondern beträchtlich excentrisch, nach dem vorderen, stumpfen Winkel hin gerückt. An der Insertionsstelle treten nun sehr lebhaft als schwarze Körnchen die von frïher her bekannten zwei Centrosomen hervor, das eine, grössere, vordere dicht am Kern, das Ende des Achsenfadens bezeichnend, das kleinere hintere unmittelbar daran, aber doch schon in den Verlanf des Achsenfadens eingeschaltet. Gegen früher lassen sich nur zwei Veränderungen nachweisen: erstens sind die Körnchen um eine Spur grösser geworden, zweitens ist das vordere Körnchen mit der Basalfläche des frïheren Spermatidenkerns und jetzigen Samenfadenkopfes nicht mehr so ganz innig verbunden wie in den letzten Reifestadien, wo wir es ja geradezu in die Kernmembran anfgenommen sahen; jetzt hat das Körnchen seine Selbstständigkeit wieder erlangt und ist mit dem Kopfe nicht mehr direkt, sondern durch Vermittelung einer geringen Menge von Kittsubstanz verbunden.

Durch die Thatsache, dass die Centrosomen bei der Ausreifung der Spermatozoen nur so geringe Veränderungen erfahren, unterscheidet sich das Spermatozoon der Ratte sehr ausgesprochen von dem vieler anderer Wirbelthiere, bei denen die beiden Körnchen oft sehr weitgehenden Netamorphosen unterliegen. Namentlich ist dies bei den Amphibien der Fall, wie wir dies durch die Untersuchungen ron Hermann, Meves u. A. wissen. Aber nicht nur bei Amphibien, auch bei manchen Säugethieren bleiben die Centrosomen nicht unverändert; so sehe ich z. B. bei der Katze, dass sich das hintere Körncben sehr bald zu einer ziemlich breiten Scheibe umformt.

Die beiden Centralkörperchen im reifen Samenfaden der 
Ratte sind schon vor einer Reihe von Jahren (1887) von Jens en entdeckt worden, eine hochbedeutsame Entdeckung, umso bedeutender als es sich dabei ïberhaupt um den ersten Nachweis jener beiden Körnchen im Spermatoroon eines Wirbelthieres handelte. Nicht nur in der Thatsache der Entdeckung selbst, sondern besonders anch in der Art and Weise, wie Jensen die einzelnen Details der von ihm als Endknöpfchen benannten Gebilde schildert, äussert sich eine seltene Schärfe der Beobachtung, für die uns ein richtiges Urtheil und Verständniss erst jetzt, nachdem wir nun in diese Dinge durch die Erkenntniss ihres Werdeganges klareren Einblick gewonnen haben, aufgegangen ist. Jensen's Schilderung (S. 386) lautet folgendermaassen: „Nach vorn endet der Acbsenfaden mit einem Knöpfchen, das viel stärker lichtbrechend ist als der übrige Achsenfaden." "Das Knöpfchen bildet bei den Samenkörper'n der Ratte und mehrerer anderer Säugethiere für sich allein das vorderste Ende des ganzen Schwanzes." Durch Goldchlorid wird es ebensowenig gefärbt wie der Achsenfaden selbst. Auf S. 390 folgt der wichtige Zusatz: „Durch genauere Untersuchungen entdeckte ich, dass das Knöpfchen bei den Samenkörpern der Ratte eigentlich aus zwei Partieen, und zwar ans einer grösseren vorderen und einer kleineren hinteren besteht, die durch einen kleinen Zwischenraum von einander getrennt sind; beide sind sehr stark glänzend und offenbar von sehr fester Beschaffenheit." Bezüglich der Verbindung des aus dem Körnchenpaar bestehenden Endknöpfchens mit dem Samenfadenkopf sagt Jensen, dass sie nicht unmittelbar mit einander zusammenhängen, sondern dass sich zwischen beiden ,in frischem Zustande konstant ein sehr kleiner Zwischenraum findet, der von einer durchsichtigen verbindenden Substanz eingenommen wird."

Die wichtigen Beobachtungen Jensen's wurden bald von Ballowitz (in mehreren Arbeiten, hauptsächlich aber in 1891, S. 260 ff.) bestätigt; diesem Forscher kommt auch das nicht unbeträchtliche Verdienst $\mathrm{zu}$, das allgemeine Vorkommen des Endknöpfchens in den Spermatozoen der Wirbelthiere durch umfangreiche, gewissenhafte Untersuchungen festgestellt $\mathrm{zu}$ haben. Nicht ganz in Einklang zu bringen mit der dargelegten Entwicklungsweise des Endknöpfchens ist nur die Angabe von Ballowitz, dass die beiden Körnchen, aus denen das Endlznöpfchen be- 
steht, also die beiden Centrosomen, bei manchen Säugethieren, wie beim Schwein, dem Maulwurf, dem Dachs u. s. w., nicht hintereinander, sondern nebeneinander am Hinterrand des Samenfadenkopfes liegen sollen, wobei jedes Körnchen sich mit einer Hälfte des aus zwei Fibrillenbündeln bestehenden Achsenfadens verbinden soll. Vielleicht wird sich an dieser Ansicht durch Wiederaufnahme des Themas mit Hülfe der neuen Methoden etwas ändern lassen.

Meine Untersuchungen bestätigen also vollauf die beute schon fast allgemein verbreitete Ansicht, dass das Centrosoma des reifen Samenfadens in dessen "Mittel- oder Verbindungsstück ${ }^{*}$ liegt; ich konnte den direkten Nachweis führen, dass es speciell die beiden von Jensen entdeckten Endknöpfchen sind, die wir als die nur wenig veränderten Centrosomen ansprechen dürfen. Es treten dadurch meine Erfahrungen in Gegensatz zu den Angaben Niessing's, der bekanntlich das Centrosoma in das Spitzenknöpfchen an dem vorderen Ende des Samenfadenkopfes verlegt.

Die ${ }_{\text {Endknöpfehen }}{ }^{4}$ sind meiner Ueberzeugung nach nicht nur für die Entstehung des Achsenfadens als dessen Matterboden wichtig, sondern auch später für dessen Bewegungen, indem von ibnen die Reize ausgehen, die in der Geissel die Bewegungserscheinungen hervorrufen.

Ein wichtiger Theil des Ausreifungsvorganges der Samenfäden ist bisher ausser Betracht geblieben: das sind die Vorgänge am Schwanze des Spermatozoons, die Bildungsgeschichte der Hüllen des Achsenfadens. Da eine erschöpfende Verfolgung dieser Verhältnisse ansserhalb der Aufgabe, die ich mir gestellt hatte, lag, so sind meine Erfahrungen über diesen Punkt etwas fragmentarisch geblieben. Sie betreffen nur die ersten Stadien der hier in Betracht kommenden Vorgänge.

Der Achsenfaden stellt sich in den zu Spermatozoen heranreifenden Spermatiden als eine ausserordentlich feine Bildung dar. Nicht nur kurz nach seinem ersten Auftauchen, sondern auch noch später, wenn er schon weit aus der Zelle hervorragt, sehen wir ihn noch als ein äusserst unscheinbares, nur mit stärkeren Vergrösserungen sichtbares Fädchen, ja es hat manchmal den An- 
schein, als würde er anfangs Hand in Hand mit seinem Längenwachsthum noch unscheinbarer. Die Verdickung der Geissel, die während des Aufenthaltes des jungen Spermatozoons in der Fusszelle allmählich erfolgt, ist in erster Reihe ein Resultat der Anlagerung der cytoplasmatischen Hülle des Achsenfadens.

Bei der Entstehung dieser Hülle, vor allem im Bereich des Verbindungsstückes, spielt eine neue, bisher in unseren Darlegungen nicht erwähnte Bildung eine grosse Rolle, die sog. "Schwanzblase". Sie ist ein altbekanntes Gebilde, indem sie schon im Jahre 1856 von Kölliker als „hyaline Röhre" beschrieben wurde. Ueber die verschiedene Ausbildung dieser Röhre, über ihre Entstehung und ihre späteren Schicksale findet man in der Literatur merkwürdig wenig Angaben.

Bei der Ratte ist die Schwanzblase verhältnissmässig sehr schwach entwickelt; will man sie in kräftiger Ausbildung sehen, so muss man sich schon an den Hoden anderer Thiere halten, z. B. an den Katerboden, in dessen unreifen Spermatozoen die Schwanzblase eine höchst auffallende Bildung darstellt. Auch bei dem Menschen tritt sie stärker lervor als bei der Ratte. Da bei der Katze, wo sie so stark entwickelt ist, ein chromatoider Nebenkörper fehlt, so scheint es mir nicht unmöglich, dass zwischen der Mächtigkeit der Schwanzblase und der des chromatoiden Nebenkörpers - die ja, wie wir sehen werden, beide in die Bildung der Umhüllung des Mittelstückes aufgehen - ein compensatorisches Verhältniss besteht.

Verfolgen wir die Entwickelung der Röhre etwas genauer bei der Ratte. Wir müssen hierbei weit zurückgreifen: bis auf das Stadium, wo die beiden Centrosomen noch in der Wanderung begriffen sind. Auf S. 302, wo die Wanderung beschrieben wurde, erwähnte ich bereits, dass die im Cytoplasma gelegenen Centralkörperchen von einem hellen Hof umgeben sind. Dieser Hof begleitet sie nun bis zu dem Kern (s. Fig. 18-24); sind die Centrosomen mit diesem in Verbindung getreten, so tritt der helle Hof um sie herum noch lebhafter hervor (s. Fig. 25). Ganz in der Nähe der beiden nunmehr als Endknöpfchen zu bezeichnenden Centralkörperchen, ja sogar noch innerhalb jenes hellen Hofes, bemerkt man den chromatoiden Nebenkörper; man trifft ihn um diese Zeit stets an dieser Stelle an. Dabei bleibt es so lange, bis der Kern länglich geworden und ganz in den vorderen 
Zellpol gerïckt ist. Jetzt (Fig. 26) stellt sich eine neue Erscheinung ein. Zu beiden Seiten der Endknöpfehen und des Halstheiles des Achsenfadens tritt, die Grenze des hellen Hofes bezeichnend, zuerst kaum wahrnehmbar, dann stärker hervortretend, je eine dunkle Linie auf. Die Linien entspringen an den beiden Winkeln der schrägen Grundfläche des Spermatozoenkopfes und begleiten leicht convergirend das erste Stück, den "Hals" des Achsenfadens, um aber schon nach sehr kurzem Verlauf frei und etwas verschwommen auszulaufen. Natürlich sind die beiden Linien nichts anderes als Seitenkonturen einer ganz durchsichtigen manschettenartigen Bildung, eines kurzen Schlauches, der am Spermatozoenkopf in der Nähe seines Hinterrandes befestigt ist und unten offen steht. Das Innere des Schlauches ist von einer helleren homogenen Plasmasubstanz - der Substanz des früheren "hellen Hofes" — ausgefüllt; ausserdem enthält der Schlauch den cbromatoiden Nebenkörper und natülich auch den Achsenfaden mitsammt den Endknöpfehen.

Der Ansatz des Röhrchens erfolgt nicht streng am Rande der Grundfläche des Kopfes, sondern etwas weiter vorn, so dass der hintere Kernpol wie in das Röhrchen hineingesteckt ist. Dabei kann man in günstigen Fällen constatiren, dass die Röhre von dem Kopfe von Anfang an unabbängig, gegen ihn vollkommen abgegrenzt ist. Betrachtet man sehr genau (Fig. 26) den hintersten Theil des Kopfes, so bemerkt man oft unweit vom hinteren Pol, quer über den Kopf wegziehend, eine feine aber doch scharf gezeichnete Linie, die nichts anderes ist als der vordere freie Rand der hyalinen "Manschette".

Diese Bildung ist nun das, was man, nicht ganz richtig, „Schwanzblase" nennt, nicht ganz richtig;, weil sie, wenigstens bei der Ratte, niemals eine geschlossene Blase, sondern immer nur eine offene Röhre, einen Trichter bildet. Wie ist sie entstanden? Die meisten Anhänger hat in dieser Beziehung die Ansicht gefunden, dass die Schwanzblase aus einer Vorbuchtung und Ablösung der Kernmembran zu Stande kommt. Zu dieser Ansicht bekennen sich Biondi, Benda, Hermann, Niessing u. A. Einen strikten Beweis dafür hat aber noch Niemand beigebracht. Ich halte diese Ansicht wenigstens für die Ratte für vollkommen haltlos. Eine derartige Entstehungsweise der Schwanzblase scheint mir hier direkt ansgeschlossen zu sein erstens durch den Um- 
stand, dass sich die Röhre sozusagen von Anfang an durch einen scharfen Rand nach vorn, gegen den Kern hin abgrenzt, zweitens dadurch, dass man am hinteren Pol des Kerns niemals derartige Veränderungen wahrnehmen kann, die auf eine Ablösung der Kernmembran oder dgl. binweisen würden. Nach der ganzen Sachlage kann es meiner Ansicht nach nicht zweifelhaft sein, dass hier einfach eine spontane Differenzirung ats dem Cytoplasma heraus vorliegt, wodurch eine geringe Plasmamenge, die dem Spermatozoon auf seinen Weg mitgegeben werden soll, vom ïbrigen Cytoplasma abgegrenzt wird. Ebenso wie man schon an anderweitigen Zellen eine membranartige Differenzirung der Grenzlinie zwischen Sphäre und übrigem Cytoplasma, die Entstehung einer "Sphärenmembran" beobachtet hat, sehen wir auch hier die die Centrosomen umgebende helle, wie es scheint von dem übrigen Cytoplasma der Spermatide substantiell etwas verschiedene Plasmalage sich gegen den übrigen Zellkörper in unvollkommener Weise durch eine Membran abgrenzen. Vielleicht aber kommen in der Bildungsweise der Schwanzblase je nach dẹn verschiedenen Thierformen mehrere Varianten vor. So geht nach den Erfahrungen von Meves bei Salamandra die Entstehung der byalinen Hülle nach einer ganz besonderen Art vor sich. Bei der Einwärtswanderung der Centrosomen von der Oberfläche der Zelle zur Kernwand wird hier das Cytoplasma in Form eines Trichters eingestülpt, und, indem sich die Wände dieses Trichters nähern, kommt die Röhre zu Stande. Bei der Ratte kann von einer solchen Entstehungsweise keine Rede sein, doch lassen sich die Beobachtungen von Meves insofern als Beweis für die Richtigkeit der im obigen dargelegten Ansicht über die Entwickelung der Röhre heranziehen, als sie zeigen, dass die Schwanzblase auch bei Salamandra nicht aus der Kernmembran, sondern aus dem Zellprotoplasma hervorgeht.

Wenn wir ein etwas späteres Stadium ins Auge fassen, ein Stadium, wo der Spermatidenkern bereits stark in die Länge gezogen, an seinem vorderen Ende sogar schon etwas umgekrümmt ist (Fig. 27 u. 28), so finden wir an der Schwanzblase ein folgendes Verbalten. Von den beiden Grenzlinien erscheint jetzt die eine bedeutend schärfer ausgeprägt als die andere. Die schärfer hervortretende Linie ist diejenige, die sich an dem nach binten ausgezogenen Winkel der Grundfläche des Spermatozoenkopfes 
inserirt. Offenbar hat die Wandung des Röhrchens auf der einen Seite eine beträchtliche Verdickung erfahren. Ein zweiter Unterschied gegen früher besteht darin, dass die Convergenz der beiden Linien jetzt beträehtlich zugenommen hat, so dass sie sich nun an ihren Enden beinahe berühren, aber nur beinahe; zu einer wirklichen Verbindung der Linien und damit zu einem Verschluss des Schwanzbläschens kommt es bei der Ratte niemals, stets bleibt unten eine kleine Oeffnung erhalten. $\mathrm{N}$ iessing's Angabe (1896, S. 137), dass man die Schwanzblase bei der Ratte in der ersten Zeit ihres Auftretens ebenso oft geschlossen wie offen finde, vermag ich nicht zu bestätigen. Aus dem länglichen Trichter oder der ${ }_{n}$ Manschette ${ }^{u}$ von früber ist jetzt ein niedriger Kegel geworden, wozu zu bemerken ist, dass die Kegelform nicht durch gleichmässiges Zusammenneigen beider Grenzlinien entsteht, sondern durch stärkeres Hinneigen der von dem hinteren Winkel der Kopfbasis entspringenden Linie zu der vom vorderen Winkel entspringenden, welch' letztere eher geradlinig in der Längsrichtung der Spermatide nach hinten zieht.

Als Inhalt des ,Schwanzkegels" finden wir in erster Linie wieder, wie früher, die homogene protoplasmatische Substanz, mit dem Unterschied aber, dass sie jetzt (Fig. 28 und 29) nicht mehr heller erscheint als das umgebende Cytoplasma, sondern im Gegentheil mit der Eisenhämatoxylinfärbung; einen dunkleren Farbenton annimmt. Als zweiter Inhaltsbestandtheil erscheint der chromatoide Nebenkörper, aber nicht mehr in unveränderter Form: er wird nun allmählich kleiner, indem sich seine Substanz in dem im Inneren des Schwanzkegels gelegenen Protoplasma wahrscheinlich allmählich auflöst. Vielleicht hängt mit dieser Beimischung die dunklere Färbungsnuance, die dieses Protoplasma jetzt angenommen hat, zusammen, der chromatoide Nebenkörper ist ja, wie wir sahen, wahrscheinlich ein Product des Zellkerns, der sich ja im Ganzen durch stärkere Färbbarkeit gegen das Cytoplasma auszeichnet. Man sieht den chromatoiden Nebenkörper oft auch in 2-3 kleinere Körnchen zerfallen. Sehr häufig ist ferner der chromatoide Nebenkörper von einem kleinen hellen Hof umgeben. Hier will ich noch einschalten, dass um diese Zeit die Grundfläche des Kopfes durch besonders dichte Substanz gebildet zu sein scheint: sie tritt an Eisenhämatoxylinpräparaten in Form einer kräftigen schwarzen Linie hervor (Fig. 28). 
In dem geschilderten kegelförmigen Zustande erhält sich nun die Schwanzblase eine geraume Zeit hindurch. Erst in einer späteren Phase des Ausreifungsvorganges, zu einer Zeit, wo der Kopf bereits seine definitive Form vollkommen erlangt hat, bemerken wir, dass sich der kurze Kegel der Schwanzblase allmählich in die Länge streckt. Sie wird nun wieder, wie anfangs, dütenförmig, bald aber, durch weitere Verlängerung, cylindriseh, und in dieser Form wuchert sie dann, als schmaler Mantel den Achsenfaden umgebend, an diesem entlang. Sie liefert jedenfalls die protoplasmatische Umhüllung des Mittelstückes des Achsenfadens; ob und in welcher Weise sie auch die Achsenfadenhülle des Hauptstückes bildet, vermag ich nicht zu sagen. Ebensowenig besitze ich Erfahrungen über die Entstehungsweise des sog. „Spiralfadens" am Mittelstück.

Ich komme damit zum Schlusse.' Mussten bei meinen Untersuchungen auch viele Einzelheiten des Ausreifungsvorganges der Spermatozoen unberücksichtigt bleiben, so kann ich doch insofern mit Befriedigung die Feder bei Seite legen, als durch meine Befunde gerade diejenige Frage ibre Beantwortung gefunden hat, die mir am meisten am Herzen lag: die Frage, in welcher Weise im Spermatozoon die Abkömmlinge der einzelnen Bestandtheile der Spermatide lokalisirt sind. Das grösste Gewicht möchte ich in dieser Beziehung auf zwei Sätze legen, womit ich meine Ausführungeu beenden will: erstens, dass das Spermatozoon als eine ganze Zelle aufzufassen ist, als ein Gebilde, worin alle drei für die Zelle charakteristischen Bestandtheile: Cytoplasma, Centrosoma und Kern vereinigt sind, und zweitens, dass der zweite von diesen Bestandtheilen, das Centrosoma, im Mittelstück des Samenfadens liegt, in Form der Jensen'sehen Endknöpfchen.

Nachwort. Nach Abschluss des Manuskriptes, im Begriffe, es abzusenden, erhalte ich durch die Freundlichkeit der Verfasser die Mittheilung von Fr. Meves: Ueber Structur und Histogenese der Samenfäden von Salamandra maculosa, Archiv für mikrosk. Anat. Bd. 50, S. 110, und den Vortrag von C. Benda: Neuere Mittheilungen über die Histiogenese der Säugethierspermatozoen. Verhandl. der physiologischen Gesellschaft zu Berlin, Jahrg. 1896-97, Nr. 6-13. Die Arbeit von Meres stellt die ausfübrlichere Publikation der bereits in einer vorläufigen Mittheilung (s. das Literaturverzeichniss) veröffentlichten Befunde, 
auf die in der vorstehenden Arbeit bereits Rücksicht genommen wurde, dar. S. 116 erwähnt Verf. in einer Fussnote, dass nach seinen Beobachtungen die Centrosomen in den Spermatiden der Ratte eine ebensolche oberflächliche Lage zeigen, wie in denen von Salamandra. Diese Notiz veranlasst mich, nochmals hervorzuheben, dass ich alle die in der vorstehenden Arbeit mitgetbeilten Befunde und darunter auch die fragliche Thatsache schon vor mehr als vier Monaten in einer vorläufigen Mittbeilung veröffentlicht habe, die ich natürlich nicht unteriassen habe, auch Meves zuzusenden. Benda's Angaben decken sich, soweit sie sich auf die Bildungsweise der Gebilde am vorderen Pol des Spermatidenkerns beziehen, mit den früheren einschlägigen Mittheilungen dieses Forschers, sowie auch mit meinen eigenen Erfahrungen; die Darstellung dagegen, die Benda von der Entstehung der Geissel giebt (sie soll aus dem Kern hervorwachsen), halte ich für unzutreffend. - Folgende, während der Drucklegung meiner Arbeit erschienene Abhandlungen konnten nicht mehr berücksichtigt werden: F. Hermann, Beiträge zur Kenntniss der Spermatogenese. a) Die Ausreifung der Selachierspermatosomen. Archiv f. mikrosk. Anat. Bd. 50, 1897, S. 276. K. v. B ardeleben, Beiträge zur Histologie des Hodens und zur Spermatogenese 'beim Menschen. Arch. f. Anat. und Physiol., Anat. Abth. Suppl.-Bd. 1897, S. 13. - Derselbe, Dimorphismus der männlichen Geschlechtszellen bei Säugethieren. Anat. Anz. Bd. XIII, 1897, S.564.

\section{Literatur-Verzeichniss.}

Ballowitz, E., Die Bedeutung der Valentin'schen Querbänder am Spermatozoenkopfe der Siiugethiere. Arch. f. Anat. und Physiol. Anat. A'bth. Jahrg. 1891, S. 193.

Derselbe, Weitere Beobachtungen über den feineren Bau der Säugethierspermatozoen. Zeitschr. f. wissensch. Zoologie, Bd. §̋2, 1891, S. 217.

Benda, C., Untersuchungen über den Bau des funktionirenden Samenkanälchens einiger Säugethiere und Folgerungen für die Spermatogenese dieser Wirbelthierklasse. Arch. f. mikrosk. Anat., Bd. 30, 1887 , S. 49.

D e rsel be, Neue Mittheilungen über die Entwicklung der Genitaldrüsen und über die Metamorphose der Samenzellen. Verhandlungen d. 
physiol. Gesellsch. zu Berlin. Jahrg. 1891-1892, Nr. 4 u. 5. (Arch. f. Anat. u. Phys., Phys. Abth., Jahrg. 1891.)

Derselbe, Ueber die Histiogenese des Sauropsidenspermatozoons. Verhandlungen d. anatomischen Gesellschaft. VI. Versamml. Wien 1892 , S. 195.

Beneden, E. van, Recherches sur la maturation de l'oeuf, la fécondation et la division cellulaire. Archives de biologie. Tome IV, 1883, p. 256.

Boveri, Th., Ueber das Verhalten der Centrosomen bei der Befruchtung des Seeigel-Eies, nebst allgemeinen Bemerkungen über Centrosomen und Verwandtes. Verh. d. Physik.-mediz. Gesellschaft zu Würzburg. Bd. LXIX, 1895, S. 1.

Brown, Herbert H., On Spermatogenesis in the Rat. Quarterly Journal of Microscopic Science. Vol. XXV, 1885, p. 343.

Brunn, A. v., Beiträge z. Entwicklungsgeschichte d. Samenkörper. Arch. f. mikrosk. Anat., Bd. 12, 1876, S. 528.

Bühler, A., Spermatogenese bei Bufo vulgaris. Verh. d. Anat. Ges. IX. Vers. Basel, 1895, S. 62.

Ebner, V. v., Zur Spermatogenese bei den Säugethieren. Arch. f. mikrosk. Anat. Bd. 31, 1888, S. 236.

Eimer, Th. Untersuchungen über den Bau und die Bewegung der Samenfäden. Verh. d. physik.-mediz. Ges. zu Würzb. N. F., Bd. 6, 1874, S. 93.

Erlanger, R. v., Spermatogenetische Fragen. (Vier Aufsätze). Zoologisches Centralblatt, Jahrgang III, 1896, S. 81 und Jahrg. IV, 1897, S. 1 und 153.

Fick, R., Bemerkungen zu M. Heidenhain's Spannungsgesetz. Arch. f. Anat. u. Physiol. Anat. Abth., 1897, S. 97.

Flemming, W., Neue Beiträge zur Kenntniss der Zelle. Arch. f. mikrosk. Anat., Bd. 29, 1887, S. 389.

Derselbe, Neue Beiträge zur Kenntniss der Zelle, 2. Theil. Arch. f. mikrosk. Anat. Bd. 37, 1891, p. 685.

Fürst, Carl M., Bidrag till kännedom om sädes kropparnas struktur och utveckling. Nordisk Mediciniskt Arkiv. Bd. XIX, 1887. (Citirt nach Ballowitz.)

Heidenhain, M., Noch einmal über die Darstellung der Centralkörper durch Eisenhämatoxylin nebst einigen allgemeinen Bemerkungen über die Eämatox ylinfarben. Zeitschr. f. wiss. Mikrosk. Bd. XIII, 1896, p. 186.

Derselbe, Neue Untersuchungen über die Centralkörper und ihre Beziehungen zum Kern und Zellenprotoplasma. Arch. f. mikrosk. Anat. Bd. 43, 1894. S. 423.

Helman, Ueber die Entwickelung des Spermatozoon der Wirbelthiere. Inaug.-Diss. Dorpat 1879.

Hermann, F., Beiträge zur Histologie des Hodens. Archiv f. mikr. Anat. Bd. 34, 1889, S. 58.

Derselbe, Urogenitalsystem. Referat in den „Ergebnissen d. Anat. 
und Entwicklungsgesch.", herausgeg., von Merkel und Bonnet. II. Bd. 1893, S. 201.

Jensen, O. S., Untersuchungen über die Samenkörper der Säugethiere, Vögel und Amphibien. Arch. f. mikrosk. Anat., Bd. 30, 1887, S. 379.

Kölliker, A., Physiologische Studien über die Samenflüssigkeit. Zeitschrift f. wissensch. Zoologie. Bd. 7, 1856, S. 201.

Kostanecki, K. v., Ueber Centralkörperchen bei karyokinetischer Zelltheilung. Anatom. Hefte, Bd. I, 1892, p. 205.

Derselbe, Ueber diè Bedeutung der Polstrahlung während der Mitose und ihr Verhältniss zur Theilung des Zellleibes. Arch. f. mikrosk. Anat. Bd. 49, 1897, S. 651.

Lenhossék, M. v., Centrosom und Sphäre in den Spinalganglienzellen des Frosches. Archiv für mikroskopische Anatomie, Bd. 46, 1895 , S. 345.

Merkel, Fr., Frstes Entwicklungsstadium der Spermatozoiden. Untersuchungen aus dem anatomischen Institut zu Rostock, 1874.

Meves, Fr., Ueber die Zellen des Sesambeines in der Achillessehne des Frosches. Archiv f. mikrosk. Anat. Bd. 45, 1895, S. 133.

Derselbe, Ueber die Entwicklung der männlichen Geschlechtszellen von Salamandra maculosa. Archiv f. mikroskop. Anat. Bd. 48, 1896, S. 1.

Derselbe, Ueber Struktur und Histiogenese der Samenfäden. Mittheilungen $f$. $d$. Verein Schleswig-Holstein. Aerzte. Jahrgang V. Nr. 5, 1897.

Mihálkovics, G., A herecsövek szöveti szerkezete. Festschrift für Prof. Kovács. Budapest, 1895.

Moore, J. E. S., Mammalian Spermatogenesis. Anat. Anz., Bd. 8, 1893 , S. 683.

Derselbe, On the Structural Changes in the Reproductive Cells during the Spermatogenesis of Elasmobranchs. Quarterly Journal of Microscopical Science. Vol. 38, 1896, p. 275.

Niessing, C., Die Betheiligung von Centralkörper und Sphäre am Aufbau des Samenfadens bei Säugethieren. Arch. f. míkr. Anat. Bd. 48, 1896, S. 111.

Rath, O. vom., Zur Conservirungstechnik. Anatom. Anzeig. Bd. 11, 1896, S. 280.

Rawitz, B., Centrosoma und Attractionssphäre in der ruhenden Zelle des Salamanderhodens. Archiv für mikrosk. Anatomie Bd. 44, 1895, S. 555.

Renson, G., De la spermatogénèse chez les mammifères. Archives de Biologie. Tome III, 1882, p. 291.

Retzius, G., Zur Kenntniss der Spermatozoen. Biologische Untersuchungen. 1881. S 77 .

Plato, J., Die interstitiellen Zellen des Hodens und ihre physiologische Bedeutung. Archiv für mikroskopische Anatomie $\mathrm{Bd} .48$, 1896, S. 280. 
Stricht, o. Vander, De l'origine de la figure achromatique de l'ovule en mitose chez le Thysanozoon Brocchi. Verh. d. Anat. Ges. VIII. Vers. Strassburg; 1894, S. 223.

Svaen, A., et Masquelin, H., Étude sur la spermatogénèse. Archives de Biologie. Tome IV, 1883, p. 749.

\section{Erklärung der Abbildungen auf Tafel XII, XIII u. XIV.}

Fig. 1-5 sind bei Zeiss Oc. 3, Obj. D, die übrigen bei Anwendung des Zeiss'schen Apochromaten 2,0 mm, Apert. 1,30 gezeichnet. Mit Ausnahme der Fig. 8 und der Figuren 30-42 dienten allen Zeichnungen Präparate aus dem Rattenhoden als Vorlage.

Fig. 1-5. Die fünf "Leitbilder" der Spermatogenese. Gemeinsame Bezeichnungen für alle fünf Figuren:

Sp. gon $=$ Spermatogonien

Uebg. $-S p$. gon. = Uebergangsspermatogonien.

Kl. Sp. cyt. = kleine Spermatocyten.

mittelgr. $S p$. cyt. $=$ mittelgrosse Spermatocyten.

gr. Sp. cyt. = grosse Spermatocyten.

I. $S p$. cytenthetilung. $=\mathrm{I}$. Spermatocytentheilung.

Sp. tid. = Spermatiden.

Sp. zoen. = Spermatozoen.

Detritussch. $=$ Detritusschichte.

Fussz. $=$ Fusszellen.

Fig. 1. Das „typische Bild“, mit voll ausgebildeten Samenständern und noch runden Spermatiden.

Fig. 2. Stadium mit runden Spermatiden, aber obne "Samenständer". Die Spermatozoen liegen einwärts von den Spermatiden, von diesen durch eine „Detritusschicht" getrennt.

Fig. 3. Beginn der Metamorphose der Spermatiden zu Spermatozoen, Anlage des aufsteigenden Fortsatzes der Fusszellen.

Fig. 4. Das durch den Mangel von Spermatiden und durch die "Riesenspermatocyten" gekennzeichnete Stadium.

Fig. 5. Spermatocyten in Mitose (erste oder grosse Spermatocytentheilung). Links im Bilde noch ungetheilte grosse Spermatocyten, rechts „Ebner'sche Zellen" (Produkte der ersten Spermatocytentheilung).

Fig. 6. Spermatogonie mit kleiner Sphäre, die zwei Centrosomen einschliesst.

Fig. 7. Mittelgrosser Spermatocyt. Im Kern seitlich ein länglicher "Intranuclearkörper", im Cytoplasma die Sphäre mit Centrosomen darin und drei chromatoide Nebenkörper.

Fig. 8. Spermatocyt aus dem Hoden des Katers.

Fig. 9. Grosser Spermatocyt mit ringförmigen "doppelwerthigen“" Chromosomen im Kern. Im Cytoplasma grosse Sphäre mit Centrosomen und zwei chromatoide Nebenkörper in typischer Lagerung. Im Kern zwei kugelige Kernkörperchen. 
Fig. 10. Grosser Spermatocyt unmittelbar vor der Theilung. Die Chromosomen zu ganz kleinen Ringen zusammengeschrumpft. Im Cytoplasma Sphäre und chromatoide Nebenkörper.

Fig. 11. Erste Spermatocytentheilung. Umordnungsstadium. Seitlich neben einem der Pole der geschrumpfte Sphärenrest (Sphäre). Polstrahlung schön ausgebildet.

Fig. 12. „Aequatorialplattenstadium“ der ersten Spermatocytentheilung. Sphärenrest, Polstrahlung.

Fig. 13. Tochterkerne in der Reconstruction begriffen. Erste Anlage des Kernsaftes und der Kernmembran. Bandförmige Spindel. Zelltheilung bereits vollzogen. Zwischen den Spindelfäden einige "Centralspindelkörperchen".

Fig. 14. Ein etwas späteres Stadium. Spindelrest brückenförmig zwischen den etwas auseinandergewichenen Tochterzellen ausgespannt, in der Mitte mit einem knopfförmigen Zwischenkörperchen. Seitlich verschobene Insertion des Spindelrestes an der neugebildeten Kernmembran.

Fig. 15. Zweite (kleine) Spermatocytentheilung. Spindelpole dicht an der Zelloberfläche. Im Cytoplasma ein chromatoider Nebenkörper sichtbar.

Fig. 16-24. Spermatiden mit noch rundem Kern. Chromatoider Nebenkörper in allen als schwarze Kugel sichtbar. Erste Stadien der Bildung der Kopfkappe und des Spitzenknöpfchens aus der Sphäre. Erste Anlage des Achsenfadens, als Auswuchs der Centrosomen. In den Figuren 16, 17 u. 20 liegen die Centrosomen noch auf der Oberfläche der Zelle, in Fig. 18 und 19 sind sie in der Wanderung begriffen, in Fig. 21-24 haben sie den Kern schon fast oder ganz erreicht.

Fig. 25-29. Umwandlungsstadien des Spermatidenkerns zum Spermatozoenkopfe. Fig. 25, Verlängerung des Kerns; 26, erste Anlage der Schwanzblase, unsymmetrische Form der Kopfkappe; Fig. 27, der Kern streckt sich weiter in die Lünge, die Schwanzblase tritt lebhafter hervor; Fig. 28, Umkrümmung des vorderen Kernpols, kegelförmige Schwanzblase; Fig. 29, fast reifer Spermatozoenkopf; die Kopflsappe hebt sich noch stark ab, Sehwanzblase noch kegelförmig, darin Reste des zerfallenen chromatoiden Nebenkörpers.

Fig. 30-39. Bildung der Appendiculargebilde am vorderen Kernpol beim Meerschweinchen; Fig. 30, Sphäre ohne Akrosoma; Fig. 31, Auftreten des letzteren; Fig. 32-35, das Akrosoma wächst allmählig zu einer grossen Kugel heran, in Fig. 36-37 erscheint sie halbmondförmig, in Fig. 38 dreieckig, in Fig. 39 mitraförmig. In letzterer Figur ist auch die bei dem Meerschweinchen wohl ausgebildete Schwanzblase dargestellt.

Fig. 40. Kopf des reifen Samenfadens vom Meerschweinchen. 